\title{
Characterization and Reuse of Residuals Collected from Street Sweeping Operations
}

\author{
A Thesis \\ Presented to \\ the faculty of the School of Engineering and Applied \\ Science \\ University of Virginia
}

\author{
in partial fulfillment \\ of the requirements for the degree \\ Master of Science
}

by

Lewis N. Lloyd 
May 2017 


\title{
APPROVAL SHEET
}

\author{
This Thesis \\ is submitted in partial fulfillment of the requirements \\ for the degree of \\ Master of Science
}

Author Signature:

This Thesis has been read and approved by the examining committee:

Advisor: Dr. James Smith

Committee Member: Dr. Teresa Culver

Committee Member: Dr. Michael Fitch

Committee Member:

Committee Member:

Committee Member:

Accepted for the School of Engineering and Applied Science: 


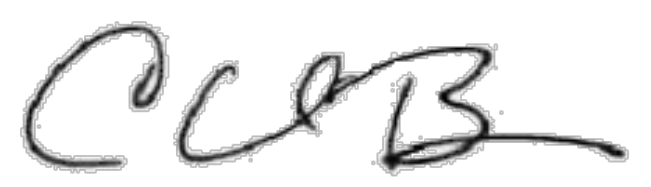

Craig H. Benson, School of Engineering and Applied Science

May 2017 
Characterization and Reuse of Residuals Collected from Street Sweeping Operations

Lewis N. Lloyd

April 20, 2017 


\begin{abstract}
Street sweeping is a non-structural best management practice (BMP) implemented by the Virginia Department of Transportation (VDOT) in order to meet total maximum daily loads for the Chesapeake Bay watershed in Virginia. This BMP functions by removing the roaddeposited sediment and debris from the roadway before it enters receiving waters. Currently the material collected by VDOT during street sweeping operations is considered a solid waste and must be disposed at a lined landfill. As street sweeping activity continues to increase in order for VDOT to meet the increasing TMDL requirements, a significant cost increase for disposal and transportation to the landfill are expected. In order to curtail these costs, VDOT is seeking a Beneficial Use Determination (BUD) from the Virginia Department of Environmental Quality (VADEQ) for this material. This would allow VDOT to recycle the material for use as traction sand, soil amendment, or other suitable applications. In order to attain a BUD for this waste stream the VADEQ has a number of different criteria that the material must meet, including a physical and chemical characterization of the material to ensure it is not hazardous to the population or the environment. The purpose of this research is to provide a characterization of material collected from over 80 road sites of various average daily traffic loads and land uses. This material was tested for heavy metals including $\mathrm{As}, \mathrm{Ba}, \mathrm{Cd}, \mathrm{Cr}, \mathrm{Se}, \mathrm{Ag}$, $\mathrm{Cu}$, and $\mathrm{Zn}$ as well as the 16 EPA priority polycyclic aromatic hydrocarbons (PAHs) and oil and grease. Concentrations of these metals ranged from $5.9 \times 10^{-3}-2.5 \mathrm{mg} / \mathrm{kg}, 0.225-64.9 \mathrm{mg} / \mathrm{kg}$, $7.3 \times 10^{-4}-51.1 \mathrm{mg} / \mathrm{kg}, 4.8 \times 10^{-3}-108.1,9.1 \times 10^{-3}-2 \mathrm{mg} / \mathrm{kg}, 7.3 \times 10^{-4}-1 \mathrm{mg} / \mathrm{kg}, 0-9.7 \mathrm{mg} / \mathrm{kg}, 0.3-$ $273.5 \mathrm{mg} / \mathrm{kg}$ respectively. Concentrations of $\sum \mathrm{PAHs}$ ranged from $18.5 \mu \mathrm{g} / \mathrm{kg}$ to $87,208 \mu \mathrm{g} / \mathrm{kg}$. Concentrations of oil and grease ranged from $33.6 \mathrm{mg} / \mathrm{kg}$ to $3,440.9 \mathrm{mg} / \mathrm{kg}$. Based on the results of this characterization it was found that the concentrations of these contaminants cannot be reliably predicted based on the ADT and land use of the road and surrounding areas. Rather, the particle size of the road deposited sediment had a greater influence of the level of contamination. Given this information it is suggested that VDOT screen material collected during street sweeping to remove the fines associated with this contaminant load.
\end{abstract}




\section{Acknowledgments}

This work would not have been possible without the funding of the Virginia Department of Transportation Research Council (VTRC) as well as the facilities and instrumentation provided by the University of Virginia Department of Civil and Environmental Engineering. Specifically, I would like to thank the following individuals.

- Dr. James Smith (thesis co-advisor), for his guidance throughout this project.

- Dr. Michael Fitch (thesis co-advisor), for providing me with valuable insight and motivation during this process.

- Dr. Tony Singh, for his invaluable knowledge of analytical procedures. Without his dedication, this work would not have been possible.

- My family and friends who provided me with an endless supply of moral support, and entertainment throughout this process. 
Table of Contents

ABSTRACT

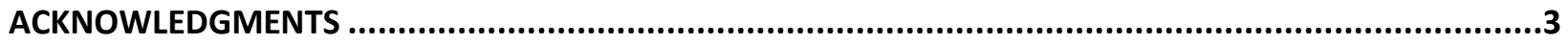

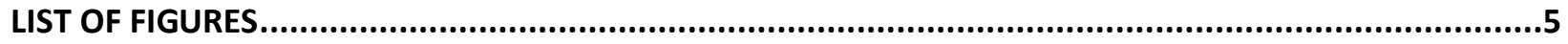

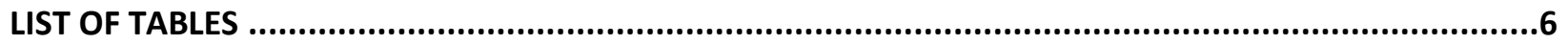

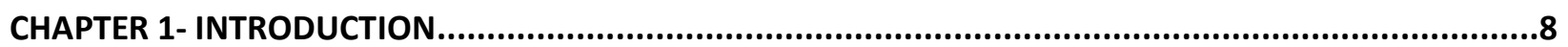

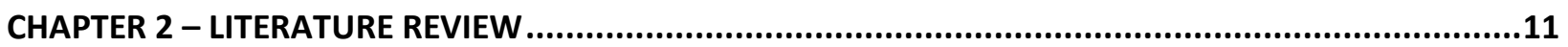

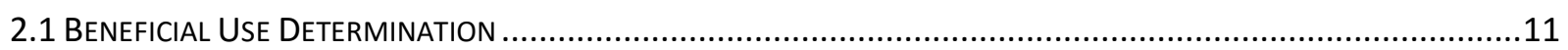

2.1.1-Beneficial Use Determinations in Other States.................................................................11

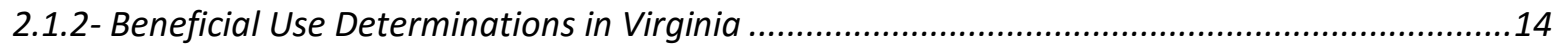

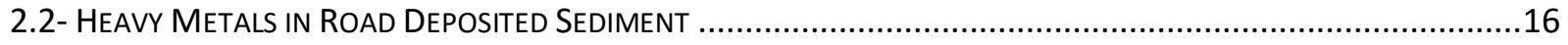

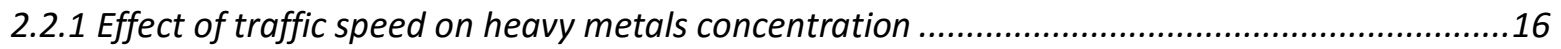

2.2.2 Effect of average daily traffic on heavy metals concentration ..............................................17

2.2.3 Effect of land use on heavy metals concentration ..............................................................19

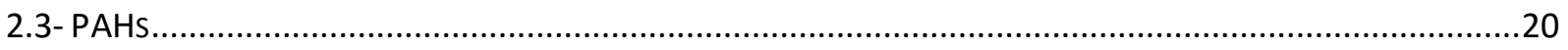

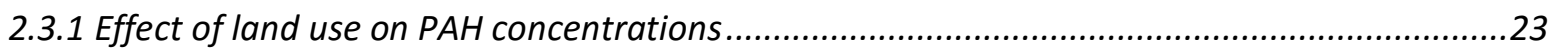

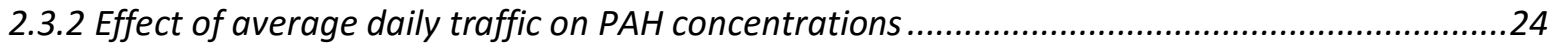

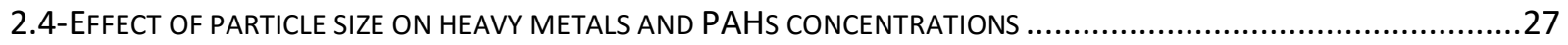

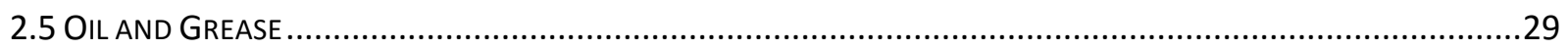

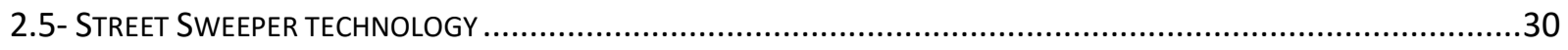

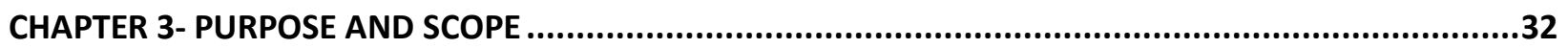

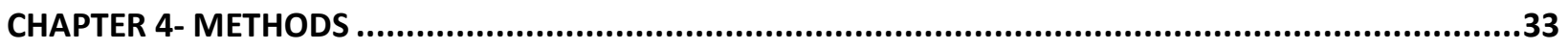

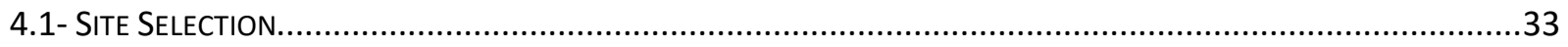

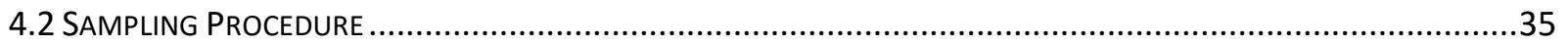

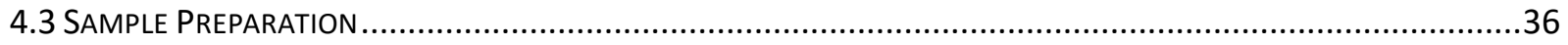

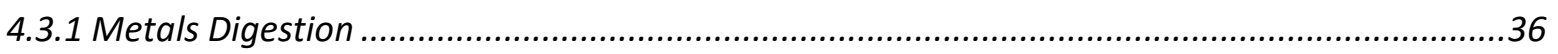

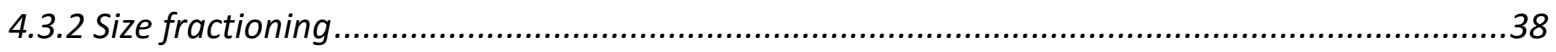

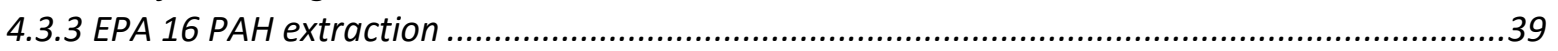

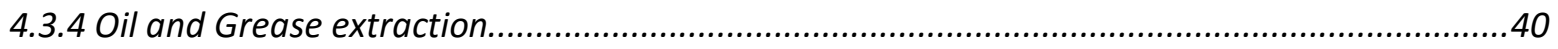

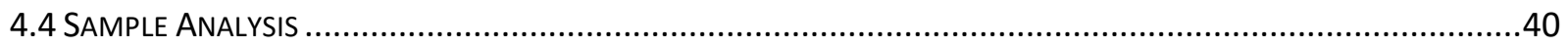

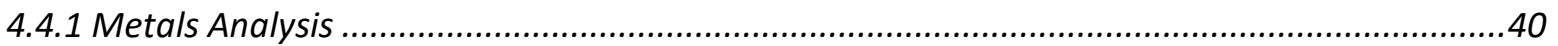

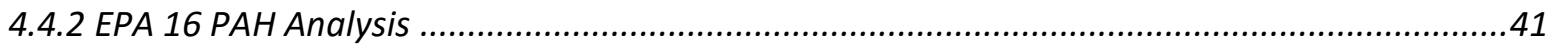

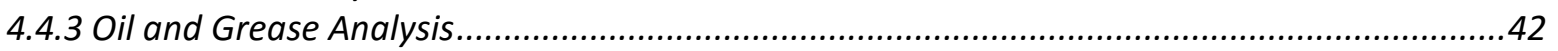

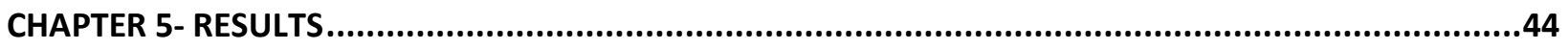

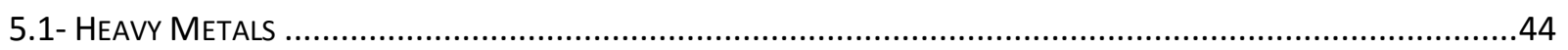

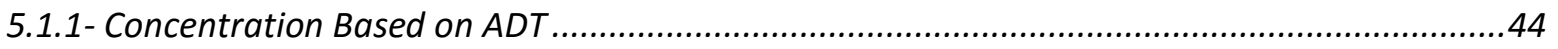

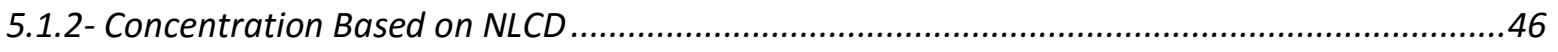

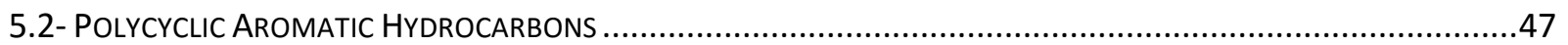

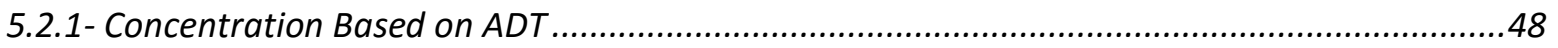

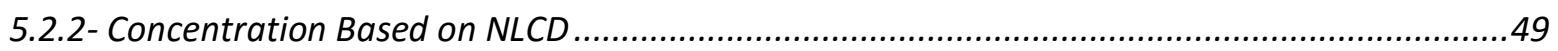

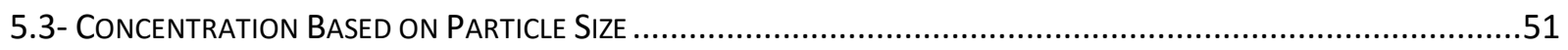

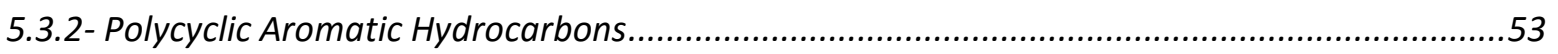

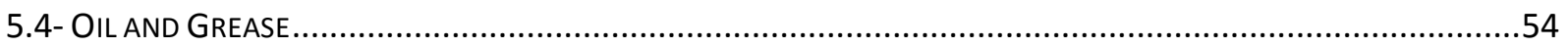




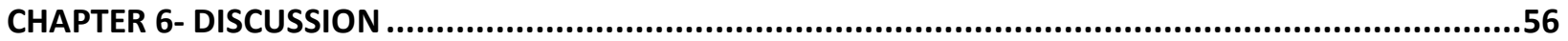

6.1 POLYCYCLIC AROMATIC HYDROCARBONS

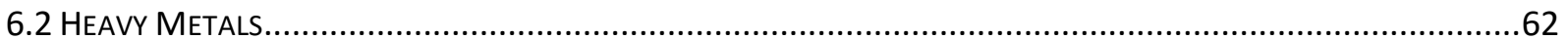

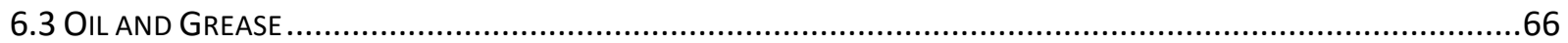

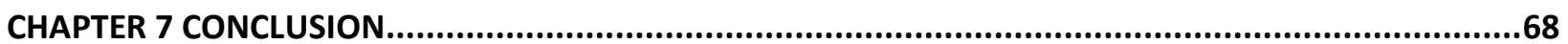

APPENDIX

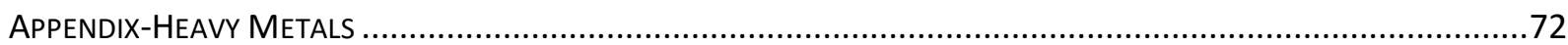

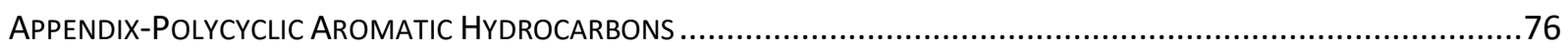

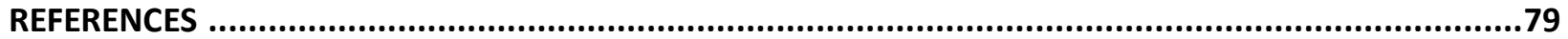

\section{List of Figures}

Figure 2: Concentration of PAHs across five different ADT classifications. (Wang et al., 2010) .. 26 Figure 3: Average concentration of $\mathrm{As}, \mathrm{Pb}, \mathrm{Se}, \mathrm{Ba}, \mathrm{Cr}, \mathrm{Ag}, \mathrm{Cd}, \mathrm{CU}$, and $\mathrm{Zn}$ across the six ADT categories. Error bars are based on the standard error of the group of samples.

Figure 4: Average concentration of $\mathrm{As}, \mathrm{Pb}, \mathrm{Se}, \mathrm{Ba}, \mathrm{Cr}, \mathrm{Ag}, \mathrm{Cd}, \mathrm{Cu}$, and $\mathrm{Zn}$ across the four National Land Cover Database categories. Error bars are the standard error within each group of samples.

Figure 5: Concentration of each individual PAH across the six different ADT categories ........... 48

Figure 6: $\Sigma$ PAH concentration across the six different average daily traffic categories............. 49

Figure 7: Concentration of each PAH in each National Land Cover Database category .............. 50

Figure 8: $\sum \mathrm{PAH}$ concentration in each National Land Cover Database category ........................ 50

Figure 9: Concentration of $\mathrm{As}, \mathrm{Pb}, \mathrm{Se}, \mathrm{Ba}, \mathrm{Cr}, \mathrm{Ag}, \mathrm{Cd}, \mathrm{Cu}$, and $\mathrm{Zn}$ in each particle size. All concentrations are reported in $\mu \mathrm{g} / \mathrm{kg}$. Error bars are based on the standard error of each

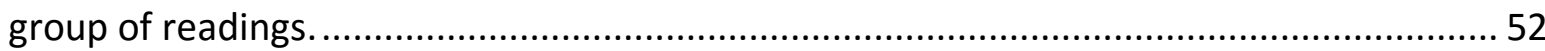

Figure 10: Concentration of each PAH across all of the particle sizes..................................... 53

Figure 11: PAH concentrations in each particle size........................................................... 54

Figure 12: Oil and Grease Concentrations of each ADT category. Error bars are based on the standard error of the series of samples.................................................................... 55

Figure 13: Oil and Grease concentrations of each NLCD category. Error bars are based on the

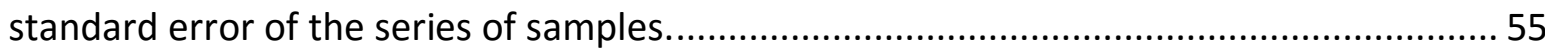

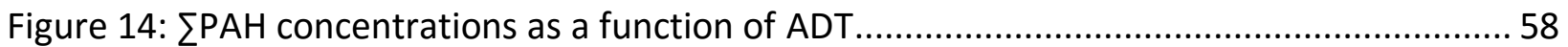

Figure 15: Sum of the average concentrations of 2 and three ring PAHs (napthalene, acenaphthene, acenaphthylene, anthracene, phenanthrene, and fluorene) across the four different NLCD categories.

Figure 16: Concentration of Benzo(a)Pyrene as a function of ADT in the four different NLCD

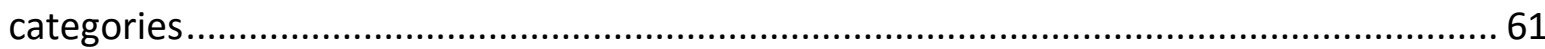

Figure 17: Concentration of each $\mathrm{PAH}$ as a function of decreasing particle size. ...................... 62

Figure 18: Concentrations of $\mathrm{As}, \mathrm{Pb}, \mathrm{Se}, \mathrm{Ba}, \mathrm{Cr}, \mathrm{Ag}, \mathrm{Cd}, \mathrm{Cu}$, and $\mathrm{Zn}$ in different particle sizes.

Error bars are based on the standard error of the group of samples. ............................. 65

Figure 19: Concentration of oil and grease as a function of average daily traffic volume.......... 67

Figure 20: Map of all sampling sites across the state of Virginia. ............................................ 70

Figure 21: Vessels used for both heavy metal digestion and PAH extraction........................... 71 
Figure 22: Concentrations of heavy metals as a function of average daily traffic volume. ........ 73 Figure 23: Concentrations of heavy metals in each national land cover database category....... 75

Figure 24: Concentration of each individual PAH as a function of ADT ................................. 78

\section{List of tables}

Table 1: Maximum Concentrations of Contaminants for the Toxicity Characteristic (EPA 40 CFR

Part 261 Subpart C, 2012 )

Table 2:Heavy metal concentrations in road deposited sediment collected from commercial/ residential land use (Irvine et al., 2009)

Table 3: Concentrations of metals in sweeper waste collected from industrial and residential areas (Miller \& Iv, 2013).

Table 4: Heavy metal loading across four different land use categories in Queensland, Australia

(Gunawardana et al., 2012)

Table 5: EPA priority PAHs, number of aromatic rings, and possible sources, $1=$ Coke Oven, $2=$ Oil Combustion, 3=Gas Combustion, 4= Diesel Combustion, 5=Incineration, 6= Wood

Combustion, 7=Coal Combustion, 8=Tire wear (L. Liu et al., 2016). 21

Table 6: The three most common street sweeper technologies and their efficiencies.............. 30

Table 7: Recovery efficiency of the microwave digestion procedure ........................................ 38

Table 8: Instrument parameters used for the ICP-MS....................................................... 41

Table 9: Average concentration of $\mathrm{As}, \mathrm{Pb}, \mathrm{Se}, \mathrm{Ba}, \mathrm{Cr}, \mathrm{Ag}, \mathrm{Cd}, \mathrm{Cu}$, and $\mathrm{Zn}$ in each ADT category . 45

Table 10: Average concentrations of $\mathrm{As}, \mathrm{Pb}, \mathrm{Se}, \mathrm{Ba}, \mathrm{Cr}, \mathrm{Ag}, \mathrm{Cd}, \mathrm{Cu}$, and $\mathrm{Zn}$ in each National Land

Cover Database category

Table 11: Concentration of $\mathrm{As}, \mathrm{Pb}, \mathrm{Se}, \mathrm{Ba}, \mathrm{Cr}, \mathrm{Ag}, \mathrm{Cd}, \mathrm{Cu}$, and $\mathrm{Zn}$ in each particle size. All concentrations are reported in $\mu \mathrm{g} / \mathrm{kg}$

Table 12: Average concentration in $\mu \mathrm{g} / \mathrm{kg}$ of each $\mathrm{PAH}$ and $\Sigma \mathrm{PAH}$ in each particle size range... 53

Table 13: Average concentrations of PAHs from soils and RDS collected in other studies. All results in $\mu \mathrm{g} / \mathrm{kg}$.

Table 14: $R^{2}$ values of each PAH when plotted against ADT assuming a linear function 59

Table 15: $R^{2}$ values of linear regression plots of metal concentration versus average daily traffic volume.

Table 16: Sites contaminated above the regulatory limit for heavy metals 65 


\section{Chapter 1- Introduction}

With ever-increasing regulations on stormwater quality in the Chesapeake Bay watershed an increasing number of stormwater best management practices (BMPs) are being employed to meet Virginia's total maximum daily loads for nutrients and suspended solids.

Street sweeping has emerged as one of the BMPs used by many municipalities and departments of transportation (DOTs) as a way to reduce stormwater contamination before it enters receiving waters. In 2011, street sweeping was officially recognized as a stormwater best management practice following a pilot study by Law et al. in 2008 (Goulet, 2011). Street sweeping is most commonly used on roads with curb and gutters that prevent road deposited sediments (RDS) from washing off of the roadway (Herra Environmetal Consultants, 2011; Seattle Public Utilities \& Herrera Environmental Consultants, 2009). While pollutant reduction is one of the increasingly popular reasons for street sweeping; it was originally implemented as a way to maintain the aesthetics of the road by removing excess trash and debris that accumulate over time. Typically, municipalities will conduct their street sweeping operations two times a year; once in the fall to remove leaves and other debris accumulated over the summer and fall, and again in the late spring/ early summer to remove winter traction sand applied during the preceding winter season (Seattle Public Utilities \& Herrera Environmental Consultants, 2009).

The amount of pollutant credits assigned to street sweeping activities is calculated using one of two methods, the Mass Loading Method or the Qualifying Street Lanes Method (Goulet, 2011; VDEQ, 2015). However, there are a certain set of criteria that must be met in order for municipalities to get pollutant credits for their street sweeping operations. These have been 
defined by the Urban Stormwater Workgroup of the Chesapeake Bay Program as "enhanced street sweeping programs" (Goulet, 2011) and consist of: a biweekly sweeping routine (or at least 26 times per year); roads with average daily traffic (ADT) higher than typical industrial, commercial, central business district, or high intensity residential ADT; credits are based on type of sweeper used ( regenerative air receives more credits while mechanical broom sweepers receive less); and finally localities must keep an accurate record of the number of lane miles swept (Goulet, 2011). Even with this relatively strict definition of street sweeping it is still expected that municipalities will continue to increase their street sweeping operations. It must be noted that pollutant credits for street sweeping are only credited for reductions in total phosphorus (TP), total nitrogen (TN), and total suspended solids (TSS); not for other pollutants such as heavy metals and hydrocarbons.

While street sweeping is conducted primarily to reduce TSS, TP, and TN concentrations; once collected a completely different set of solid waste contaminants are considered. These include heavy metals, semi-volatile organic compounds (SVOCs) like polycyclic aromatic hydrocarbons (PAHs), oil and grease (OG), as well as total petroleum hydrocarbons (TPH). Contaminants like these tend to preferentially sorb to both the organic matter on the roadway as well as to materials like traction sand applied during the winter. This makes road deposited sediments (RDS) a potential sink for contaminants in the environment and has lead the Virginia Department of Environmental Quality to consider this a solid waste. Because of this classification, RDS collected during street sweeping operations are subject to the disposal regulations of a solid waste. Due to the expected increase in street sweeping operations in the 
state of Virginia in the coming years concern has been raised about the cost of disposing this collected material.

In other states, the majority of the RDS that is collected can be lower than the solid waste specifications after a certain degree of treatment or no treatment at all (City of Edmonton, 2003; Jang et al., 2010; Townsend et al., 2002). This has led many states to reuse this material through what is called a Beneficial Use Determination (BUD) program. A BUD is a classification given to a material that was at one point considered either a solid or hazardous waste; however, through a number of different steps, has been redefined as a material that can be reused for another application. States that have successfully attained a BUD for street sweeping materials include Florida, Minnesota, lowa, New Jersey, and Massachusetts (Dierker, n.d.; Minnesota Pollution Control Agency, 2010; Minnicino, Draper, Dresden Robin TerraSciences, \& Jersey City, 1993; Sole, 2004). For example, in 2002 the state of Florida finalized its Beneficial Use Determination for street sweeping debris. This decision was made after an extensive chemical characterization of both the total and leachable concentrations of heavy metals, VOCs, SVOCs, and herbicides (Jang et al., 2010; Townsend et al., 2002). Prior to this Florida had classified street sweepings as a Class I (solid waste), meaning that the material, while not hazardous waste, must be disposed of in a properly lined and certified landfill, incurring additional disposal cost (Townsend et al., 2002). 


\section{Chapter 2 - Literature review}

\subsection{Beneficial Use Determination}

\subsection{1-Beneficial Use Determinations in Other States}

The Virginia Department of Environmental Quality (VADEQ) has identified materials collected during street sweeping operations as a solid waste. Because of this all collected material must be sent to a land fill incurring disposal costs that continue to rise as landfill space continues to dwindle. It has been found in other states and countries that the material that is collected does not meet the definition of a solid waste and can, in many cases, be reused for other purposes such as a soil amendment, landfill cover, traction sand reuse, etc.

A prime example of this took place in Edmonton, Canada in 2003. The city of Edmonton applies over 165,000 tones of traction sand each winter and in the past only reused about $25 \%$ of this material (City of Edmonton, 2003). This meant that the city was sending more than 41,250 tons of material to the landfill each year, taking up $60 \%$ of its volume. This became problematic as the cost of disposal increased due to the lack of space. The solution the city implemented involved an extensive four-phase recycling system. Phase one involves sieving the bulk material through a $10 \mathrm{~mm}$ screen to remove large debris and garbage, this removes approximately $6 \%$ of the material (City of Edmonton, 2003). Phase 2 involves washing the material in a rotary drum in order to remove material smaller than $300 \mu \mathrm{m}$ using water collected from the landfill groundwater reservoir or snowmelt piles. The material greater than $300 \mu \mathrm{m}$ is sent to dewatering facilities for drying while the material smaller than $300 \mu \mathrm{m}$ is sent to Phase 3 of the process (City of Edmonton, 2003). Phase 3 takes the fines separated out in the previous phase and dewaters the material using a cyclone dewatering device. This device 
spins the material similar to the spin cycle on a washing machine in order to separate the liquid form the solids. The water removed during this step is sent to settling ponds in order to allow ultra-fine silts to settle out of suspension (City of Edmonton, 2003). Phase 4 is the final stage of the process and involves moving the bulk sand collected in phase 1 to a dewatering screen and finally to dewatering pads where over the course of one to two months the material is allowed to drain and dry to an approximate moisture content of less than $4 \%$. At this point the material is ready for reuse as traction sand next winter (City of Edmonton, 2003). The fines collected in phase 3 of the operation are made available for use as fines in fillcrete and other applications. In total, using this method the city of Edmonton has been able to divert $88 \%$ of the material collected during its street sweeping operations from the landfill (City of Edmonton, 2003). Edmonton, Canada provides one of the most extensive examples of RDS reuse. However, there are other cities that have achieved similar results with less equipment albeit, they used much less winter traction sand.

Cedar Rapids, lowa, recovers approximately 3,000 tones of winter traction sand and other material each spring (Cedar Rapids Public Works, 2015). Following the closure of their local landfill, the city began incurring extra costs to transport and dispose of the material at an adjacent landfill. This led the city to invest $\$ 100,000$ in screening equipment. This allows the city to reuse the material not only as winter traction sand but also for other uses like fill material. However, due to increased metal concentrations, material not reused as traction sand is not allowed to be used near water ways (Cedar Rapids Public Works, 2015).

Florida, while not known for its winter maintenance program, does indeed conduct a significant amount of street sweeping to remove trash and other debris from the roadway. Due 
to a change in the definition of the term "trash" in the Florida Administrative Code in 1993, street sweepings could no longer be disposed of in unlined class III landfills without prior approval (Sole, 2004; Townsend et al., 2002). This lead to a drastic increase in the cost of disposal causing many municipalities to create stock piles of material (Sole, 2004). In contrast to other states' recovered material which is predominantly made up of winter traction sand, the material collected during street sweeping in Florida is largely made up of soil and larger pieces of garbage (Sole, 2004; Townsend et al., 2002). In the early 2000's, the Florida Department of Environmental Protection began to investigate alternative disposal and reuse options for this waste stream (Sole, 2004). Due to the revisions to the law in 1993, material collected during street sweeping operations had to meet Florida groundwater cleanup levels for total and leachable concentrations of VOCs, SVOCs, herbicides, pesticides, and metals if they were to be disposed of in class III landfills or more importantly be considered for reuse (Sole, 2004). Following an extensive chemical and physical characterization by Townsend et al. in 2002, the Florida DEP published a set of guidelines for the beneficial reuse of this material. This allowed street sweepings to be used as initial cover for class I, II, and III landfills; for use on road construction and maintenance projects "without further testing"; as fill for nonresidential or industrial construction, or as a soil amendment given that it is not contaminated with high concentrations of the PAH benzo(a)pyrene (BaP). Material that is suspected to be contaminated can be screened through both a coarse $1 \mathrm{in}^{2}$ and a $5-10 \mathrm{~mm}^{2}$ screen in order to remove the fines associated with "Class I wastes" (Sole, 2004). Furthermore, street sweepings that do not require screening also do not require special storage conditions like leaching controls (Sole, 2004). However, if the material does require screening, it cannot be stored for 
longer than three months before screening and all material must be either reused or disposed of within six months of stockpiling (Sole, 2004).

\subsection{2- Beneficial Use Determinations in Virginia}

In order for a material to attain a BUD in the state of Virginia, a number of different criteria must be met under administrative code 9VAC20-81-97 (Virginia Waste Managment Board, 2015). First a description of the material and how it will be used must be provided. Secondly, the raw material must undergo an extensive chemical and physical characterization as well as the final product. Third, there must be a demonstration of a known or reasonably probable market for the material being produced (Virginia Waste Managment Board, 2015). This must include a description of how the material will be used, a demonstration that the material meets comparable industry standards if there are any, and documentation that a market or use for the material exists (Virginia Waste Managment Board, 2015). Finally, there must be "a demonstration that the management of the solid waste under review will not adversely affect human health and safety, the environment, and natural resources" (Virginia Waste Managment Board, 2015). This final criteria must include what is called a "solid waste control plan" that consists of the following; 1 ) the source of the solid waste, 2) procedures for periodic testing of the solid waste under review and the proposed product to ensure that the proposed product's composition has not changed significantly, 3) the disposition of any solid waste that may result from the manufacture of the product into which the solid waste under review is intended to be incorporated, 4) a description of the type of storage (e.g., container, tank, or pile) and the maximum anticipated inventory of the solid waste under review (not to 
exceed 90 days) before being used, 5) procedures for run-on and run-off control of the storage areas for the solid waste under review, and 6) a program and implementation schedule of best management practices designed to minimize uncontrolled dispersion of the solid waste under review before and during all aspects of its storage as inventory and during beneficial use (Virginia Waste Managment Board, 2015). The maximum concentrations of contaminants that are allowed to be in the material to be beneficially reused are outlined in the table below (EPA 40 CFR Part 261 Subpart C, 2012 ). Note that these are leachable concentrations, therefore the units are in $\mathrm{mg} / \mathrm{L}$.

Table 1: Maximum Concentrations of Contaminants for the Toxicity Characteristic (EPA 40 CFR Part 261 Subpart C, 2012)

\begin{tabular}{|c|c|c|c|}
\hline Contaminant & $\begin{array}{l}\text { Regulatory Level } \\
\text { (mg/L) }\end{array}$ & Contaminant & $\begin{array}{c}\text { Regulatory Level } \\
\text { (mg/L) }\end{array}$ \\
\hline Arsenic & 5 & Hexachlorobenzene & 30.13 \\
\hline Barium & 100 & Hexachlorobutadiene & 0.5 \\
\hline Benzene & 0.5 & Hexachloroethane & 3 \\
\hline Cadmium & 1 & Lead & 5 \\
\hline Carbon tetrachloride & 0.5 & Lindane & 0.4 \\
\hline Chlordane & 0.03 & Mercury & 0.2 \\
\hline Chlorobenzene & 100 & Methoxychlor & 10 \\
\hline Chloroform & 6 & Methyl ethyl ketone & 200 \\
\hline Chromium & 5 & Nitrobenzene & 2 \\
\hline o-Cresol & 4200.0 & Pentrachlorophenol & 100 \\
\hline m-Cresol & 4200.0 & Pyridine & 35.0 \\
\hline p-Cresol & 4200.0 & Selenium & 1 \\
\hline Cresol & 4200.0 & Silver & 5 \\
\hline $2,4-\mathrm{D}$ & 10 & Tetrachloroethylene & 0.7 \\
\hline 1,4-Dichlorobenzene & 7.5 & Toxaphene & 0.5 \\
\hline 1,2-Dichloroethane & 0.5 & Trichloroethylene & 0.5 \\
\hline 1,1-Dichloroethylene & 0.7 & 2,4,5-Trichlorophenol & 400 \\
\hline 2,4-Dinitrotoluene & 30.13 & 2,4,6-Trichlorophenol & 2 \\
\hline Endrin & 0.02 & 2,4,5-TP (Silvex) & 1 \\
\hline $\begin{array}{c}\text { Heptachlor (and its } \\
\text { epoxide) }\end{array}$ & 0.008 & Vinyl chloride & 0.2 \\
\hline
\end{tabular}




\section{2- Heavy Metals in Road Deposited Sediment}

Heavy metals in RDS come from a number of different sources. Metals are released from vehicles through brake pad wear, corrosion of electrical components, as well as exhaust emissions. Barium, chromium, copper, lead, and Zinc are some of the most prevalent metals found in RDS (Apeagyei, Bank, \& Spengler, 2011; Cincotti, Mameli, Locci, Orrù, \& Cao, 2006;

Duong \& Lee, 2011; Herngren, Goonetilleke, \& Ayoko, 2006; Pant \& Harrison, 2013; Thorpe \& Harrison, 2008; Yuen et al., 2012). The degree of metals contamination from vehicles is dependent upon a number of different variables including the volume of traffic, land use of the surrounding area, as well as the speed of traffic (Herngren et al., 2006; Pant \& Harrison, 2013; Yuen et al., 2012).

\subsubsection{Effect of traffic speed on heavy metals concentration}

At high speeds, such as on highways, heavy metals are released at a higher rate from increased tire wear (Duong \& Lee, 2011; Pant \& Harrison, 2013). Particles resulting from tire wear typically range from $100 \mathrm{~nm}$ to $30 \mu \mathrm{m}$ in diameter. Thus, because of their larger size it is not typical for these particles to become re-suspended after deposition thus they remain on the roadway (Thorpe \& Harrison, 2008). While tires are primarily composed of petroleum products, there are certain metals used during their production, primarily zinc, that are of concern (Thorpe \& Harrison, 2008). Approximately one percent of tire tread material is made up of zinc (Zn) which is used as a catalyst during the production process (cite Bloke, 2005 (Thorpe \& Harrison, 2008). In a study by Kennedy and Gadd (2003), Zn concentrations in tire treads were found to range from 5,650-9,640 mg/kg. This poses a substantial contamination source for $\mathrm{Zn}$ as tires begin to wear and $\mathrm{Zn}$ is released into the environment and deposited on the roadway. 
Concentrations of $\mathrm{Zn}$ have been found to be higher than Lead (Pb), Copper ( $\mathrm{Cu})$, Chromium ( $\mathrm{Cr}$ ), and Nickle (Ni) regardless of surrounding land use (Bian, Lin, \& Wu, 2015). At slow speeds, heavy metals like $\mathrm{Cu}, \mathrm{Cd}, \mathrm{Cr}, \mathrm{Fe}, \mathrm{Pb}$ and again $\mathrm{Zn}$ are released from increased brake wear typical of stop-and-go traffic (Apeagyei et al., 2011; Duong \& Lee, 2011; Thorpe \& Harrison, 2008). Break pad wear generates very fine dust particles in the $100 \mathrm{~nm}$ to $\mu \mathrm{m}$ size range (Thorpe \& Harrison, 2008). These finer particles are much more prone to adsorb to particles already on the road and can have concentrations of $\mathrm{Cu}, \mathrm{Cd}, \mathrm{Cr}, \mathrm{Fe}, \mathrm{Zn}$, and $\mathrm{Pb}$ ranging from 70-39,400 $\mathrm{mg} / \mathrm{kg}, 0.06-2.6 \mathrm{mg} / \mathrm{kg}, 135-1320 \mathrm{mg} / \mathrm{kg}, 1.1-53.7 \mathrm{mg} / \mathrm{kg}, 120-27,300 \mathrm{mg} / \mathrm{kg}$, and 4-1,290 $\mathrm{mg} / \mathrm{kg}$, respectively (Thorpe \& Harrison, 2008). These fines can also easily become resuspended in the atmosphere by traffic and deposited elsewhere in the environment.

\subsubsection{Effect of average daily traffic on heavy metals concentration}

Average daily traffic (ADT) has been found to be one of the possible primary contributing factors to the degree of heavy metal contamination of RDS (Ghezzi, Moore, \& Bretsch, 2001; Miller \& Iv, 2013). A positive correlation has been found between increasing ADT and heavy metal concentrations. For instance, Irving et al. (2009) found that the concentrations of $\mathrm{Cd}, \mathrm{Cu}, \mathrm{Pb}$, and $\mathrm{Zn}$ found in street sweeping material collected from commercial/residential land use increased as ADT increased. In the case of $\mathrm{Cu}$ and $\mathrm{Pb}$ the concentrations found in street sweepings doubled with the increase in ADT (Irvine, Perrelli, Ngoen-Klan, \& Droppo, 2009). Their results are listed in table 2 below. 
Table 2:Heavy metal concentrations in road deposited sediment collected from commercial/ residential land use (Irvine et al., 2009)

\begin{tabular}{|c|c|c|c|c|}
\hline $\begin{array}{c}\text { Average Daily } \\
\text { Traffic } \\
\text { (cars/day) }\end{array}$ & $\mathrm{Cd}(\mathrm{mg} / \mathrm{kg})$ & $\mathrm{Cu}(\mathrm{mg} / \mathrm{kg})$ & $\mathrm{Pb}(\mathrm{mg} / \mathrm{kg})$ & $\mathrm{Zn}(\mathrm{mg} / \mathrm{kg})$ \\
\hline $13,560-70,137$ & 2 & 164 & 165 & 544 \\
\hline$<13,560$ & 1.5 & 73.5 & 84.9 & 413 \\
\hline
\end{tabular}

However, on higher ADT roads it appears that the volume of traffic becomes less of an influencing factor in comparison to the congestion of the traffic. This was made evident in a study by Liu et al. (2015). The authors measured the buildup of $\mathrm{Cu}, \mathrm{Zn}, \mathrm{Pb}, \mathrm{Cd}, \mathrm{Cr}$, and $\mathrm{Ni}$ on roads from ten different locations in Southern China. The ADTs of these locations ranged from 7,440 to 177,600 vehicles per day. Traffic congestion of these roads was determined using a traffic congestion coefficient defined as the reciprocal of the average vehicle speed and ranged from 0.022 to 0.040 hours per kilometer (A. Liu, Liu, Li, \& Guan, 2015). While the authors found a positive correlation between the increased heavy metal loads and traffic congestion (correlation coefficients ranging from 0.070 to 0.222 ), there was a negative correlation between traffic volume and $\mathrm{Cu}, \mathrm{Zn}, \mathrm{Cd}$, and $\mathrm{Ni}$ loads. Furthermore, they found a positive correlation between heavy metal loads and the roughness of the road (A. Liu et al., 2015). This would indicate that on higher ADT roads the volume of traffic becomes less important than the amount of stop and go traffic in conjunction with the roughness of the road. 


\subsubsection{Effect of land use on heavy metals concentration}

The land use of the surrounding area is another important factor that has been found to have an effect on heavy metals concentration in RDS (Gunawardana et al., 2012; Miller \& Iv, 2013; Yuen et al., 2012). Previous studies have found that as the land use becomes more industrialized and/or developed the levels of heavy metals found in RDS increases as well. For example, in 2009, Herra Consulting and Seattle Public Utilities conducted a pilot study of street sweeping operations in the Seattle metropolitan area. They found a consistent trend of increased average levels of cadmium, copper, lead, and zinc in industrial sweeper waste vs. residential sweeper waste (Miller \& Iv, 2013).

Table 3: Concentrations of metals in sweeper waste collected from industrial and residential areas (Miller \& IV, 2013)

\begin{tabular}{|c|c|c|}
\hline Metal & Industrial Concentration $(\mathrm{mg} / \mathrm{kg})$ & Residential Concentration $(\mathrm{mg} / \mathrm{kg})$ \\
\hline Cadmium & 0.7 & $0.5-0.7$ \\
\hline Copper & 72.6 & $34.6-37.7$ \\
\hline Lead & 192 & $51.5-63.5$ \\
\hline Zinc & 211 & $176-180$ \\
\hline
\end{tabular}

In many cases the concentrations of metals present in the RDS collected at industrial sites exceeded marine sediment standard limits. In another study conducted in Queensland, Australia RDS samples were collected from a number of different locations based on land use. These land uses included industrial, residential, commercial, as well as mixed industrial, residential, and commercial. Samples collected from these sites were analyzed for $\mathrm{Fe}, \mathrm{Al}, \mathrm{Zn}$, 
$\mathrm{Mn}, \mathrm{Cu}, \mathrm{Pb}, \mathrm{Ni}, \mathrm{Cr}$, and $\mathrm{Cd}$. The results of their analysis can be seen below in table 3. Again, a

distinct trend can be seen between industrial and residential concentrations of these metals.

Table 4: Heavy metal loading across four different land use categories in Queensland, Australia (Gunawardana et al., 2012)

\begin{tabular}{|c|c|c|c|c|c|c|c|c|c|}
\hline Land Use & $\begin{array}{c}\mathrm{Fe} \\
\left(\mathrm{mg} / \mathrm{m}^{2}\right)\end{array}$ & $\begin{array}{c}\mathrm{Al} \\
\left(\mathrm{mg} / \mathrm{m}^{2}\right)\end{array}$ & $\begin{array}{c}\mathrm{Zn} \\
\left(\mathrm{mg} / \mathrm{m}^{2}\right)\end{array}$ & $\begin{array}{c}\mathrm{Mn} \\
\left(\mathrm{mg} / \mathrm{m}^{2}\right)\end{array}$ & $\begin{array}{c}\mathrm{Cu} \\
\left(\mathrm{mg} / \mathrm{m}^{2}\right)\end{array}$ & $\begin{array}{c}\mathrm{Pb} \\
\left(\mathrm{mg} / \mathrm{m}^{2}\right)\end{array}$ & $\begin{array}{c}\mathrm{Ni} \\
\left(\mathrm{mg} / \mathrm{m}^{2}\right)\end{array}$ & $\begin{array}{c}\mathrm{Cr} \\
\left(\mathrm{mg} / \mathrm{m}^{2}\right)\end{array}$ & $\begin{array}{c}\mathrm{Cd} \\
\left(\mathrm{mg}^{2} \mathrm{~m}^{2}\right)\end{array}$ \\
\hline Industrial & 110 & 51 & 5.25 & 2.35 & 1.63 & 0.73 & 0.163 & $9.7 \times 10^{-2}$ & $5.8 \times 10^{-3}$ \\
\hline Residential & 53 & 36.5 & 2 & 1.15 & 0.69 & 0.24 & $5.5 \times 10^{-2}$ & $7.5 \times 10^{-2}$ & $3.4 \times 10^{-3}$ \\
\hline Mixed & 101 & 55 & 4.85 & 1.7 & 1.18 & 0.97 & 0.122 & 0.211 & $5.2 \times 10^{-3}$ \\
\hline Commercial & 55 & 23 & 2.3 & 1.25 & 1.67 & 0.81 & $7.8 \times 10^{-2}$ & $5.7 \times 10^{-2}$ & $1.7 \times 10^{-2}$ \\
\hline
\end{tabular}

2.3- PAHs

Polycyclic aromatic hydrocarbons (PAHs) are a group of semi-volatile chemical

compounds that can be found in all petroleum products like fuel oils as well as resulting from

the incomplete combustion of materials like wood, oil, coal, gasoline, etc. (Abdel-Shafy \&

Mansour, 2015; Dickhut E. et al., 2000). Their chemical structures are characterized as having

from two to six aromatic rings (Abdel-Shafy \& Mansour, 2015). While there are over one

hundred PAHs that can be found throughout the environment, the EPA has selected sixteen as

priority pollutants of concern. These are listed in table 3. PAHs have been shown to have

adverse effects on both human and environmental health such as cancer and birth defects. Not

only are these chemical compounds toxic but they have also been found to persist in the

environment for long periods of time in the sediments of rivers and lakes (Bostrom et al., 2002).

This can be attributed to their non-polar structure giving them a strong hydrophobicity and

preference to sorb to particulate matter (Abdel-Shafy \& Mansour, 2015). While the majority of

PAHs remain sorbed onto particulate matter once deposited in a lake or stream, lighter

molecular weight PAHs, like naphthalene, can still be dissolved back into the interstitial pore 
water of sediment (Dickhut \& Gustafson, 1995). When in the dissolved phase, PAHs are much more bioavailable and mobile in the environment. In RDS, increased levels of PAHs are most commonly found during the colder winter months due to their volatile nature (Abdel-Shafy \& Mansour, 2015; Harrison, Smith, \& Luhana, 1996; G. Liu, Tong, Luong, Zhang, \& Sun, 2010). Furthermore, not only are the concentrations of PAHs higher, there are also a greater number of PAH compounds present in the particulate phase (Harrison et al., 1996). Concentrations of lower weight more volatile PAHs like napthalene, acenaphthene, and flourene have been found to have over five times the concentration during the winter months than from the same location during the heat of the summer (Harrison et al., 1996). This is significant in terms of street sweeping due to the fact that typical sweeping operations take place in the spring and late fall in Virginia. It could be said that increased PAH concentrations should be expected from the spring sweeping campaign as these pollutants have built up in the RDS over the cold winter months.

Table 5: EPA priority PAHs, number of aromatic rings, and possible sources, 1=Coke Oven, 2=Oil Combustion, 3=Gas Combustion, 4= Diesel Combustion, 5=Incineration, 6= Wood Combustion, 7=Coal Combustion, 8=Tire wear (L. Liu et al., 2016).

\begin{tabular}{|l|l|l|l|l|l|}
\hline PAH & $\begin{array}{l}\text { Number of } \\
\text { Rings }\end{array}$ & Possible Source & PAH & $\begin{array}{l}\text { Number of } \\
\text { Rings. }\end{array}$ & $\begin{array}{l}\text { Possible } \\
\text { Source }\end{array}$ \\
\hline Naphthalene (Nap) & 2 & $1,2,3$ & Chrysene (CHR) & 4 & $3,4,7$ \\
\hline Acenaphthene (Ana) & 3 & $1,3,4$ & Pyrene (Pyr) & 4 & $3,5,6,7,8$ \\
\hline Acenaphthylene (Any) & 3 & $1,2,3$, & Benzo(a)pyrene (BaP) & 5 & $3,4,7,8$ \\
\hline Anthracene (Ant) & 3 & 4 & Benzo(b)fluoranthene (BbF) & 5 & $2,3,4$ \\
\hline Phenanthrene (Phen) & 3 & $3,4,5,6,7$ & Benzo(k)fluoranthene (BkF) & 5 & 6 \\
\hline Fluorene (Flu) & 3 & $1,2,3,4,5$ & $\begin{array}{l}\text { Dibenz(a,h)anthracene } \\
\text { (DahA) }\end{array}$ & $6,3,4$ & $2,3,4,8$ \\
\hline Fluoranthene (Fla) & 4 & $3,4,5,6,7$ & Benzo(g,h,i)perylene (BghiP) & 6 & \\
\hline Benzo(a)anthracene (BaA) & 4 & $3,4,7$ & Indeno[1,2,3-cd]pyrene (IP) & 6 & $2,3,4,8$ \\
\hline
\end{tabular}


Currently there are no regulatory limits for the concentration of PAHs in soil. However, the EPA has established a drinking water standard for one of the most carcinogenic PAHs benzo(a)pyrene (BaP), of $0.2 \mathrm{ppb}$ (Environmetal Protection Agency, 2010). It is common for the concentration of PAHs in a sample to be represented as the sum of the concentration of the sixteen PAHs ( $16 \mathrm{PAH})$. This is done in order to make comparison of results easier. However, while this can provide quick insight into the relative contamination level of a site, it can prove to be misleading from a toxicological standpoint. This is due to the fact that higher molecular weight PAHs with more than four rings like BkF and BaP are much more toxic due to their increased tendency to bind to DNA causing mutations that lead to cancer (Bojes \& Pope, 2007; Bostrom et al., 2002). Therefore, if a sample produces a result with a low $\Sigma 16 P A H$ but that sum is made up predominantly of four to six ring PAHs it has the potential to be more toxic than a higher I16PAH made up of lighter weight PAHs like Napthalene (L. Liu et al., 2016).

Since PAHs have become much more prevalent in the environment due to the increased use of fossil fuels and petroleum products it is important to determine which of these can be attributed to increased PAH concentrations of a material. A number of different methods can be used to do this. One of the most common methods involves looking at the ratio of concentrations of low molecular weight ( $\mathrm{LMW}, \leq 3$ rings) to high molecular weight (HMW, $\geq 4$ rings) PAHs (Abdel-Shafy \& Mansour, 2015; Pantano, Ferrizzi, Bisinoti, \& Moreira, 2016). Samples containing a greater degree of LMW than HMW PAHs typically can be attributed to pyrolytic sources like the burring of wood or other organic matter. Furthermore, since LMW PAHs are characteristically more volatile it can be assumed that the contamination event occurred more recently or is chronic (Cai et al., 2007). On the other hand, samples exhibiting 
higher concentrations of HMW PAHs can typically be attributed to petrogenic sources, such as oil and gas (Abdel-Shafy \& Mansour, 2015; Pantano et al., 2016).

\subsubsection{Effect of land use on PAH concentrations}

The land use of an area can have a significant impact on the concentrations of PAHs present in the environment. Increased concentrations of PAHs have been found in industrial and commercial land use areas when compared to single and multi-family residential areas (Bucheli, Blum, Desaules, \& Gustafsson, 2004; Lau \& Stenstrom, 2005; Mielke et al., 2004). For instance, Lau \& Stenstrom (2005) took RDS samples from 18 different locations in Los Angeles, California with the following land use categories: industrial, multifamily residential, single family residential, roads, and commercial. They found that of the five land use categories sampled the commercial land use had the highest $\Sigma 16 \mathrm{PAH}$ concentration with an average of $14.5 \mu \mathrm{g} / \mathrm{g}$, followed by roads with an average $\Sigma 16 \mathrm{PAH}$ concentration of $10.2 \mu \mathrm{g} / \mathrm{g}$, industrial $\Sigma 16 \mathrm{PAH}$ concentration of $9.2 \mu \mathrm{g} / \mathrm{g}$, multifamily residential $7.2 \mu \mathrm{g} / \mathrm{g}$, and the lowest $\Sigma 16 \mathrm{PAH}$ concentration of $2.2 \mu \mathrm{g} / \mathrm{g}$ (Lau \& Stenstrom, 2005). This is not surprising since a lot of manufacturing, car repair shops, and a whole sale chemical distribution center were located in the three industrial sites. Furthermore, the roads land use category consisted of large intersections with gas stations adjacent to them. These are definite sources of PAHs and are typical of these land uses. Another study conducted in Louisiana found similar results in soil samples taken adjacent to busy streets, residential streets, open areas, and at the foundations of buildings in both suburban and urban areas (Mielke et al., 2004). They found that samples collected from busy streets in both the urban and suburban areas had over double the average $\Sigma 16 \mathrm{PAH}$ concentration of $2.469 \mathrm{mg} / \mathrm{kg}$ compared to the second highest concentration of 1.188 
$\mathrm{mg} / \mathrm{kg}$ taken from building foundations (Mielke et al., 2004). The land use with the lowest $\sum 16 \mathrm{PAH}$ concentration were the open space areas with an average concentration of 0.975 $\mathrm{mg} / \mathrm{kg}$ (Mielke et al., 2004). Furthermore, Benzo(b)fluoranthene, Benzo(a)pyrene, and Indeno[1,2,3-cd]pyrene were the three PAHs with the highest concentrations in the majority of the samples collected. This is most likely due to their heavier molecular weight and lower volatility (Mielke et al., 2004).

\subsubsection{Effect of average daily traffic on PAH concentrations}

Since a number of PAHs like Anthracene, Fluoranthene, Chrysene, and Benzo(a)anthracene have been identified as resulting from petroleum combustion (Cai et al., 2007; G. Liu et al., 2010), it would be expected that as the traffic load increases, an increase in PAH concentrations would be seen as well. However, this does not appear to be the case according to the literature. A number of studies looking at PAHs in both RDS as well as the soil adjacent to the road have found that some of the lowest concentrations were in the highest ADT categories considered. For instance, Wang et al. (2010), took samples of RDS from roads across five different ADT classifications including 110,000 cars/day, 45,000 cars/day, 17,000 cars/day, 3,000 cars/day, and finally a walking street with zero cars/day. The authors found that the walking street with no exposure to vehicle traffic had the second highest $\Sigma 16 \mathrm{PAH}$ concentration of $3.4 \mathrm{mg} / \mathrm{kg}$ with the highest $\Sigma 16 \mathrm{PAH}$ concentration of $3.52 \mathrm{mg} / \mathrm{kg}$ being found in the 3,000 cars/day classification (Wang et al., 2010). The results of this study can be found in Figure 1 below. Furthermore, the highest concentration of Benzo(a)pyrene, one of the most carcinogenic of EPA 16 PAHs, was found at the walking street location. 
Similar trends have also been found in the soil adjacent to roads as well. Van Dolah et al. (2005) conducted experiments measuring the concentrations of 25 different PAHs from soil samples taken adjacent to roads in South Carolina. A total of twelve different locations across three different ADT classifications ( $<5,000$ cars/day, 10,000-15,000 cars/day, and >25,000 cars/day) were sampled. The authors found that samples taken from the $>25,000$ cars/day consistently had lower average concentrations of the 25 PAHs than both of the other ADT classifications (Van Dolah et al., 2005). Both of these papers provide interesting results. While it could be argued that the increased traffic volume could be causing the PAH contaminated particulate matter to be blown off of the road thus reducing the pollutant load on the road surface, one would then expect to see an increase in PAH concentrations in the soil adjacent to the roadway. However, as both of these papers have shown this is not the case. 


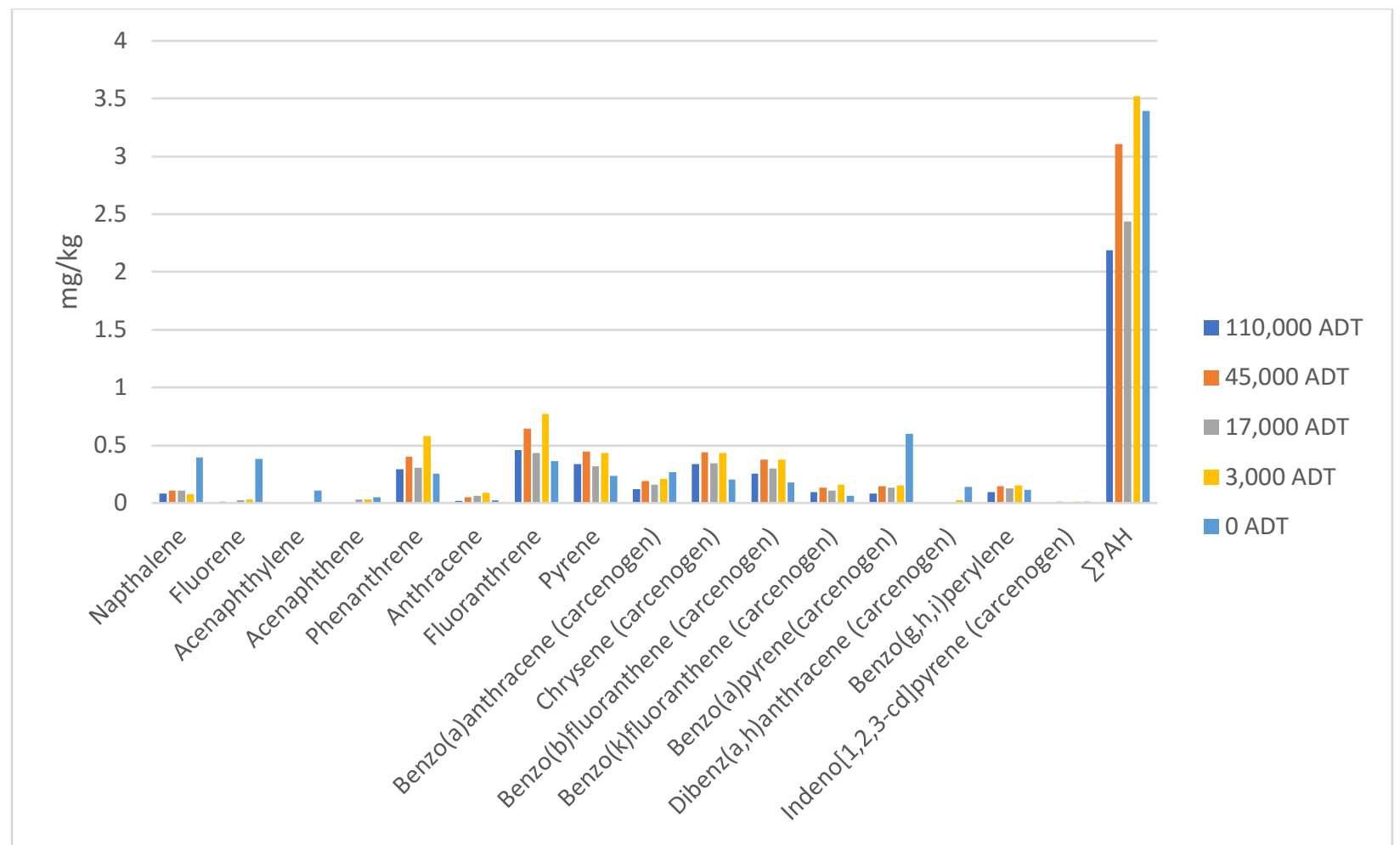

Figure 1: Concentration of PAHs across five different ADT classifications. (Wang et al., 2010) 


\section{4-Effect of particle size on heavy metals and PAHs concentrations}

There are a number of factors that can affect the particle size distribution of RDS. Increased levels of ADT can lead to mechanical weathering of RDS thus increasing the amount of fines. It has also been found that variations in wet and dry periods can lead to fines either washing off or building up on the roadway, while large particles remain unaffected (Wijesiri, Egodawatta, McGree, \& Goonetilleke, 2015). The time of year also plays an important role in particle-size distribution. During the winter, traction sand is applied to the roadway increasing the amount of coarse particles.

It is well understood that as the particle size decreases the specific surface area increases assuming that all particles are spheres. This greater specific surface area typically correlates with increased sorption of contaminants, like PAHs and heavy metals, to attach to (Azah, Kim, \& Townsend, 2015; Gunawardana, Egodawatta, \& Goonetilleke, 2014; Lau \& Stenstrom, 2005; Wang et al., 2010). A number of studies have found that the majority of pollutants in RDS can be found in the smaller size fractions from the 0-300 $\mu \mathrm{m}$ range. For instance Sutherland et al. (2012) measured the concentration of $\mathrm{Zn}, \mathrm{Pb}$, and $\mathrm{Cu}$ in six different grain size classes $(1000-2000 \mu \mathrm{m}, 500-1000 \mu \mathrm{m}, 250-500 \mu \mathrm{m}, 125-250 \mu \mathrm{m}, 63-125 \mu \mathrm{m}$, and $<63 \mu \mathrm{m}$ ) from various sites across the island of Oahu, Hawaii. They consistently found that the lowest concentration of all of these metals was found in the 1,000-2,000 $\mu \mathrm{m}$ fraction $(\mathrm{Zn}=300$ $\mathrm{mg} / \mathrm{kg}, \mathrm{Pb}=375 \mathrm{mg} / \mathrm{kg}, \mathrm{Cu}=150 \mathrm{mg} / \mathrm{kg}$ ). On the other hand the highest concentrations of $\mathrm{Zn}, \mathrm{Pb}$ and Cu were found in the $<63 \mu \mathrm{m}(900 \mathrm{mg} / \mathrm{kg}), 63-126 \mu \mathrm{m}(1,000 \mathrm{mg} / \mathrm{kg}) \mathrm{m}$ and $63-125 \mu \mathrm{m}(475$ $\mathrm{mg} / \mathrm{kg}$ ) respectively (Sutherland, Tack, \& Ziegler, 2012). Another study in Beijing, China measured the concentrations of $\mathrm{Cr}, \mathrm{Cu}, \mathrm{Ni}, \mathrm{Cd}, \mathrm{Pb}$, and $\mathrm{Zn}$ in five different particle sizes from a 
high ADT road (109,500 vehicles/day) (Tian, Li, \& Yang, 2009). The authors found that over $45 \%$ of the heavy metal concentration was found in the size fraction smaller than $125 \mu \mathrm{m}$ (Tian et al., 2009). Furthermore, the authors compared the heavy metal concentration in each particle size before and after rain events. They found that rain events have a much more prominent effect on smaller size particles, washing them off the road. This led to a heavy metal concentration reduction of up to $55.4 \%$. However, this was dependent on the intensity of the rain event. During higher intensity rain events larger particles were increasingly washed away (Tian et al., 2009).

PAHs show a similar affinity for finer particles as heavy metals. For instance, in a study by Wang et al. (2010), the distribution of PAHs across a range of particle sizes from street dust was investigated. The authors broke down their samples into five different size fractions including: $<40 \mu \mathrm{m}, 40-74 \mu \mathrm{m}, 74-125 \mu \mathrm{m}, 125-300 \mu \mathrm{m}$, and 300-500 $\mu \mathrm{m}$. While on average the $125-300 \mu \mathrm{m}$ size fraction made up the majority of the sample mass at $31 \%$, they found that the particles smaller than $40 \mu \mathrm{m}$ had the highest concentration of $\Sigma 16 \mathrm{PAHs}$ (Wang et al., 2010). Another study in Florida tested material from a stock pile and found similar results with the greatest concentration of all PAHs present to be in the finest fraction tested, in this case $<785$ $\mu \mathrm{m}$ (Azah et al., 2015). 


\subsection{Oil and Grease}

Oil and Grease $(O \& G)$ is a range of contaminants made up of both fatty material from plants and animals as well as aliphatic hydrocarbons (Boxall \& Maltby, 1995; Khan, Lau, Kayhanian, \& Stenstrom, 2006; Rauckyte et al., 2010; Stenstrom, Silverman, \& Bursztynsky, 1984). On a roadway these contaminants are most commonly associated with motor oil and other lubricating oils used in cars and trucks and their presence can easily be identified by the iridescent sheen they give to surface waters (Khan et al., 2006; Stenstrom et al., 1984). Oil and Grease is commonly considered an important stormwater runoff contaminant and has been studied predominantly in the liquid fraction of runoff. For instance, Stenstrom et al. (1984) measured the concentration of oil and grease in stormwater runoff from a number of different locations with varying land use in Richmond, California. They found that of the five land uses sampled, open land, residential, industrial, commercial, parking lots, and freeways and railroads, commercial property and parking lots had the highest oil and grease concentrations at $13.13 \mathrm{mg} / \mathrm{l}$ and $12.81 \mathrm{mg} / \mathrm{l}$ respectively (Stenstrom et al., 1984). The next highest O\&G concentrations were 7.10 and $4.04 \mathrm{mg} / \mathrm{l}$ and were found at industrial properties and freeways respectively (Stenstrom et al., 1984). These are interesting results because it emphasizes the effect parked non-moving cars have on the release of $O \& G$ into the environment. Another more recent study by Chow, Yusop, and Shirazi (2013) compared the pollutant load in runoff from residential, commercial and industrial land uses. The authors found that the event mean concentration of O\&G in stormwater runoff increased as land use intensity increased, (residential< commercial< light industrial), with event mean concentrations equal to $2.32 \mathrm{mg} / \mathrm{l}$, $3.66 \mathrm{mg} / \mathrm{l}$, and $4.47 \mathrm{mg} / \mathrm{l}$ respectively (Chow, Yusop, \& Shirazi, 2013). Interestingly enough no 
correlation has been found between ADT and O\&G concentrations in road runoff (Khan et al., 2006). While the results from these papers give a good idea of the range of concentrations of oil and grease in stormwater runoff there is very little, if any information on oil and grease in RDS.

\section{5- Street Sweeper technology}

Street sweeper technology has seen a significant increase in effectiveness in recent years (Amato, Querol, Johansson, Nagl, \& Alastuey, 2010; Curtis, 2002). There are a number of common types of street sweepers currently in use. These include mechanical broom sweepers, vacuum assisted mechanical broom, regenerative air sweepers, and vacuum sweepers (Amato et al., 2010). Table 4 below, outlines how each sweeper works and their effectiveness at picking up various particle sizes.

Table 6: The three most common street sweeper technologies and their efficiencies.

\begin{tabular}{|c|c|c|c|}
\hline & Mechanical Broom & $\begin{array}{l}\text { Vacuum assisted. } \\
\text { Mechanical Broom }\end{array}$ & Regenerative Air \\
\hline Overview & $\begin{array}{l}\text { Uses two large gutter } \\
\text { brushes to push } \\
\text { material into a } \\
\text { central pick-up } \\
\text { brush. The pick-up } \\
\text { brush then pulls the } \\
\text { material off the } \\
\text { roadside and into an } \\
\text { onboard container. }\end{array}$ & $\begin{array}{c}\text { Similar to the } \\
\text { Mechanical Broom } \\
\text { sweeper but with a } \\
\text { vacuum to assist in } \\
\text { pickup. }\end{array}$ & $\begin{array}{l}\text { Uses gutter brooms } \\
\text { to sweep material } \\
\text { into a pick-up head } \\
\text { where air is blown } \\
\text { down to loosen and } \\
\text { suspend particles } \\
\text { before it is vacuumed } \\
\text { back up. }\end{array}$ \\
\hline Effectiveness & $\begin{array}{l}\text { - Most effective at } \\
\text { picking up larger } \\
\text { particles. } \\
\text { •80\% efficiency with } \\
\text { particles larger than } \\
2 \mathrm{~mm}\end{array}$ & $\begin{array}{c}\bullet \text { Very effective at } \\
\text { picking up ultra-fines } \\
(0-10 \mu \mathrm{m}=>90 \% \\
\text { efficiency) } \\
\bullet \text { Only } 50 \% \text { efficiency } \\
\text { for particle > } 2 \mathrm{~mm} \text {. }\end{array}$ & $\begin{array}{c}\bullet \text { Moderately } \\
\text { effective at picking } \\
\text { up all sizes of } \\
\text { particles. }\end{array}$ \\
\hline
\end{tabular}


In terms of pollutant removal, it has been found that street sweeping has very low effectiveness at reducing the load of pollutants from effluent stormwater (Selbig \& Bannerman, 2007; Yee, 2005). This is primarily due to their relative ineffectiveness at removing the finer particle sizes associated with the pollutant load (Selbig \& Bannerman, 2007). While regenerative air street sweepers have proven to be very effective at removing particles smaller than $60 \mu \mathrm{m}$, they have yet to be widely implemented (Seattle Public Utilities \& Herrera Environmental Consultants, 2009). However, this can be a benefit from a reuse stand point due to the fact that in many cases, coarser material is much more useful for reuse. For example, in a pilot study by Seattle Public Utilities, RDS samples were taken directly from the road as well as from stock piles of waste collected by street sweepers. They found that samples collected directly from the road had a percent of particles $<75 \mu \mathrm{m}$ up to $12 \%$, while material taken from the stock piles consisted of at most $8 \%$ particles $<75 \mu \mathrm{m}$; the same can be said for the $75-250 \mu \mathrm{m}$ particle size range (Seattle Public Utilities \& Herrera Environmental Consultants, 2009). However, the particle size ranges greater than $250 \mu \mathrm{m}$ were all equal to or greater than that of the samples taken directly from the road (Seattle Public Utilities \& Herrera Environmental Consultants, 2009). 


\section{Chapter 3- Purpose and Scope}

The purpose of this research endeavor was to conduct an extensive characterization of RDS collected throughout the state of Virginia. This information can be used to help attain a BUD for this waste stream. Eighty sampling locations were selected based on average daily traffic and the National Land Cover Database designation of the surrounding area. All of these sites were characterized for heavy metals including $\mathrm{Zn}, \mathrm{Cu}, \mathrm{As}, \mathrm{Ba}, \mathrm{Cd}, \mathrm{Cr}$, Se, $\mathrm{Pb}$, and $\mathrm{Ag}$ as well as the sixteen EPA priority Polycyclic Aromatic Hydrocarbons, and oil and grease concentrations. These contaminants were chosen due to their relevance in storm water contamination, toxicity, as well as their persistence in the environment. Furthermore, the quantification of a number of these contaminants in RDS is required by the VADEQ under the BUD code (Virginia Waste Managment Board, 2015).

By attaining a BUD for RDS collected during street sweeping operations a significant waste stream could potentially be reduced and reused. It is estimated that VDOT collects hundreds of tons of RDS each year. Currently, all of this material is sent either to a maintenance facility and stored until disposal or sent directly to a landfill. A substantial portion of this material has been found by other states and municipalities to be useful material. Efforts made in Edmonton Canada have led to the reuse of $80 \%$ of the 115,000 tones of winter traction sand used each year (City of Edmonton, 2003). This would represent a huge savings for VDOT as winter maintenance makes up a large majority of the annual budget. 


\section{Chapter 4- Methods}

\section{1- Site Selection}

Eighty sampling locations were selected throughout the state of Virginia using ArcMap 10.4.1. These locations were selected based on both average daily traffic volumes (ADT) as well as the land cover of the surrounding area. Roads were sorted into six ADT groups as follows: 1400; 401-1,500; 1,501-2,000; 2,001-4,000; 4,001-10,000; >10,000 cars per day. This grouping was chosen due to its common usage within the Virginia Department of Transportation. Land cover data for the state of Virginia was obtained from the 2011 National Land Cover Database (NLCD). This data set was created by the Multi-Resolution Land Characteristics Consortium (MRLC) and provides raster data with a spatial resolution of 30 meters and represents land cover data as sixteen different classifications in raster format (Homer et al., 2015). This data is commonly used to determine various surface characteristics such as land use, percent impervious surface, and the amount of tree cover. The classifications implemented for site selection in this research included: developed, open space; developed, low intensity; developed, medium intensity, and developed, high intensity. These classifications are defined as follows in Table 5. A map of all 80 sampling sites is provided in Figure 18 of the appendix. 


\begin{tabular}{|c|c|}
\hline Classification & Description \\
\hline Developed, Open Space & $\begin{array}{l}\text { Areas with a mixture of some constructed } \\
\text { materials, but mostly vegetation in the form } \\
\text { of lawn grasses. Impervious surfaces account } \\
\text { for less than } 20 \% \text { of total cover. These areas } \\
\text { most commonly include large-lot single } \\
\text { family housing units, parks, golf courses, and } \\
\text { vegetation planted in developed settings for } \\
\text { recreation, erosion control, or aesthetic } \\
\text { purposes. }\end{array}$ \\
\hline Developed, Low Intensity & $\begin{array}{l}\text { Areas with a mixture of constructed } \\
\text { materials and vegetation. Impervious } \\
\text { surfaces account for } 20 \% \text { to } 49 \% \text { of total } \\
\text { cover. These areas most commonly include } \\
\text { single-family housing units. }\end{array}$ \\
\hline Developed, Medium Intensity & $\begin{array}{l}\text { Areas with a mixture of constructed } \\
\text { materials and vegetation. Impervious } \\
\text { surfaces account for } 50 \% \text { to } 79 \% \text { of the total } \\
\text { cover. These areas most commonly include } \\
\text { single-family housing units. }\end{array}$ \\
\hline Developed, High Intensity & $\begin{array}{l}\text { Highly developed areas where people reside } \\
\text { or work in high numbers. Examples include } \\
\text { apartment complexes, row houses and } \\
\text { commercial/ industrial. Impervious surfaces } \\
\text { account for } 80 \% \text { to } 100 \% \text { of the total cover. }\end{array}$ \\
\hline
\end{tabular}

Table 5: NLCD categories used and their descriptions (Homer et al., 2015)

Using these two data sets in ArcMap, sites were located first based on ADT. Once a potential sampling site was located a $\mathbf{1 5 2 . 4}$ meter buffer from the center line was placed along the section of road to extract the NLCD data for that given area. This distance was chosen due to the resolution of the land cover data available (about 30.48 meters) (Homer et al., 2015). With the NLCD data extracted the land cover category was assigned based on the category with the greatest number of pixels present. Care was taken to ensure that no two sampling sites were located too closely together. Since the majority of street sweeping activity takes place on roads with curb and gutter, all efforts were made to limit site selection to locations with these 
characteristics. However, this was not possible with all sites, thus 16 sites have no curb and gutter and transition directly from the driving surface to a grass or dirt shoulder. A map of all sites sampled in provided in the appendix.

\subsection{Sampling Procedure}

Sampling was commenced Wednesday, July 6, 2016. All samples were taken after no less than two days of antecedent dry period. This ensured that the RDS collected was relatively dry and would not stick excessively to the inside of the shop-vac hose and contaminate subsequent samplings. Furthermore it has been found that PAH contaminant load of RDS increases with the number of dry days, peaking at 14 days (L. Liu et al., 2016).

A 5 gallon, 4.5 hp wet dry shop-vac model number $87762-76$ was used to collect samples from the roadway. Similar methods of sampling have been used in the past by Wang et al. 2010, Tian et al. 2009, Duong and Lee 2011. Gunawardana et al. 2012 used a vacuuming technique that involved a water filter to collect the ultra-fine fraction of RDS in order to characterize the heavy metal build up on roads. However, while this method was capable of collecting very small particle sizes it involved oven drying the samples. This is acceptable for metals analysis but poses a concern when analyzing for PAHs due to their volatility. High efficiency disposable Shop-Vac brand bags (model number 906719) were used as collection bags inside the shop vac. These bags were selected due to their similar performance when compared to high-efficiency particulate air filter bags. While the high-efficiency particulate air filter bags had a smaller pore diameter of less than $0.3 \mu \mathrm{m}$, removal of the sample from the bag was much more difficult and resulted in loss of more fines from the sample. Power was supplied to the shop vac using a Honda generator placed 6.1 meters away from the sampling 
location in order to reduce the possibility of contamination. Using straight hose extensions, a rectangular vacuum tip was drawn perpendicular to traffic from about two meters from the shoulder of the road outward. This was repeated until enough volume of RDS had been collected to provide a representative sample. The average mass of sample collected from each site was about 1,500 grams. Once the sample was collected the bag was removed from the shop vac and placed in two self-closing plastic bags and labeled with the time, date, and location. All samples were stored on ice while in transport back to the lab. In order to minimize and prevent cross contamination of samples the shop vac hose was cleaned using an air duct brush and the inside of the shop vac tank were wiped down after every three samples. This cleaning method was confirmed in the lab by passing virgin sand through the vacuum at the end of a sampling day. Results from this experiment showed no signs of significant cross contamination. While some of the fines smaller than $75 \mu \mathrm{m}$ are inevitably lost during sampling this method provides similar if not higher particulate removal efficiencies as regenerative air street sweepers.

\subsection{Sample Preparation}

Upon return to the lab samples were stored at $2.8^{\circ} \mathrm{C}$ until extraction and digestion. At the time of digestion and extraction the samples were removed from the shop vac bags, rebagged in plastic ziploc bags and weighed. Portions of each bulk sample were taken from these bags for sieving, digestion, and extractions.

\subsubsection{Metals Digestion}

Microwave digestion was used to prepare samples for analysis on the inductively coupled mass spectrometry. A MARS 6 microwave digester produced by CEM Corporation was 
used to perform the digestions. EPA method 3051 was followed. From each bulk sample bag, $0.5 \mathrm{~g}$ was taken and placed in a digestion vessel. The Mars 6 digestion vessels are comprised of three parts (as seen in figure 19 of the appendix), a perfluoroalkoxy alkane (PFA) tube and screw cap, and an inner plastic pressure release cap. After the $0.5-\mathrm{g}$ sample was placed in the digestion vessel, $10 \mathrm{~mL}$ of Fisher Scientific trace metals grade concentrated nitric acid was added to each vessel as well as one empty vessel to act as a method blank. The vessels were then screwed closed using the manufacturers provided torque wrench. Once closed the vessels were then transferred into the microwave rotor for processing. The microwave heating cycle was programmed according to EPA method 3051. This method calls for a heating ramp of $5^{\circ} \mathrm{C}$ per minute until the temperature inside the vessels reached $112^{\circ} \mathrm{C}$ where it was held for ten minutes. At the end of the ten-minute heating cycle the vessels were allowed to cool to about $80^{\circ} \mathrm{C}$, after which they were removed from the microwave and placed in the fume hood and allowed to cool to room temperature. The contents of each vessel were then transferred to labeled $50 \mathrm{~mL}$ polypropylene centrifuge tubes and centrifuged for twenty minutes at 3,000 rpm. After being centrifuged $9 \mathrm{~mL}$ of the supernatant was pipetted off of the top layer of the vessels and transferred to new centrifuge tubes. The samples were then diluted to a $14 \%$ nitric acid concentration using $36 \mathrm{~mL}$ of ASTM type 1 water and refrigerated until analysis. Prior to analysis the samples were again centrifuged at 3,000 rpm for twenty minutes. In order to reduce the acid concentration of samples for analysis on the ICP-MS, the samples were further diluted to $3 \%$ nitric acid by transferring $3 \mathrm{~mL}$ of the sample to a $16.5 \mathrm{~mL}$ auto sampler tube along with $11 \mathrm{~mL}$ of ASTM type 1 water. Following this dilution, the samples were transferred to the ICP-MS auto sampler for analysis. The recovery efficiency of this digestion method have 
been verified using SRM 2704 (Buffalo River Sediment) and have values of $98.5 \%$ for Cd, $62.7 \%$ for $\mathrm{Cr}$, and $101.2 \%$ for $\mathrm{Pb}$ (Link, Walter, \& Kingston, 1998). Further confirmation was conducted by spiking a blank four g sediment sample with four $\mu \mathrm{g}$ of silver as silver nitrate. The mixture was allowed to sit covered overnight in the refrigerator and then digested in quadruplicate in the microwave along with four other blanks. The samples were then diluted to $3 \%$ nitric acid thus giving an expected silver concentration of $5 \mathrm{ppb}$. The results of this experiment are provided below.

Table 7: Recovery efficiency of the microwave digestion procedure

\begin{tabular}{|l|l|l|l|}
\hline Sample & Reported Conc. $(\mu \mathrm{g} / \mathrm{l})$ & $\mathrm{SD}$ & $\%$ Recovery \\
\hline 1 & 2.161 & $1.17 \times 10^{-3}$ & 43.22 \\
\hline 2 & 5.721 & $9.45 \times 10^{-3}$ & 114.42 \\
\hline 3 & 4.041 & $3.58 \times 10^{-3}$ & 80.82 \\
\hline 4 & 7.555 & $4.21 \times 10^{-3}$ & 151.1 \\
\hline
\end{tabular}

\subsubsection{Size fractioning}

In order to determine the relationship between particle size and concentration of heavy metals and PAH concentration samples from the 4,001-10,000 ADT categories (totaling 16 sites) were screened into five different particle sizes. This ADT category was chosen due to the increased likelihood of PAH contamination from its increased traffic load. These particle sizes included $<75 \mu \mathrm{m}, 75-150 \mu \mathrm{m}, 150-300 \mu \mathrm{m}, 300-600 \mu \mathrm{m}$, and 600 $4 \mathrm{~m}-1.18 \mathrm{~mm}$. About five hundred grams of sample was screened from each sample site. This provided enough material to maintain a representative sample as well as enough mass of sample in each size for analysis. Five screen sizes were used during the sieve analysis; these included $75 \mu \mathrm{m}, 150 \mu \mathrm{m}, 300 \mu \mathrm{m}$, $600 \mu \mathrm{m}$, and $1.18 \mathrm{~mm}$. All sieves used were Gilson brand six-inch brass ringed stainless steel 
screened sieves. Samples were sieved for ten minutes on Gilson model SS-15D sieve shaker, as per ASTM D6913 specifications. Following sieving each particle size was placed into a labeled plastic bag, weighed, and refrigerated until analysis. In between each sample the sieves were scrubbed clean with a stainless-steel brush to remove trapped particles, scrubbed again with soap and water, and then rinsed thoroughly with ASTM type 1 water and dried at $100^{\circ} \mathrm{C}$.

\subsubsection{EPA 16 PAH extraction}

PAH extraction was completed using a CEM Mars 6 Microwave digestion/ extraction apparatus following EPA method 3546. A 10-g sample was placed into the extraction vessel along with $15 \mathrm{~mL}$ of Optima grade hexane, $15 \mathrm{~mL}$ of HPLC grade acetone and a stir bar, one vessel contained only $30 \mathrm{~mL}$ of 1:1 hexane and acetone and a stir bar to act as a method blank. The vessels were then capped and tightened according to the manufacturers specification and placed into the microwave rotor for extraction. The microwave was then programmed according to the EPA method 3546 heating profile. This consisted of heating the vessels to $115^{\circ} \mathrm{C}$ and holding this temperature for 20 minutes. Twelve samples and one method blank were extracted during each run. Once the heating cycle completed the samples were allowed to cool to room temperature and placed in the fume hood. Following cooling, each vessel was opened individually to avoid the evaporation of the solvent. The sample was then pipetted out of the extraction vessel and into one of two $7 \mathrm{ml}$ borosilicate glass screw top vials and capped with a foil lined screw top cap. Care was taken to ensure that as there was as little headspace as possible in each vial. Samples were refrigerated until analysis. Prior to analysis, $2 \mathrm{ml}$ of each sample was filtered through $0.45 \mu \mathrm{m}$ PTFE syringe filters using glass leur lock syringes. The filtrate was collected in $2 \mathrm{~mL}$ crimp top amber glass auto sampler vials with red rubber septum. 
Again, car was taken to ensure a small amount of headspace. These samples were then transferred to the GC-MS auto sampler and analyzed.

\subsubsection{Oil and Grease extraction}

Oil and Grease extraction was conducted using Horiba Instruments S-316 solvent $\left(\mathrm{Cl}\left(\mathrm{CF}_{2}-\mathrm{CFCl}\right)_{2} \mathrm{Cl}\right)$. This solvent has a low volatility, not miscible in water, and stable at a wide range of temperatures. From each sample, 1-g of RDS was weighed out to the nearest tenth of a gram in a $40 \mathrm{~mL}$ glass beaker. About 1-g of anhydrous sodium sulfate was then added to each beaker to dry the sample. Using a $10 \mathrm{~mL}$ pipette, $30 \mathrm{~mL}$ of S-316 solvent was added to each beaker and stirred using a metal spatula for one minute. The samples were then allowed to sit for one minute to allow the solids to settle to the bottom of the beaker. After one minute, approximately one gram of 100-200 mesh chromatographic grade silica gel was added to Whatman \#41 filter papers and the samples were gravity filtered into clean $40 \mathrm{ml}$ glass beakers. Following this process, the samples were then ready for analysis on the OCMA 350 Oil Content analyzer.

\subsection{Sample Analysis}

\subsubsection{Metals Analysis}

An Agilent 7900 Quadripole inductively coupled mass spectrometry was used to quantify the concentrations of $\mathrm{As}, \mathrm{Ba}, \mathrm{Cd}, \mathrm{Cr}, \mathrm{Pb}, \mathrm{Se}, \mathrm{Ag}, \mathrm{Cu}$, and $\mathrm{Zn}$ in each of the samples. Prior to each analysis run the instrument was calibrated using a multi-metal CIÅRITAS PPT ${ }^{\circledR}$ certified reference material. The calibration concentrations used were $0.01 \mathrm{ppb}, 1 \mathrm{ppb}, 10 \mathrm{ppb}$, $100 \mathrm{ppb}$, and $1 \mathrm{ppm}$ in a 3\% nitric acid solution. Dilutions of the stock standard were made using trace metals grade $\mathrm{HNO}_{3}$ and ASTM type 1 water. Prior to the analysis of each sample a 
tuning solution was injected containing $1 \mu \mathrm{g} / \mathrm{L}$ of $\mathrm{Ce}, \mathrm{Co}, \mathrm{Li}, \mathrm{Mg}, \mathrm{Tl}$, and $\mathrm{Y}$ in $2 \% \mathrm{HNO}_{3}$. A $1 \mathrm{mg} / \mathrm{L}$ internal standard containing $6 \mathrm{Li}, \mathrm{Sc}, \mathrm{Ge}, \mathrm{Rh}, \mathrm{In}, \mathrm{Tb}, \mathrm{Lu}$, and $\mathrm{Bi}$ in $3 \% \mathrm{HNO}_{3}$ was used throughout the analysis. Both the internal standard and the tuning solution were obtained from Agilent Technologies. Argon was used as the carrier gas and helium was used as the collision gas. Every ten samples a $1 \mu \mathrm{g} / \mathrm{L}$ continuing calibration verification standard, made using the same stock standard as the calibration standards and in the same matrix, was tested for quality assurance. Table 7 below is an overview of the general instrument parameters used on the IPC-MS.

\section{Table 8: Instrument parameters used for the ICP-MS}

\begin{tabular}{|c|c|}
\hline Parameter & Setting \\
\hline Carrier gas flow (L/min) & 50 \\
\hline Dilution gas flow (L/min) & 50 \\
\hline $\begin{array}{c}\text { Collision gas flow } \\
\text { (mL/min) }\end{array}$ & 10 \\
\hline Nebulizer pump (rps) & 0.3 \\
\hline ISIS & 30 \\
\hline Load Time (s) & 0.3 \\
\hline Load Speed (rps) & 40 \\
\hline Stabilization Time (s) & 10 \\
\hline Rinse Time (s) & 0.1 \\
\hline Rinse Speed (rps) & 1 \\
\hline Acquisition & 3 \\
\hline Points Per Peak & 100 \\
\hline Replicates
\end{tabular}

\subsubsection{EPA 16 PAH Analysis}

Samples from each NLCD and ADT combination as well as fractionated samples were selected for PAH analysis. The analysis was conducted on a Shimadzu GCMS-QP2010 SE gas chromatograph-mass spectrometer with an Agilent J\&W DB-EUPAH column. The column 
dimensions were $20 \mathrm{~m} \times 0.18 \mathrm{~mm}$ with a $.14 \mu \mathrm{m}$ film thickness. This column is specifically designed for the analysis of the 16 EU and EPA regulated PAHs. Helium was used as the carrier gas and had a constant flow rate of $1.8 \mathrm{~mL} / \mathrm{min}$. The oven temperature was set initially to $70^{\circ} \mathrm{C}$ for 0.8 minutes followed by heating ramps of $70^{\circ} \mathrm{C} / \mathrm{min}$ to $180^{\circ} \mathrm{C}, 7^{\circ} \mathrm{C} / \mathrm{min}$ to $230^{\circ} \mathrm{C}$ and holding for 6 minutes, $40^{\circ} \mathrm{C} / \mathrm{min}$ to $280^{\circ} \mathrm{C}$ and holding for 5 minutes, and finally $25^{\circ} \mathrm{C} / \mathrm{min}$ to $320^{\circ} \mathrm{C}$ and holding for 5 minutes. The inlet temperature was set to $300^{\circ} \mathrm{C}$ and a splitless injection was used due to the low concentration of the samples. The purge rate was set at $100 \mathrm{~mL} / \mathrm{min}$ at 0.25 minutes. The sample injection volume was $1 \mu \mathrm{L}$. Prior to analysis the instrument was calibrated using 10 ppb, 50 ppb, 100 ppb, 500 ppb, and 1 ppm calibration standards. These standards were prepared from a certified reference solution containing 2000 ppm of each EPA $16 \mathrm{PAH}$ in a solution of 50:50 Benzene: Methylene Chloride and was supplied by SPEXOrganics. The certified reference solution was diluted down to the required concentrations using pesticide grade Methylene Chloride from Fisher Scientific and stored in amber glass crimp top vials in a refrigerator until calibration. The storage time of these standards was kept to a minimum to reduce concentration of the standards by volatilization.

\subsubsection{Oil and Grease Analysis}

Oil and grease analysis was conducted on RDS collected from all 80 locations. Analysis was conducted using a Horiba Instruments OCMA 350 oil content analyzer. This instrument uses non-dispersive infrared absorption spectroscopy to measure the oil content in both soil and water samples. The instrument has a detection range of 0 to $1000 \mathrm{mg} / \mathrm{kg}$ and a variable resolution of $0.01 \mathrm{mg} / \mathrm{kg}$ for 0 to $9.9 \mathrm{mg} / \mathrm{kg}, 0.1 \mathrm{mg} / \mathrm{kg}$ for 10 to $99.99 \mathrm{mg} / \mathrm{kg}$, and $1 \mathrm{mg} / \mathrm{kg} 100$ to $1000 \mathrm{mg} / \mathrm{kg}$. Prior to analysis a $200 \mathrm{mg} / \mathrm{l}$ span calibration standard was prepared using $56 \mu \mathrm{l}$ 
of Horiba Heavy B-oil standard dissolved in $250 \mathrm{~mL}$ of S-316 solvent. The instrument was calibrated using clean S-316 solvent as the zero-span solution and the $200 \mathrm{mg} / \mathrm{L}$ span solution. Following calibration, the analysis cuvette was rinsed with approximately $2 \mathrm{~mL}$ of S-316 solvent and shaken upside down over a dry Kim wipe to remove any excess solvent. The sample was then transferred to the cuvette using a pipette and filled to the fill line (approximately $6 \mathrm{~mL}$ ). The outside of the cuvette was wiped thoroughly with a dry Kim wipe to remove any spilled solvent or lint that could affect the results. Great care was taken to ensure there were no particles on the sides of the vessel exposed to the infrared light path. The cuvette was then placed into the OCMA 350 and measured. Once the reading had stabilized the cuvette was promptly removed to prevent excessive heating of the cuvette that could affect the accuracy of the results. Each sample was run in duplicate and the cuvette was rinsed using S-316 between each sample, the time between each sample was approximately one minute. The Calibration of the instrument was confirmed after every sixteen samples and at the end of each run to prevent any errors in analysis. 


\section{Chapter 5- Results}

The results of the chemical and physical characteristics of the RDS collected during the summer of 2016 through the winter of 2017 are presented in this chapter. This information can be used by VDOT to predict the level of contamination of RDS collected during street sweeping and thus determine whether or not the material is suitable for reuse.

\section{1- Heavy Metals}

All sampling locations were characterized for $\mathrm{As}, \mathrm{Pb}, \mathrm{Se}, \mathrm{Ba}, \mathrm{Cr}, \mathrm{Ag}, \mathrm{Cd}, \mathrm{Cu}$, and $\mathrm{Zn}$. The analysis was completed in two separate runs on ICP-MS due to limitations in the argon gas supply as well as necessary maintenance to ensure accuracy of results. These results are not accounting for the recovery efficiency of the EPA 3051 microwave digestion procedure. This is due to the fact that these efficiencies were determined using different microwave digestion equipment than what was used in this study. Further work needs to be done to determine the exact recovery efficiencies of this specific microwave.

\subsection{1- Concentration Based on ADT}

Table 8 provides an overview of the average concentration of each metal across the six ADT categories considered in this study. The 1-400, 401-1,500, 1,501-2,000, 2,001-4,000, 4,001-10,000, and >10,0000 ADT categories consisted of 9, 10, 11, 14, 17, and 18 sampling sites respectively. 
Table 9: Average concentration of $\mathrm{As}, \mathrm{Pb}, \mathrm{Se}, \mathrm{Ba}, \mathrm{Cr}, \mathrm{Ag}, \mathrm{Cd}, \mathrm{Cu}$, and $\mathrm{Zn}$ in each ADT category

\begin{tabular}{|c|c|c|c|c|c|c|}
\hline \multirow{2}{*}{ Metal } & \multicolumn{7}{|c|}{ Average Daily Traffic Category } \\
\cline { 2 - 7 } & $1-400$ & $401-1500$ & $1501-2000$ & $2001-4000$ & $4001-10000$ & $>10000$ \\
\hline Arsenic (mg/kg) & 0.095 & 0.288 & 0.160 & 0.031 & 1.322 & 0.220 \\
\hline Lead (mg/kg) & 1.017 & 4.183 & 11.544 & 2.326 & 20.140 & 3.076 \\
\hline Selenium (mg/kg) & 0.051 & 0.298 & 0.245 & 0.020 & 0.873 & 0.230 \\
\hline Barium (mg/kg) & 3.248 & 11.239 & 7.128 & 5.880 & 27.875 & 16.495 \\
\hline Chromium (mg/kg) & 0.485 & 3.269 & 2.273 & 0.466 & 19.705 & 3.655 \\
\hline Silver (mg/kg) & 0.012 & 0.018 & 0.016 & 0.009 & 0.160 & 0.018 \\
\hline Cadmium (mg/kg) & 0.010 & 0.041 & 0.020 & 0.019 & 0.700 & 2.914 \\
\hline Copper $(\mathrm{mg} / \mathrm{kg})$ & 0.303 & 0.383 & 1.051 & 0.984 & 0.350 & 1.870 \\
\hline Zinc $(\mathrm{mg} / \mathrm{kg})$ & 2.084 & 16.006 & 12.920 & 2.103 & 98.730 & 19.352 \\
\hline
\end{tabular}

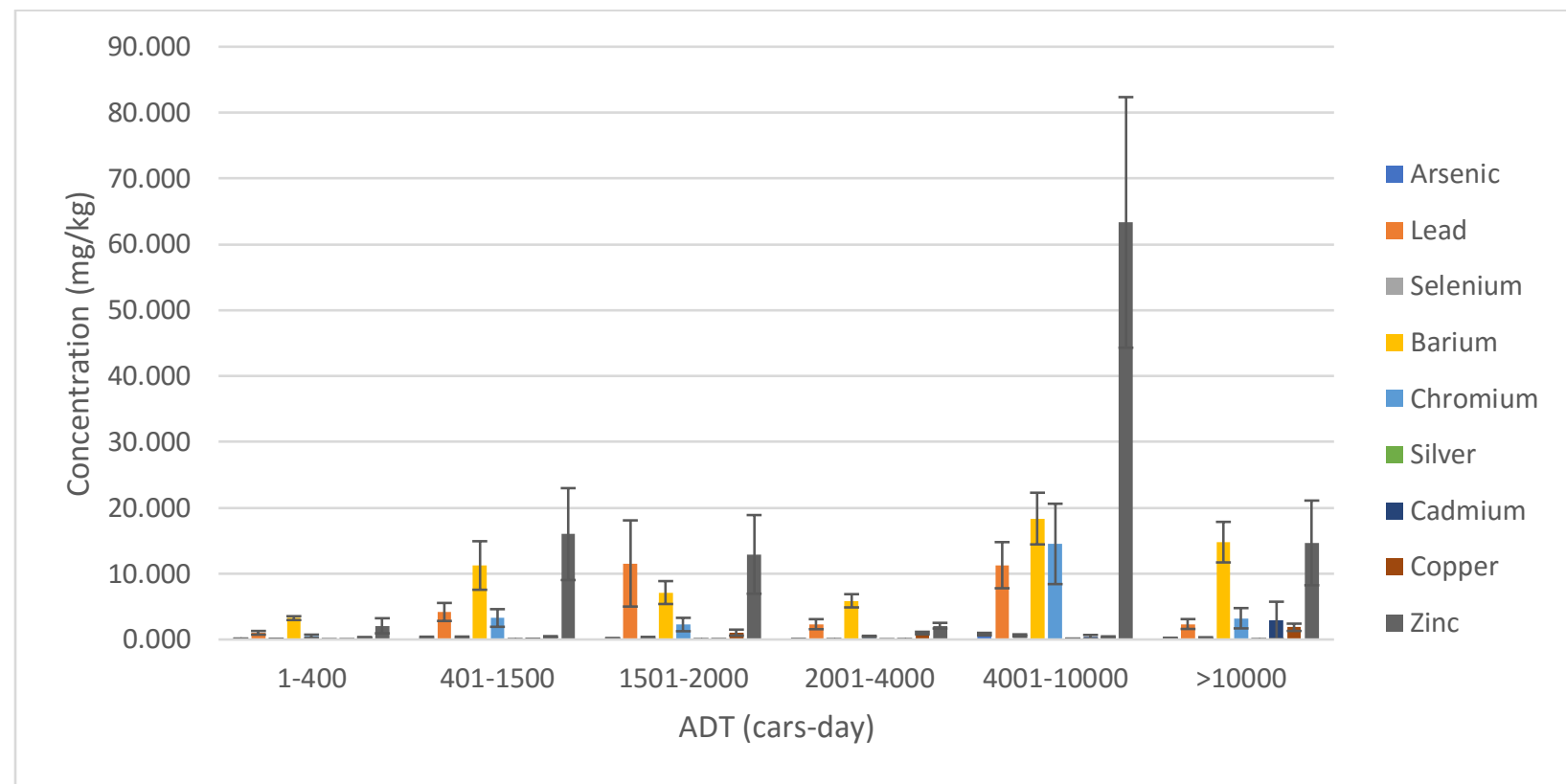

Figure 2: Average concentration of $\mathrm{As}, \mathrm{Pb}, \mathrm{Se}, \mathrm{Ba}, \mathrm{Cr}, \mathrm{Ag}, \mathrm{Cd}, \mathrm{CU}$, and $\mathrm{Zn}$ across the six ADT categories. Error bars are based on the standard error of the group of samples. 


\subsection{2- Concentration Based on NLCD}

Below are the results of the heavy metals characterization with respect to NLCD category. These results are the averages within each NLCD category consisting of $14,20,24$, and 22 sites in the high intensity, medium intensity, low intensity, and open space categories respectively.

Table 10: Average concentrations of $\mathrm{As}, \mathrm{Pb}, \mathrm{Se}, \mathrm{Ba}, \mathrm{Cr}, \mathrm{Ag}, \mathrm{Cd}, \mathrm{Cu}$, and $\mathrm{Zn}$ in each National Land Cover Database category

\begin{tabular}{|c|c|c|c|c|}
\hline $\begin{array}{c}\text { Average } \\
\text { Concentration } \\
(\mathrm{mg} / \mathrm{kg})\end{array}$ & $\begin{array}{c}\text { Developed, } \\
\text { High Intensity }\end{array}$ & $\begin{array}{c}\text { Developed, } \\
\text { Medium Intensity }\end{array}$ & $\begin{array}{c}\text { Developed, } \\
\text { Low Intensity }\end{array}$ & $\begin{array}{c}\text { Developed, } \\
\text { Open Space }\end{array}$ \\
\hline Arsenic & 0.672 & 0.300 & 0.385 & 0.330 \\
\hline Lead & 17.200 & 6.788 & 5.304 & 4.048 \\
\hline Selenium & 0.220 & 0.300 & 0.350 & 0.401 \\
\hline Barium & 19.355 & 16.817 & 11.560 & 9.820 \\
\hline Chromium & 13.720 & 4.680 & 3.600 & 5.143 \\
\hline Silver & 0.177 & 0.030 & 0.020 & 0.014 \\
\hline Cadmium & 4.741 & 0.078 & 0.046 & 0.050 \\
\hline Copper & 1.305 & 1.304 & 0.680 & 0.490 \\
\hline Zinc & 48.920 & 28.611 & 30.600 & 20.050 \\
\hline
\end{tabular}




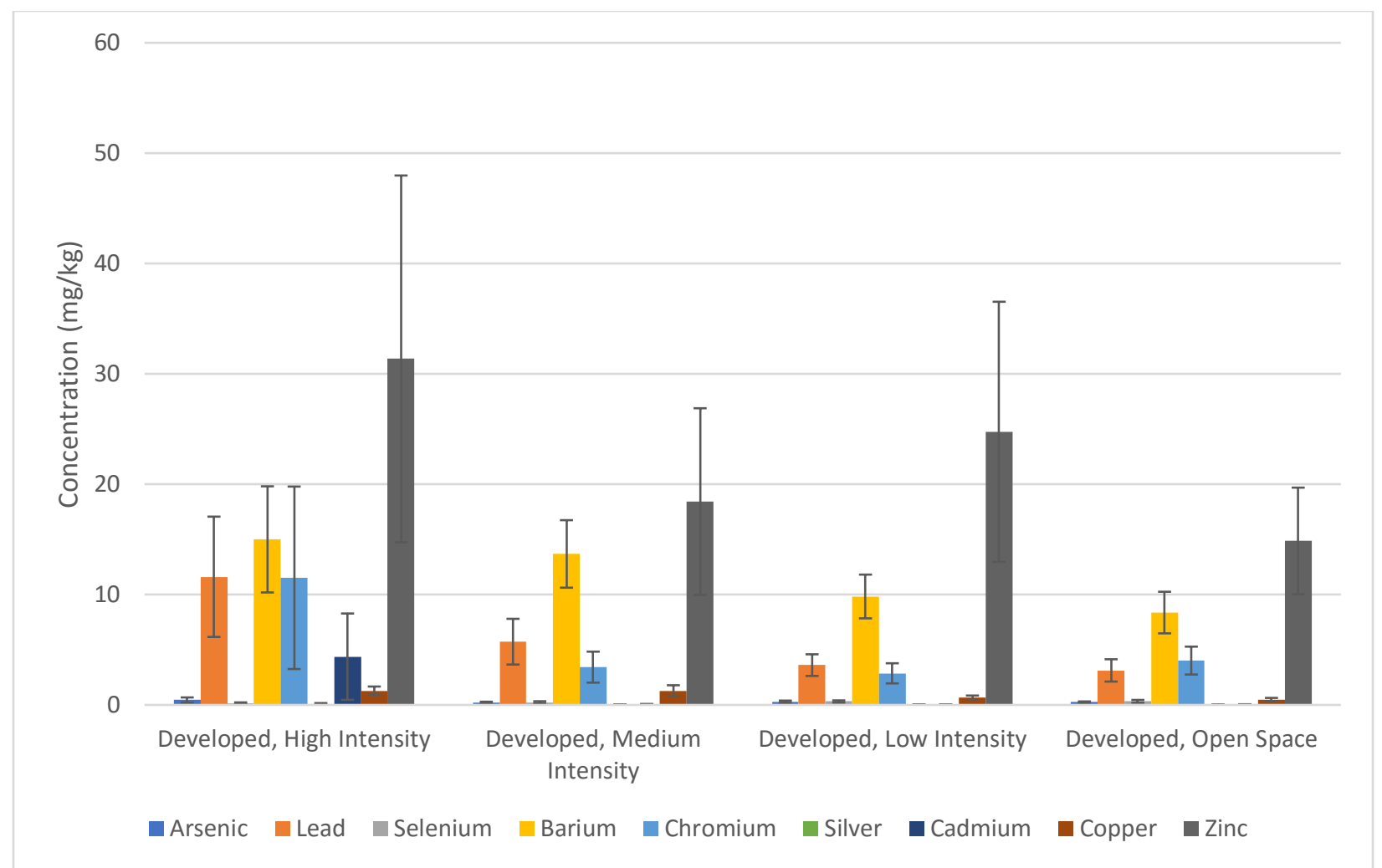

Figure 3: Average concentration of $\mathrm{As}, \mathrm{Pb}, \mathrm{Se}, \mathrm{Ba}, \mathrm{Cr}, \mathrm{Ag}, \mathrm{Cd}, \mathrm{Cu}$, and $\mathrm{Zn}$ across the four National Land Cover Database categories. Error bars are the standard error within each group of samples.

\section{2- Polycyclic Aromatic Hydrocarbons}

A total of 27 locations were selected for PAH analysis. This allowed for at least one sample for each ADT and NLCD classification. Concentrations of $\sum$ PAHs ranged from $18.4 \mu \mathrm{g} / \mathrm{kg}$ to $87,200 \mu \mathrm{g} / \mathrm{kg}$. On average the PAH with the highest concentration was fluoranthene with an average concentration across all samples of $2,890 \mu \mathrm{g} / \mathrm{kg}$. The compound with the lowest average concentration was found to be naphthalene with an average concentration of 14.1 $\mu \mathrm{g} / \mathrm{kg}$. All but one of the sixteen EPA PAHs were successfully quantified in all of the samples. Chrysene was not quantified, due to errors in the calibration possibly resulting from interference from other compounds in solution. Because of this the results for this compound have been removed from the data set. 


\subsection{1- Concentration Based on ADT}

Figure 4 shows the results of the PAH analysis with regards to ADT. Two distinct drops can be seen in the $\sum \mathrm{PAH}$ concentrations across the ADT categories. Figure five depicts the average concentration of each PAH detected in each ADT category. The 1-400, 401-1,500, 1,501-2,000, 2,001-4,000, 4,001-10,000, and >10,000 ADT categories had 4, 2, 4, 4, 7, and 5 sites tested for PAHs respectively. Figure six depicts the sum of the fifteen PAHs detected in each ADT category.

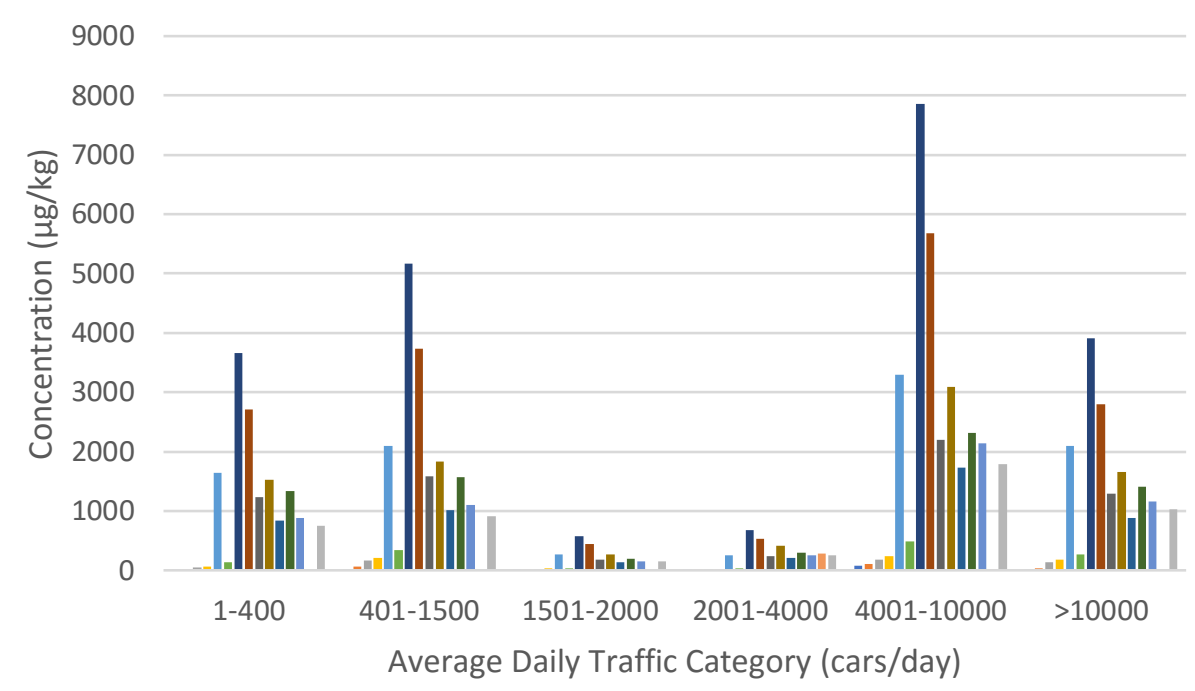

Naphthalene
Acenaphthylene
Acenaphthene
Fluorene
Phenanthrene
Anthracene
- Fluoranthene
- Pyrene
- Benz[a]anthracene
Benzo[b]fluoranthene
- Benzo[k]fluoranthene

Figure 4: Concentration of each individual PAH across the six different ADT categories 


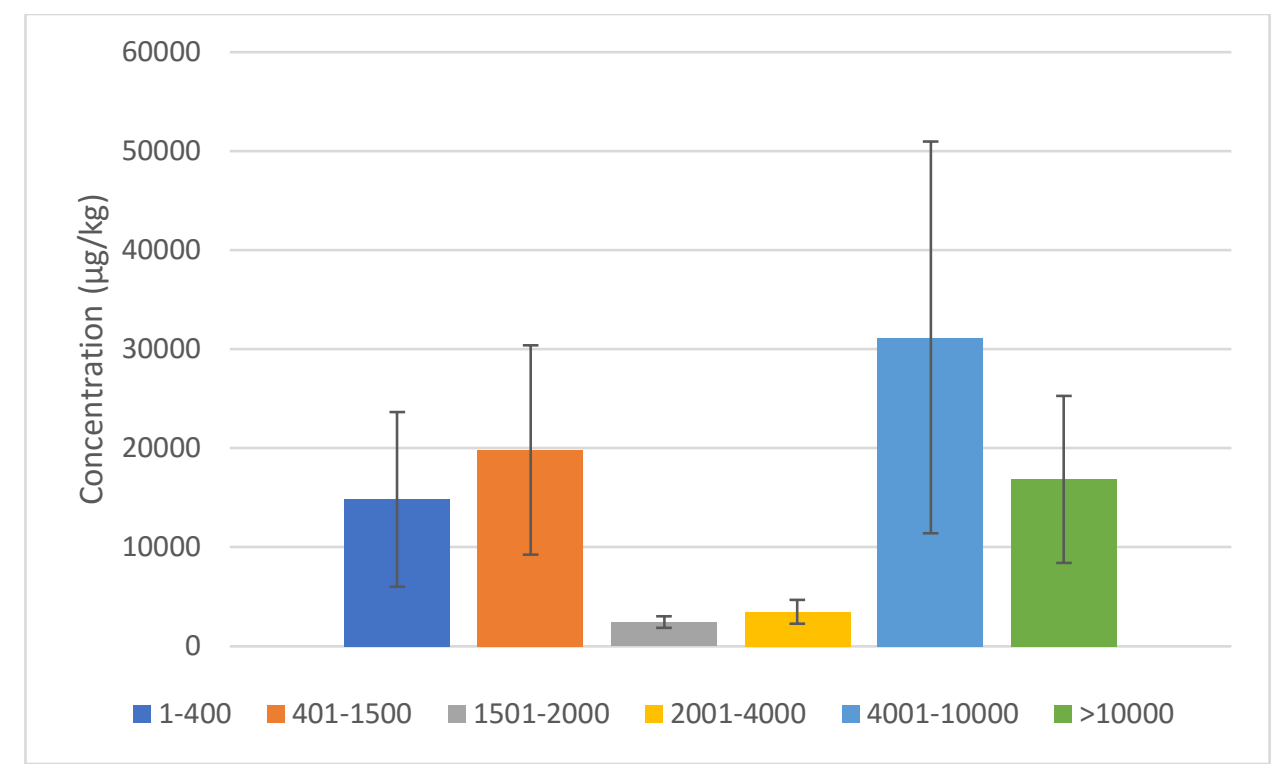

Figure 5: $\triangle P A H$ concentration across the six different average daily traffic categories.

\subsection{2- Concentration Based on NLCD}

Figures 6 and 7 are the results of the PAH analysis in terms of NLCD category. The four NLCD categories: developed, open space; developed, low intensity; developed, medium intensity; and developed, high intensity had 7, 7, 7, and 6 samples respectively. Figure 5 is the average concentration of each PAH over each group of sites according to NLCD. Figure 6 is the average of the $\Sigma \mathrm{PAH}$ for each NLCD category. 


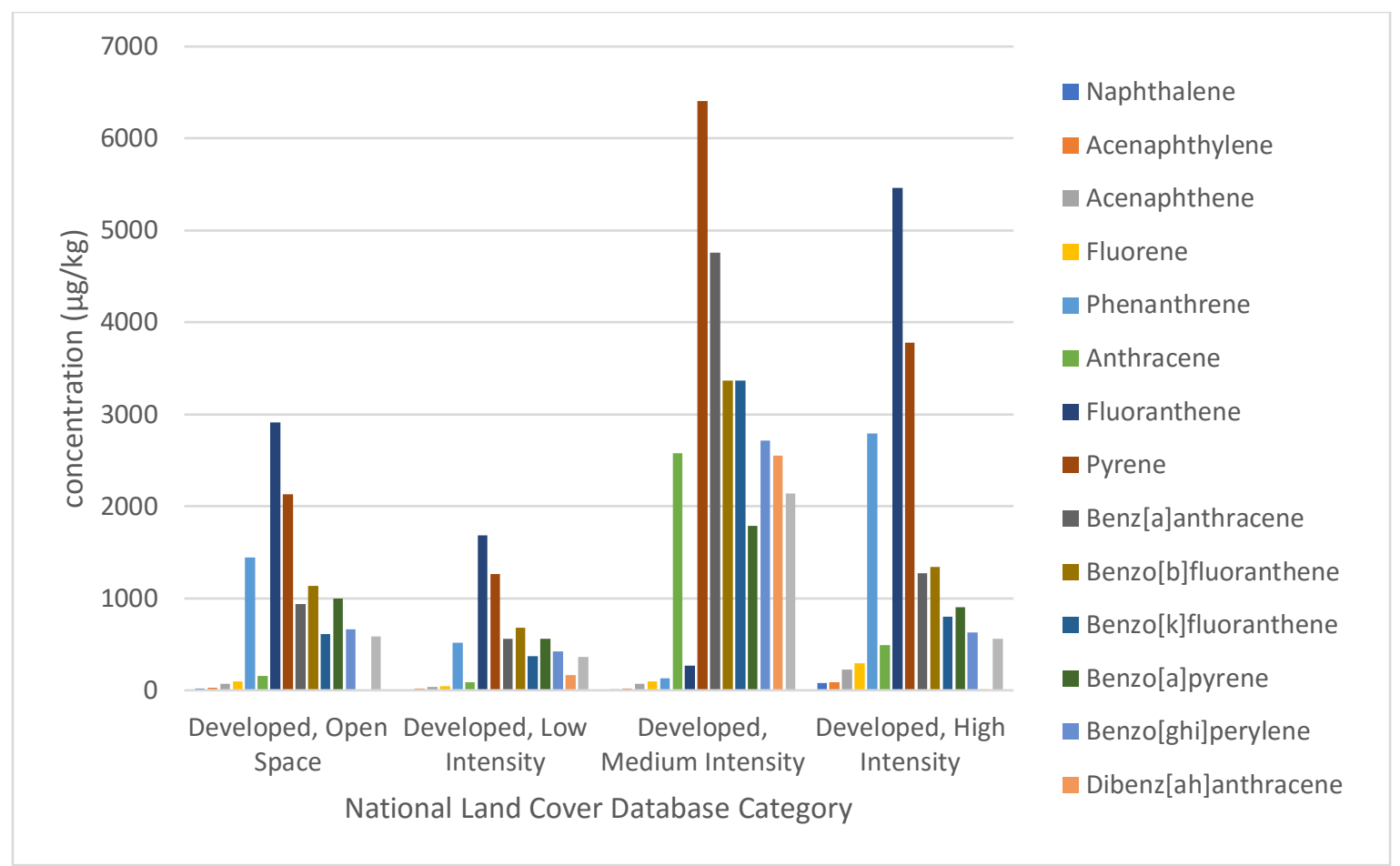

Figure 6: Concentration of each PAH in each National Land Cover Database category

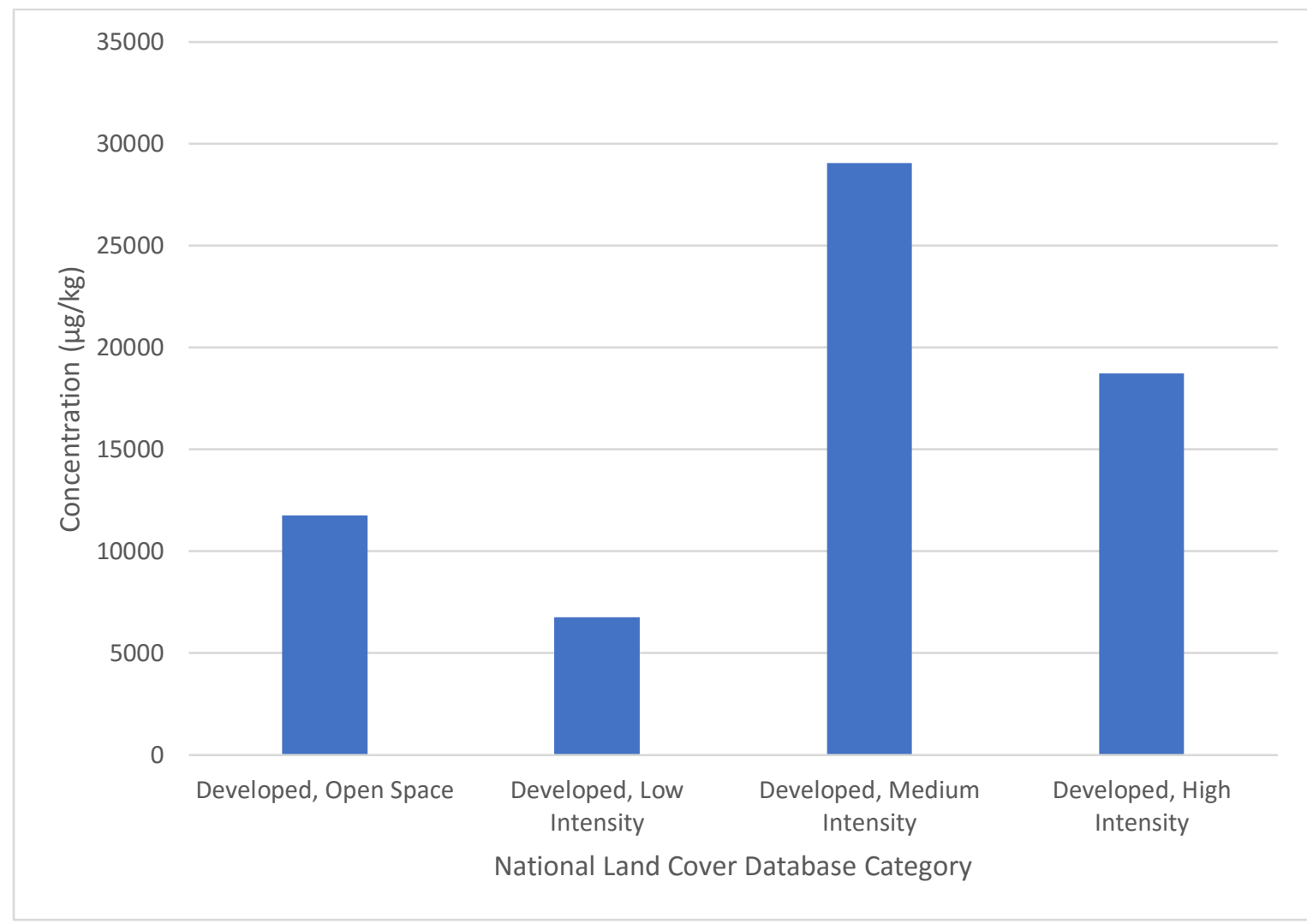

Figure 7: $\Sigma$ PAH concentration in each National Land Cover Database category 


\section{3- Concentration Based on Particle Size}

Samples from two of the 4,001-10,000 ADT categories in all four NLCD classifications were used to determine the concentration of both heavy metals and PAHs in the $\geq 1.18 \mathrm{~mm}$, 600 $\mu \mathrm{m}-1.18 \mathrm{~mm}, 300-600 \mu \mathrm{m}, 150-300 \mu \mathrm{m}, 75-150 \mu \mathrm{m}, 150-75 \mu \mathrm{m}$, and $<75 \mu \mathrm{m}$ screen sizes. The results of this analysis are presented in Table 10 and Figure 8 below. All of the samples selected were screened through a stack of brass ringed sieves. Since brass is an alloy of both copper and zinc, there is some concern that this set of samples exhibits artificially high concentrations of these two elements. In order to account for this, virgin natural sand was sampled before and after sieving to determine the relative level of contamination of the samples. There was no detectable concentration of copper found in both the before and after sieve samples. The concentration of zinc in these samples saw an increase in concentration from $0.24 \mathrm{mg} / \mathrm{kg}$ before sieving to $0.69 \mathrm{mg} / \mathrm{kg}$ after sieving. While this is an increase, it is small in comparison to the concentrations of zinc in the actual field samples, which range from 16.7$289 \mathrm{mg} / \mathrm{kg}$.

Table 11: Concentration of $\mathrm{As}, \mathrm{Pb}, \mathrm{Se}, \mathrm{Ba}, \mathrm{Cr}, \mathrm{Ag}, \mathrm{Cd}, \mathrm{Cu}$, and $\mathrm{Zn}$ in each particle size. All concentrations are reported in $\mu \mathrm{g} / \mathrm{kg}$

\begin{tabular}{|c|c|c|c|c|c|c|}
\hline Metal & $>1.18 \mathrm{~mm}$ & $1.18 \mathrm{~mm}-600 \mu \mathrm{m}$ & $600-300 \mu \mathrm{m}$ & $300-150 \mu \mathrm{m}$ & $150-75 \mu \mathrm{m}$ & $<75 \mu \mathrm{m}$ \\
\hline Arsenic & 0.38 & 0.77 & 0.72 & 1.19 & 1.95 & 3.51 \\
\hline Lead & 3.15 & 4.56 & 9.12 & 25.39 & 32.79 & 55.08 \\
\hline Selenium & 0.65 & 0.48 & 0.46 & 0.85 & 1.39 & 2.33 \\
\hline Barium & 10.70 & 13.32 & 16.14 & 29.59 & 45.21 & 81.41 \\
\hline Chromium & 7.45 & 13.40 & 18.68 & 23.84 & 28.41 & 38.13 \\
\hline Silver & 0.02 & 0.03 & 0.27 & 0.06 & 0.14 & 0.50 \\
\hline Cadmium & 0.05 & 0.21 & 0.11 & 3.09 & 0.32 & 0.77 \\
\hline Copper & 0.16 & 0.13 & 0.16 & 0.22 & 0.24 & 0.28 \\
\hline Zinc & 16.70 & 102.97 & 46.51 & 90.07 & 153.01 & 288.66 \\
\hline
\end{tabular}




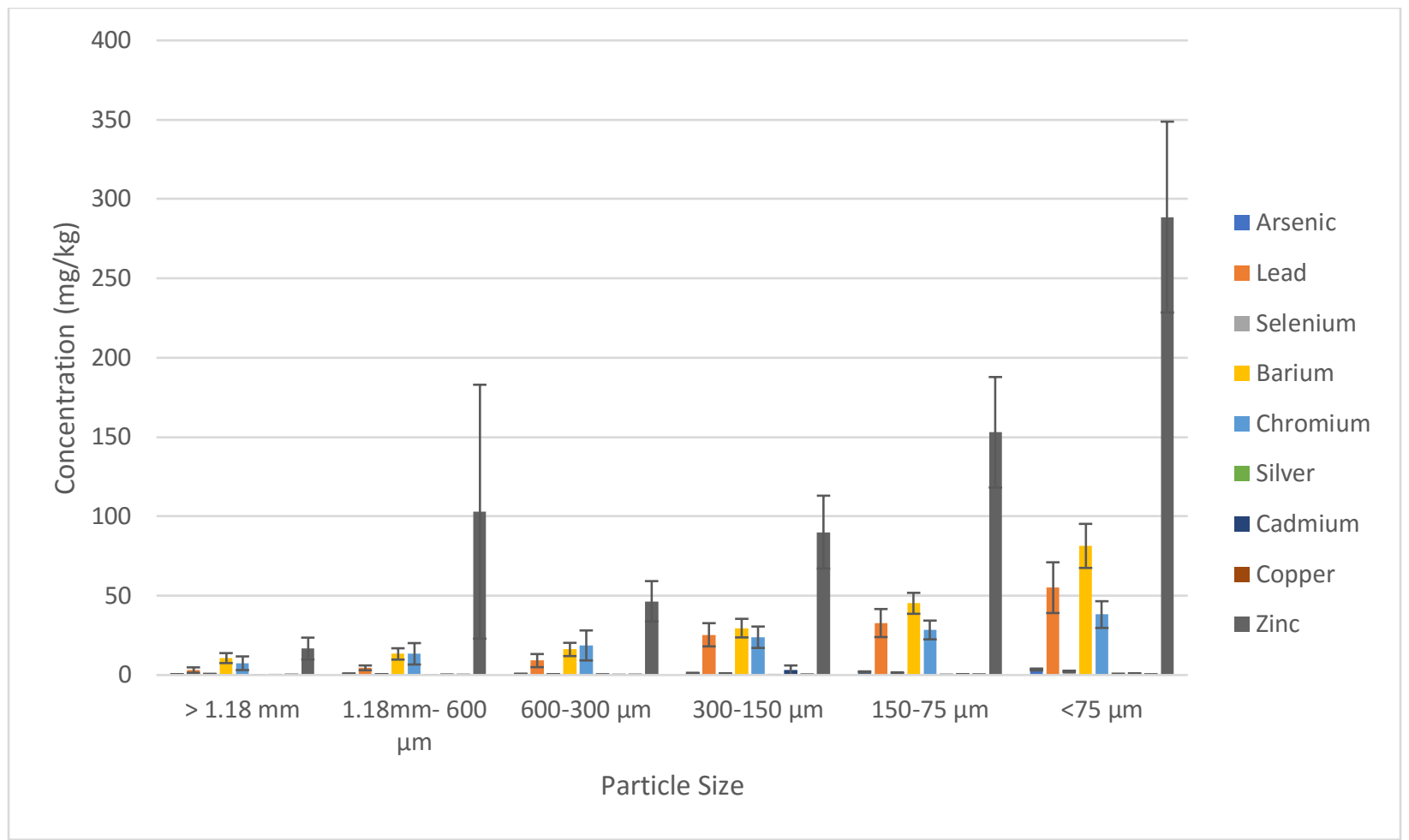

Figure 8: Concentration of $\mathrm{As}, \mathrm{Pb}, \mathrm{Se}, \mathrm{Ba}, \mathrm{Cr}, \mathrm{Ag}, \mathrm{Cd}, \mathrm{Cu}$, and $\mathrm{Zn}$ in each particle size. All concentrations are reported in $\mu \mathrm{g} / \mathrm{kg}$. Error bars are based on the standard error of each group of readings. 


\subsection{2- Polycyclic Aromatic Hydrocarbons}

Table 11 and Figure 8 are the results of the PAH analysis from the fractionated samples.

Table 12: Average concentration in $\mu \mathrm{g} / \mathrm{kg}$ of each $P A H$ and $\triangle P A H$ in each particle size range.

\begin{tabular}{|c|c|c|c|c|c|c|}
\cline { 1 - 1 } PAH & $>1.18 \mathrm{~mm}$ & $\begin{array}{c}1.18 \mathrm{~mm}- \\
600 \mu \mathrm{m}\end{array}$ & $\begin{array}{c}600-300 \\
\mu \mathrm{m}\end{array}$ & $\begin{array}{c}300-150 \\
\mu \mathrm{m}\end{array}$ & $150-75 \mu \mathrm{m}$ & $<75 \mu \mathrm{m}$ \\
\hline Nap & 3.15 & 32.55 & 52.25 & 81.83 & 115.71 & 121.45 \\
\hline Any & 3.98 & 30.96 & 60.36 & 132.03 & 208.55 & 212.83 \\
\hline Ana & 5.65 & 97.29 & 141.28 & 248.10 & 299.11 & 232.43 \\
\hline Flu & 11.05 & 93.17 & 192.49 & 334.08 & 428.80 & 364.73 \\
\hline Phen & 174.46 & $1,270.37$ & $2,454.50$ & $4,906.31$ & $6,381.20$ & $5,310.25$ \\
\hline Ant & 58.90 & 278.31 & 301.78 & 603.43 & 854.87 & 783.88 \\
\hline Fla & 361.63 & $2,828.22$ & 5230.41 & $11,074.39$ & $15,266.91$ & $13,641.38$ \\
\hline Pyr & 276.46 & $1,990.51$ & 3665.87 & $8,064.87$ & $11,137.94$ & $9,828.56$ \\
\hline BaA & 73.67 & 734.84 & 1371.15 & $3,312.50$ & $4,592.25$ & $3,661.29$ \\
\hline BaF & 131.18 & 730.91 & 1795.20 & $4,354.62$ & $6,396.38$ & $6,096.73$ \\
\hline BkF & 61.01 & 384.29 & 941.07 & $2,351.42$ & $3,387.60$ & $3,664.12$ \\
\hline BaP & 81.04 & 533.54 & 1415.25 & $3,592.17$ & $5,036.67$ & $4,199.43$ \\
\hline BghiP & 81.28 & 430.44 & 1228.46 & $3,172.75$ & $4,645.78$ & $4,212.67$ \\
\hline DahA & 3.59 & 0.66 & 0.00 & 0.00 & 0.00 & 51.37 \\
\hline IP & 96.30 & 395.31 & $1,072.89$ & $2,678.96$ & $3,892.85$ & $3,499.46$ \\
\hline EPAHs & $1,423.34$ & $9,831.36$ & $19,922.96$ & $44,907.47$ & $62,644.63$ & $55,880.57$ \\
\hline
\end{tabular}

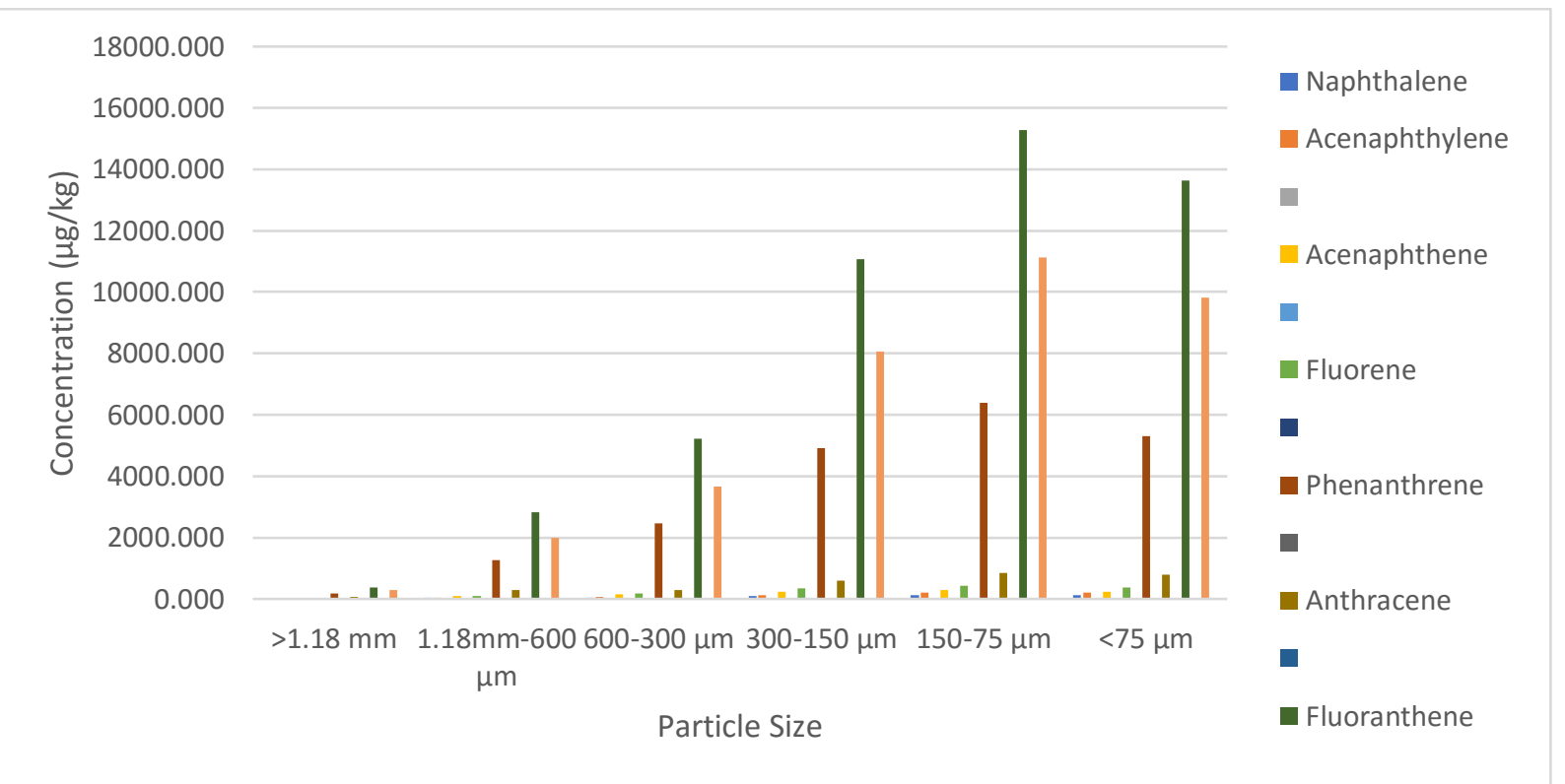

Figure 9: Concentration of each PAH across all of the particle sizes 


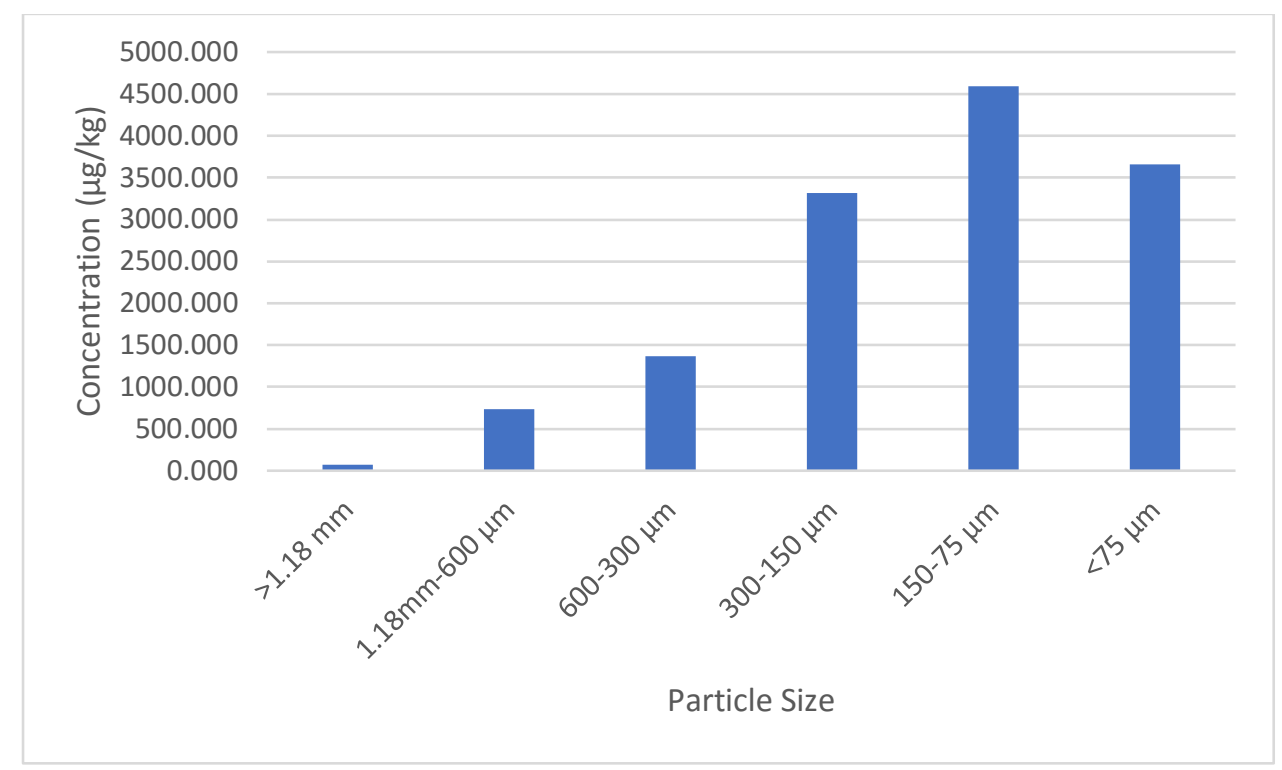

Figure 10: $\Sigma P A H$ concentrations in each particle size

\section{4- Oil and Grease}

All samples were tested for oil and grease. Concentrations ranged from $125.385 \mathrm{mg} / \mathrm{kg}$

to $1,938.749 \mathrm{mg} / \mathrm{kg}$. These concentrations corresponded to the develop, open space 1-400 ADT and developed, high intensity 4,001-10,000 ADT categories. The developed, high intensity NLCD category consistently had the highest oil and grease concentrations across all ADT categories except at the 1-400 and 1,501-2,000 ADTs. In contrast, developed, open space had the lowest average oil and grease concentration across all ADTs at $308.433 \mathrm{mg} / \mathrm{kg}$. Similar to the results from the PAH analysis, oil and grease concentrations peaked at the $4,001-10,000$ ADT category and then dropped in the $>10,000$ ADT category. In this ADT category, the concentration of oil and grease in the developed, high intensity NLCD category was about $43 \%$ greater than the next highest concentration found in the developed, medium intensity NCLD category. This peak in the 4,001-10,000 ADT category was true for all NLCD categories except developed, low intensity. This category experienced a small drop at the $>10,000$ ADT but also 
had a more significant drop at 2,001-4,000 ADT. This ADT category had the lowest oil and grease concentration of the entire NLCD series at $272.317 \mathrm{mg} / \mathrm{kg}, 65 \%$ lower than the series' peak concentration. The results from this analysis are presented in Figures 10 and 11 below.

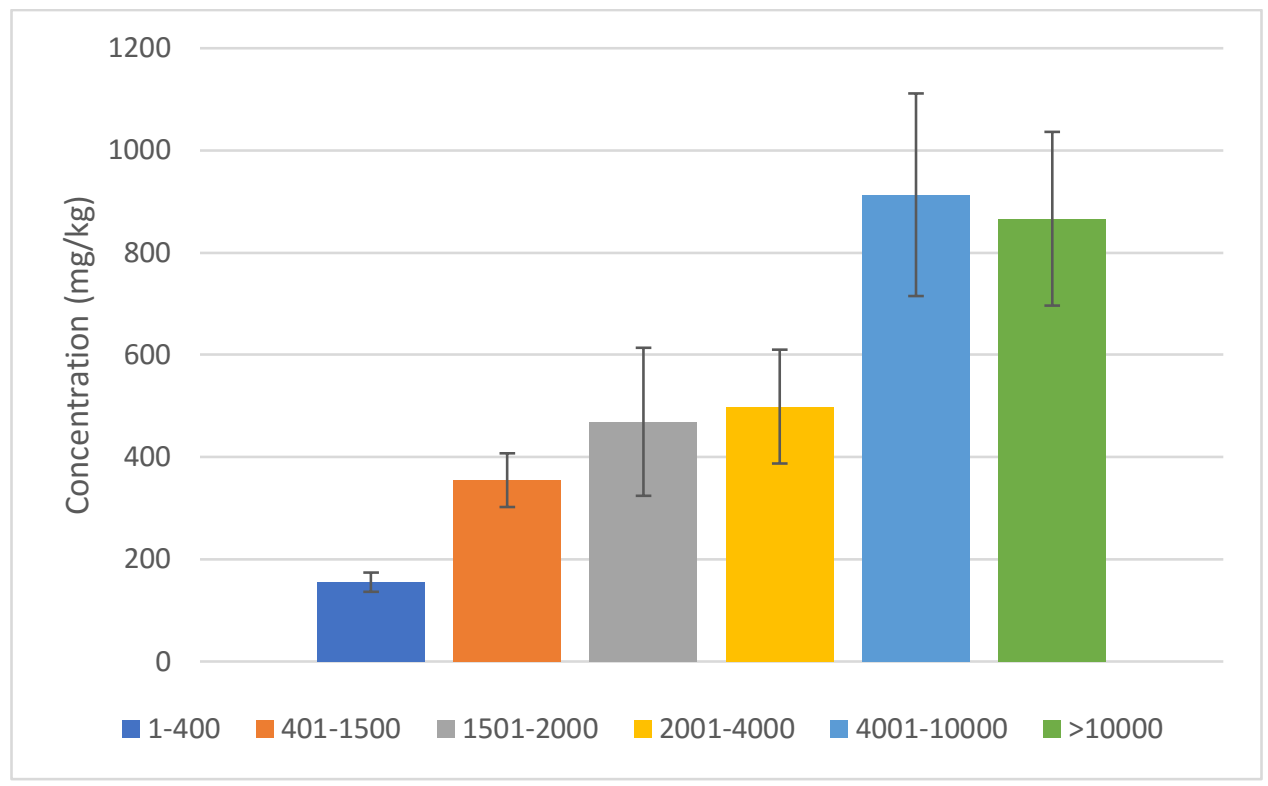

Figure 11: Oil and Grease Concentrations of each ADT category. Error bars are based on the standard error of the series of samples

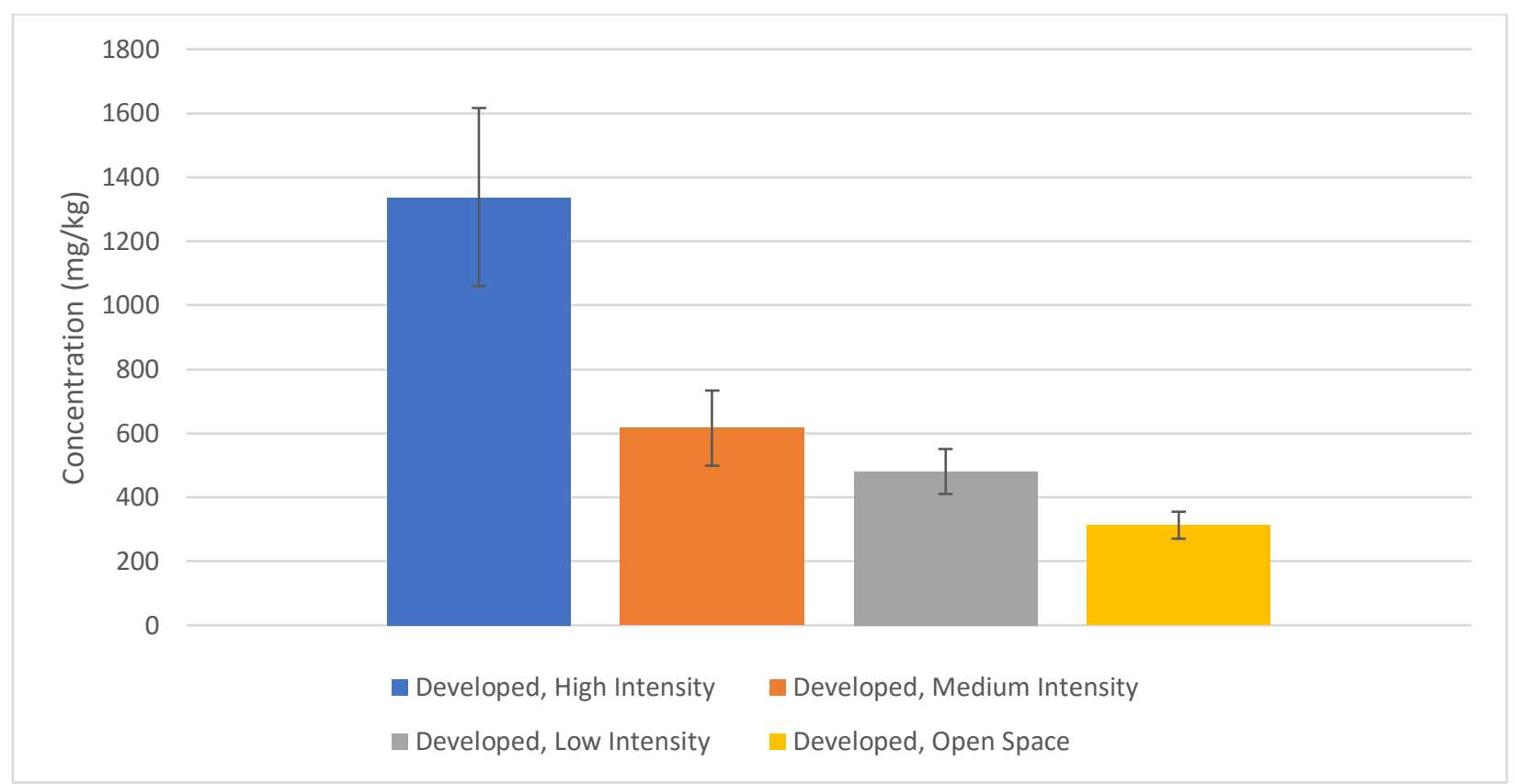

Figure 12: Oil and Grease concentrations of each NLCD category. Error bars are based on the standard error of the series of samples. 


\section{Chapter 6- Discussion}

The purpose of this research was to provide a comprehensive characterization of RDS collected during street sweeping operations across the Commonwealth. This characterization can then be used by VDOT to determine if all, or parts, of this waste stream are possible candidates for reuse under the VADEQ Beneficial Reuse program. There were a number of different hypothesis considered during this project. These included the idea that the concentrations of contaminants like heavy metals, PAHs, and oil and grease are related to the ADT, and land use of the road and the surrounding area. Another hypothesis was that the concentrations of these contaminants are also linked to the size of the particles in the collected RDS, with increasing concentration as the particle size decreases. The results of this research and how they impact these hypotheses are discussed in the following chapter.

\subsection{Polycyclic Aromatic Hydrocarbons}

As has previously been noted, PAHs have been a contaminant of interest since the 1970's due to their toxicology and their ubiquitous and persistent presence in the environment. The results of this study have found that concentrations of PAHs in RDS are slightly impacted by the traffic load of the road, have little relation to the NLCD of the surrounding area, and of the variables considered in this study, are most strongly correlated to the particle size of the RDS. As can be seen in the table below the results from this study fall in line with the results from other studies looking at PAH concentrations in RDS as well as from soils surrounding roads. 
Table 13: Average concentrations of PAHs from soils and RDS collected in other studies. All results in $\mu \mathrm{g} / \mathrm{kg}$.

\begin{tabular}{|c|c|c|c|c|c|c|}
\hline Compound & $\begin{array}{l}\text { Q. Cai } \\
\text { et al. } \\
(2007 \\
\text { ) }\end{array}$ & $\begin{array}{l}\text { H. Mielkle et al. } \\
\qquad(2004)\end{array}$ & $\begin{array}{c}\text { T. Bucheli et al. } \\
\text { (2004) }\end{array}$ & $\begin{array}{l}\text { G. Pantano } \\
\text { (2016) }\end{array}$ & $\begin{array}{l}\text { S. Sengupta } \\
(2007)\end{array}$ & $\begin{array}{l}\text { This } \\
\text { study }\end{array}$ \\
\hline Nap & $\begin{array}{l}35- \\
280\end{array}$ & $2-10$ & $1-33$ & $1.3-441.5$ & ND & 14.12 \\
\hline Ana & $4-93$ & $1-5$ & $0.3-5.1$ & $0.3-5.5$ & NA & 74.68 \\
\hline Any & $\begin{array}{l}28- \\
690 \\
\end{array}$ & $0-9$ & $0.2-2$ & NA & NA & 29.79 \\
\hline Ant & $\begin{array}{c}6.9- \\
29 \\
\end{array}$ & $7-38$ & $0.3-5.2$ & $0.1-11$ & $87-150$ & 172.65 \\
\hline Phen & $11-49$ & 21-133 & $7-43$ & $2.6-107.2$ & $270-1200$ & 1315.11 \\
\hline Flu & $\begin{array}{l}60- \\
250\end{array}$ & $0-3$ & $0.4-4.3$ & $1.4-16.8$ & ND & 99.18 \\
\hline Fla & $\begin{array}{l}3.1- \\
400 \\
\end{array}$ & $82-266$ & $6-94$ & $5.6-450.6$ & $760-2500$ & 2889.38 \\
\hline $\mathrm{BaA}$ & $\begin{array}{c}6.6- \\
48\end{array}$ & $28-145$ & $1-44$ & $0.2-10.7$ & $290-780$ & 922.00 \\
\hline Chry & $\begin{array}{c}9.5- \\
34 \\
\end{array}$ & $32-111$ & $2-62$ & n.d & $400-1300$ & n.d \\
\hline Pyr & $\begin{array}{c}6.8- \\
74 \\
\end{array}$ & $67-237$ & $4-72$ & $0.8-88.4$ & $660-1900$ & 2113.75 \\
\hline $\mathrm{BaP}$ & $\begin{array}{l}4.8- \\
370 \\
\end{array}$ & $141-255$ & $2-69$ & n.d. & $330-1000$ & 994.21 \\
\hline $\mathrm{BbF}$ & $\begin{array}{c}20- \\
1100\end{array}$ & $94-319$ & $3-78$ & $0.3-530$ & $370-2100$ & 1200.66 \\
\hline $\mathrm{BkF}$ & $\begin{array}{l}6.7- \\
150 \\
\end{array}$ & $24-95$ & $2-44$ & $0.3-56.3$ & $410-1100$ & 646.18 \\
\hline DahA & $\begin{array}{c}3.2- \\
17\end{array}$ & $123-208$ & $1-11$ & n.d. & $110-210$ & 42.72 \\
\hline BghiP & $\begin{array}{c}7.4- \\
21\end{array}$ & $122-237$ & $4-59$ & $1.0-759.6$ & $350-730$ & 790.17 \\
\hline IP & $\begin{array}{c}7.4- \\
10 \\
\end{array}$ & $202-322$ & $3-59$ & n.d. & $280-750$ & 681.18 \\
\hline$\sum \mathrm{PAH}$ & $\begin{array}{l}600- \\
2500\end{array}$ & $975-2469$ & $50-619$ & $34-2476$ & $4317-13720$ & 11985.78 \\
\hline
\end{tabular}

In Figure 13 below, the sum of all fifteen PAHs detected in this study are plotted against the exact ADT of site. With an $\mathrm{R}^{2}$ of $2.9 \times 10^{-4}$, this figure indicates that there is little correlation between ADT and PAH concentrations. When considered individually, the PAH with the highest $R^{2}$ value was acenaphthen $\left(R^{2}=0.062\right)$. This $P A H$ has been identified as resulting from the combustion of gasoline and diesel fuel, so a correlation with acenaphthen concentration and ADT is expected for roadside particles (L. Liu et al., 2016). However, this $R^{2}$ value still inspires 
little confidence in the correlation of ADT and PAH concentration. All PAHs with the exception of acenaphthene and flourene, had their highest concentrations in one site with an ADT of 4,100 cars/day. This site could be contributing to some skewedness of the data. However, if removed the next highest concentration was found at a site with an ADT of 210 cars/day. While a number of PAHs have been found to result from the combustion of automotive fuels, it appears that traffic volume may be preventing these compounds from depositing themselves on the roadway, possibly due to the dispersion of particles from the road by passing vehicles. It has been shown that increasing the traffic volume can lead to finer particles in the RDS (Cai et al., 2007). Perhaps these finer particles are being kicked up into the air and deposited elsewhere, leading to a decrease in concentration on the roadway. Plots of each individual PAH compound as a function of ADT are provided in Figure 22 of the appendix.

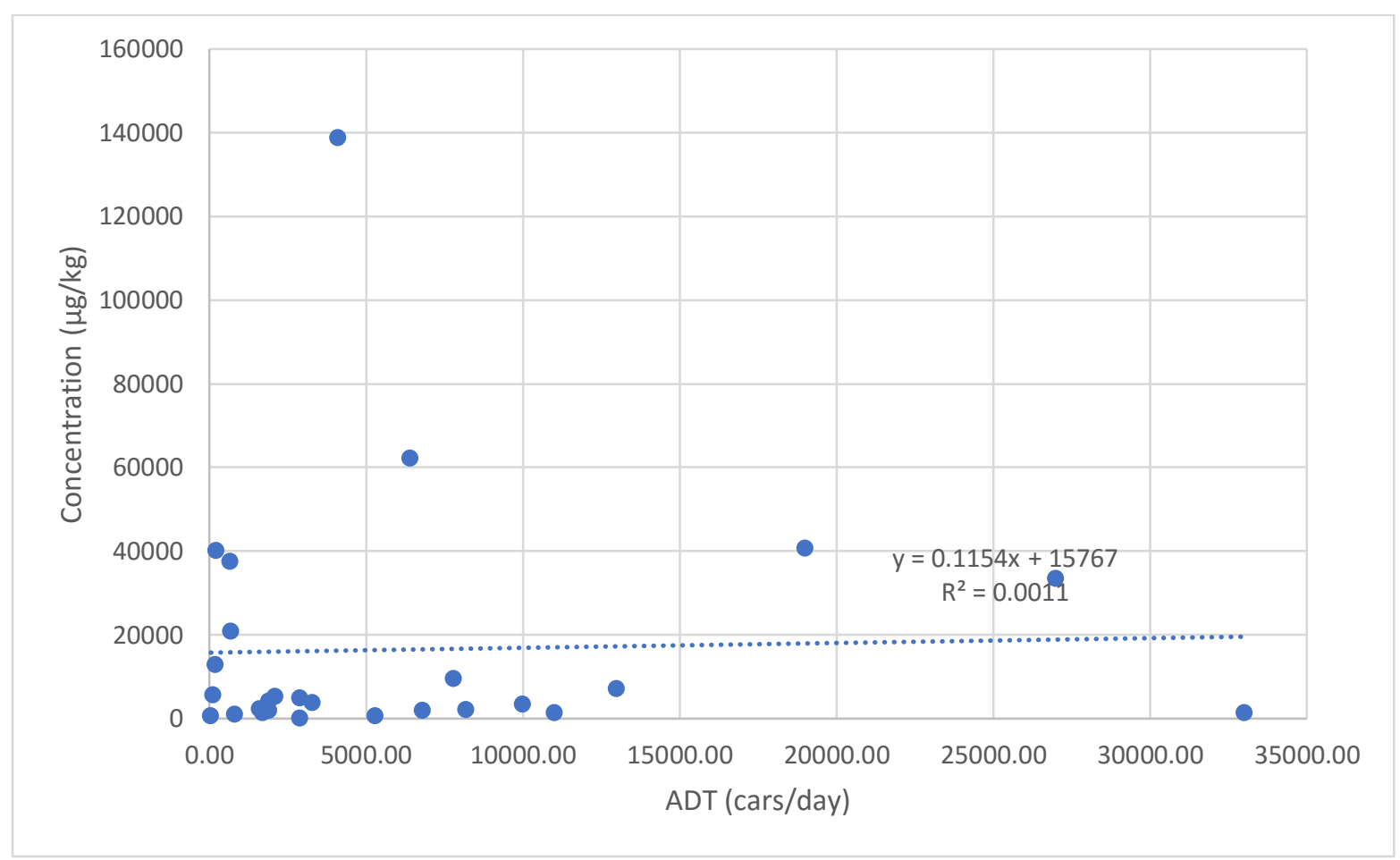

Figure 13: $\sum P A H$ concentrations as a function of $A D T$ 
Table 14: $R^{2}$ values of each PAH when plotted against ADT assuming a linear function

\begin{tabular}{|c|c|c|c|}
\hline Compound & $\mathrm{R}^{2}$ & Compound & $\mathrm{R}^{2}$ \\
\hline Naphthalene & $2.97 \times 10^{-3}$ & Benz[a]anthracene & $8.50 \times 10^{-4}$ \\
\hline Acenaphthylene & $4.30 \times 10^{-5}$ & Benzo[b]fluoranthene & $1.70 \times 10^{-4}$ \\
\hline Acenaphthene & $3.50 \times 10^{-2}$ & Benzo[k]fluoranthene & $1.00 \times 10^{-4}$ \\
\hline Fluorene & $2.82 \times 10^{-2}$ & Benzo[a]pyrene & $3.10 \times 10^{-4}$ \\
\hline Phenanthrene & $1.04 \times 10^{-2}$ & Benzo[ghi]perylene & $3.50 \times 10^{-4}$ \\
\hline Anthracene & $1.21 \times 10^{-2}$ & Dibenz[ah]anthracene & $10.79 \times 10^{-3}$ \\
\hline Fluoranthene & $6.70 \times 10^{-4}$ & Indeno[1,2,3-cd]pyrene & $7.40 \times 10^{-4}$ \\
\hline Pyrene & $3.5 \times 10^{-4}$ & $\sum 16 \mathrm{PAHs}$ & $10.5 \times 10^{-4}$ \\
\hline
\end{tabular}

In terms of land cover, a similar result was found. While it was expected that the most highly developed and industrialized areas would produce the highest concentrations of PAHs, as can be seen in Figure 6 above, this is not the case. The highest average concentration of $\sum$ PAHs was found in the developed, medium intensity NLCD category followed by the developed, open space category. Lighter PAHs like naphthalene, acenaphthylene, and acenaphthene on the other hand did exhibit a slightly increasing trend with increasing intensity of land use. Since these PAHs are naturally more volatile and short lived in the environment this could indicate that higher intensity land uses experience chronic contamination of PAHs (Cai et al., 2007; Mielke et al., 2004). This trend can be seen in Figure 13 which depicts the sum of the two and three ring PAHs. 


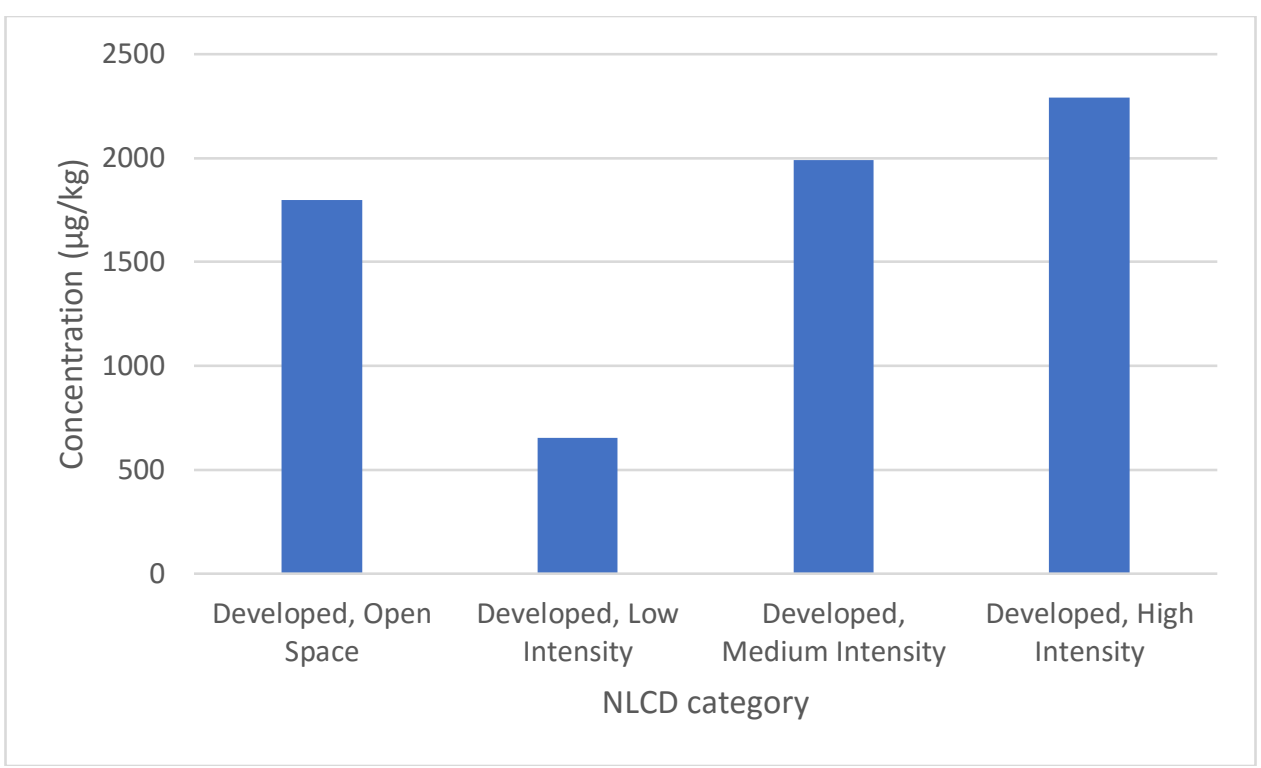

Figure 14: Sum of the average concentrations of 2 and three ring PAHs (napthalene, acenaphthene, acenaphthylene, anthracene, phenanthrene, and fluorene) across the four different NLCD categories

Within each NLCD category there was some correlation between ADT and PAH concentration. This finding was most prominent in the high intensity NLCD category. Using Benzo(a)pyrens as an example of this you can see that in the high intensity category there is a strong positive correlation between ADT and PAH concentration. However, as the land use intensity decreases the slope of the line becomes negative. All fifteen PAHs detected in this study exhibited similar trends as Benzo(a)pyrene, the data for the rest of the PAH compounds is provided in the appendix. 

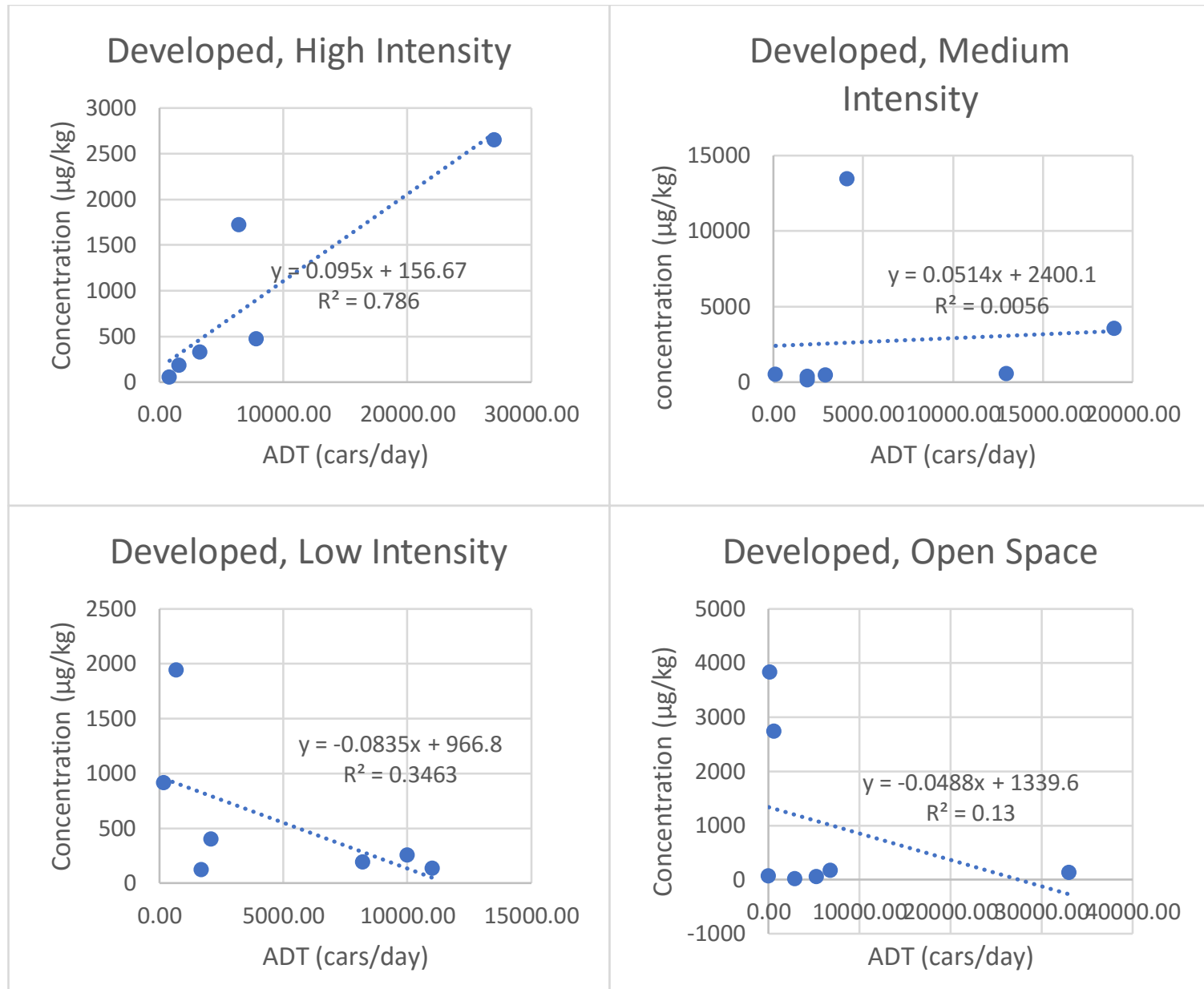

Figure 15: Concentration of Benzo(a)Pyrene as a function of ADT in the four different NLCD categories

Particle size was found to be by far the most influential factor with regards to $\mathrm{PAH}$ concentrations. All PAHs experienced a steady rise in concentration as the particle size decreased. This result can be seen in figure 15 where the line of best fit for all PAHs has a negative slope. Since PAHs preferentially partition into the soil organic matter and finer size fractions typically have a higher percentage of soil organic matter, these results are to be expected (Bucheli et al., 2004). These results also show that PAH concentrations could be reduced by up to $82 \%$ by simply screening out particles smaller than $300 \mu \mathrm{m}$ in size. 


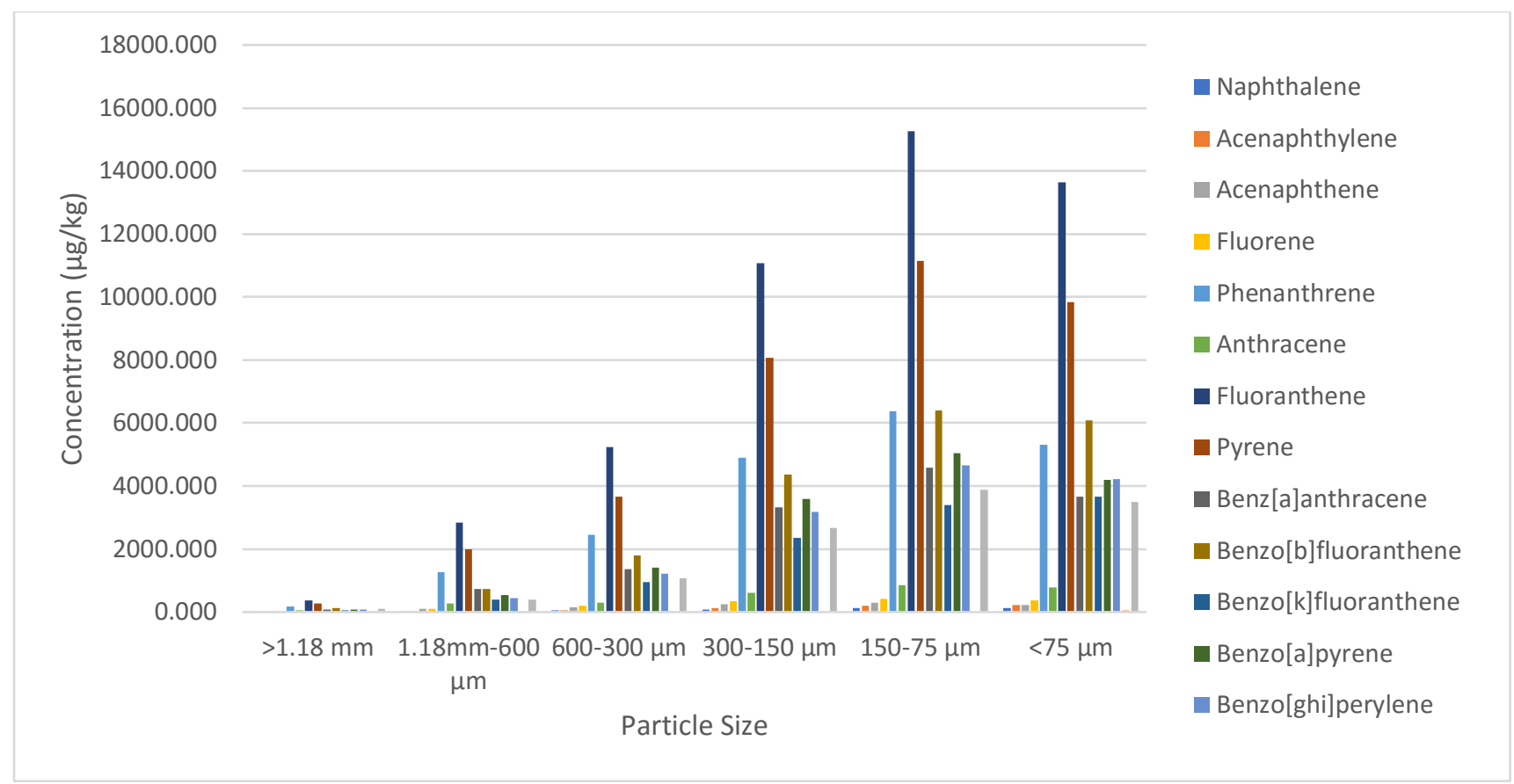

Figure 16: Concentration of each PAH as a function of decreasing particle size.

\subsection{Heavy Metals}

There are many different sources of heavy metals in RDS. These can range from the vehicles themselves to the guard rails adjacent to the roads. Similar to the results found with PAHs, the concentrations for all of the metals considered in this study show a very weak correlation with ADT. When plotted against ADT the metal with the highest $R^{2}$ value was copper $\left(R^{2}=9.28 \times 10^{-2}\right)$. The second highest $R^{2}$ was found with cadmium $\left(R^{2}=3.75 \times 10^{-2}\right)$. Similar results were found when considering the ADT within each NLCD category. Plots of each individual metal as a function of ADT are provided in Figure 20 of the appendix. 
Table 15: $R^{2}$ values of linear regression plots of metal concentration versus average daily traffic volume.

\begin{tabular}{|c|c|c|c|}
\hline Metal & $\mathrm{R}^{2}$ & Metal & $\mathrm{R}^{2}$ \\
\hline Arsenic & $1.21 \times 10^{-3}$ & Silver & $5.10 \times 10^{-5}$ \\
\hline Lead & $2.20 \times 10^{-3}$ & Cadmium & $3.63 \times 10^{-2}$ \\
\hline Selenium & $5.50 \times 10^{-4}$ & Copper & $9.21 \times 10^{-2}$ \\
\cline { 1 - 2 } Barium & $1.70 \times 10^{-2}$ & \multirow{2}{*}{ Zinc } & $1.60 \times 10^{-4}$ \\
\cline { 1 - 2 } Chromium & $4.60 \times 10^{-5}$ & & \\
\hline
\end{tabular}

In terms of land use, each metal behaved differently. For example, lead, barium, and silver concentrations decreased with decreasing land use intensity. By contrast, selenium showed an increase in concentration with decreasing land use intensity. Other metals like chromium, cadmium, and arsenic had a spike in concentration in the developed, high intensity land use category but remained relatively constant across the medium, low, and open space categories. This shows that while the concentration of certain metals in RDS can be predicted by land use, the contamination level of heavy metals in general cannot.

Eight of the nine metals considered in this study exhibited the same increase in concentration with decreasing particle size. Cadmium was the one exception to this trend as can be seen in Figure 16 below. The spike in the $150 \mu \mathrm{m}$ size was due to one reading in the data set that was well above the rest in the series. If this data point is removed from the data set then cadmium exhibits a similar trend as the rest of the metals. Gunawardana et al. (2012) found similar results in the concentrations of $\mathrm{Mn}, \mathrm{Cu}, \mathrm{Pb}, \mathrm{Ni}, \mathrm{Cr}$, and $\mathrm{Cd}$ in RDS across the same particle sizes. The authors measured the specific surface area of these particles and found that the specific surface area decreases exponentially with increasing particle size. Interestingly enough the authors did not find an increase in organic matter content with an increase in specific surface area. While organic matter has been found in the past to increase the specific 
surface area of a particle the authors in this case attribute this effect to other materials on the road like worn tires and brake pads (Gunawardana et al., 2012).

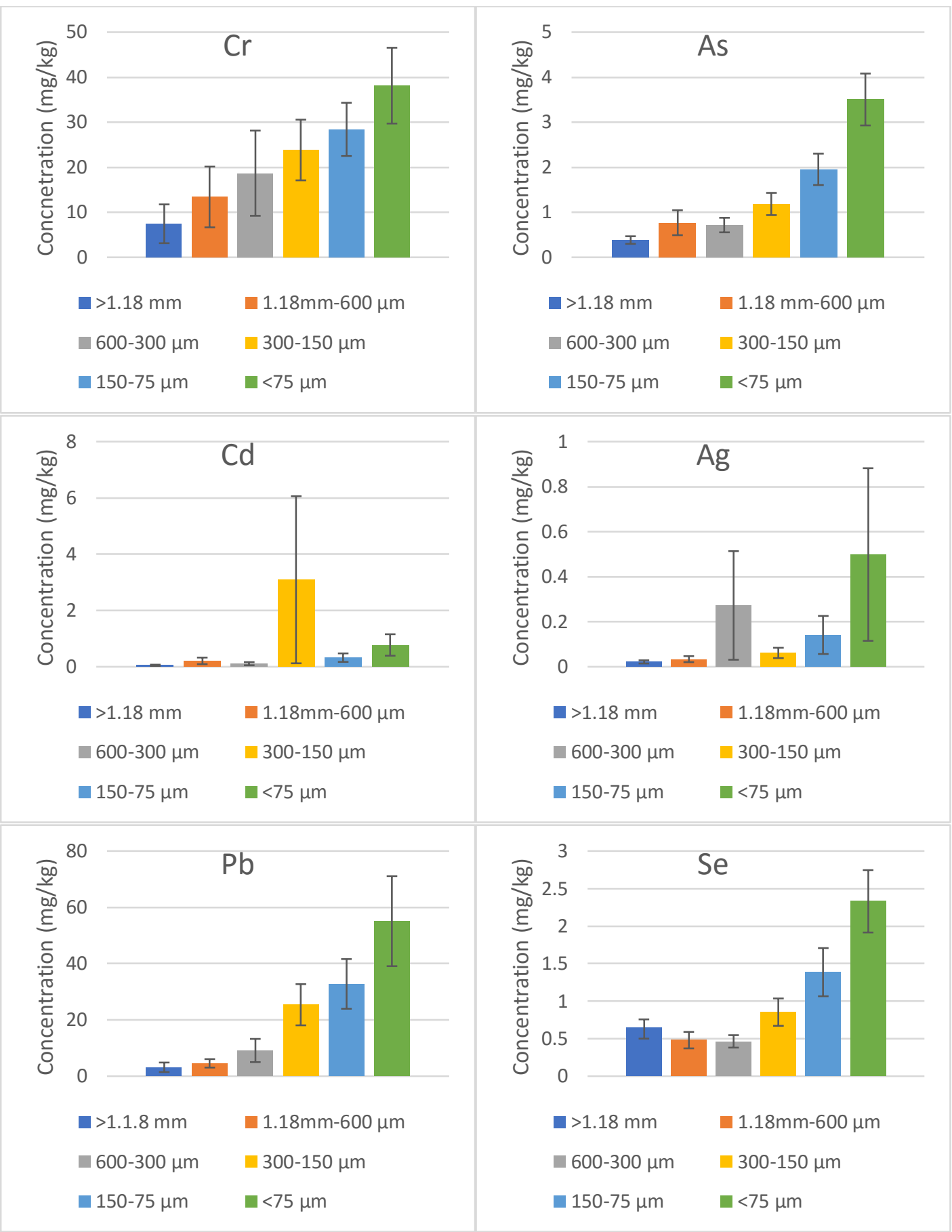



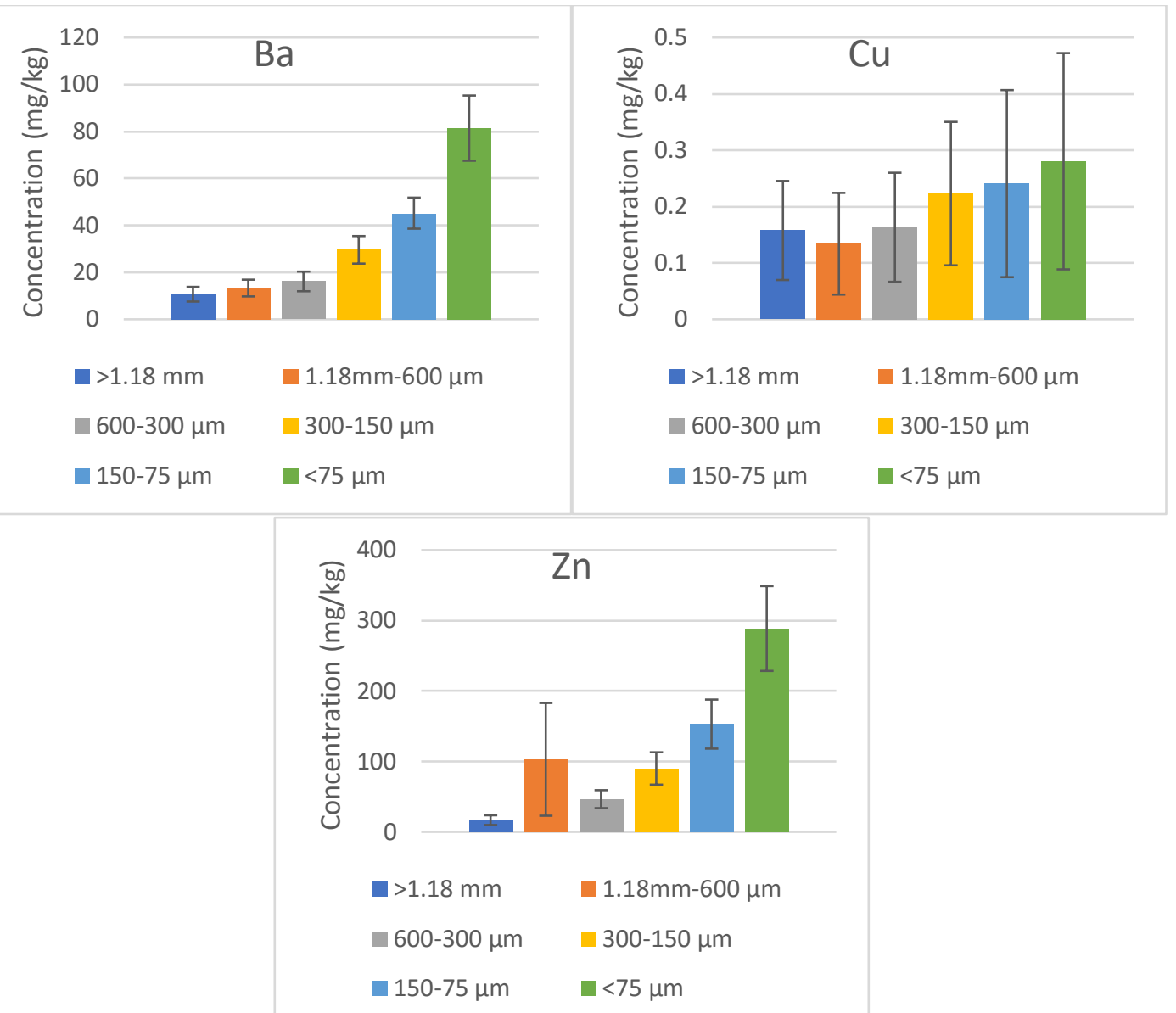

Figure 17: Concentrations of $\mathrm{As}, \mathrm{Pb}, \mathrm{Se}, \mathrm{Ba}, \mathrm{Cr}, \mathrm{Ag}, \mathrm{Cd}, \mathrm{Cu}$, and $\mathrm{Zn}$ in different particle sizes. Error bars are based on the standard error of the group of samples.

Of the 80 sites sampled 3 of them had elevated levels of either lead, chromium, and cadmium each that was above the EPA 40 CFR 261.24 regulatory limit. The details of these three sites are provided in Table 16 below.

Table 16: Sites contaminated above the regulatory limit for heavy metals

\begin{tabular}{|c|c|c|c|c|c|}
\hline Metal & Location & ADT & Land Use & $\begin{array}{c}\text { Concentration } \\
(\mathrm{mg} / \mathrm{L})\end{array}$ & $\begin{array}{c}\text { TCLP Regulatory } \\
\text { Limit (mg/L) }\end{array}$ \\
\hline Lead & 7625 N Brook Road & 7800 & $\begin{array}{c}\text { Developed, High } \\
\text { Intensity }\end{array}$ & 5.07 & 5 \\
\hline Chromium & $\begin{array}{c}\text { UR-8010E } \\
\text { Shenandoah Ave }\end{array}$ & 9800 & $\begin{array}{c}\text { Developed, High } \\
\text { Intensity }\end{array}$ & 5.6 & 5 \\
\hline Cadmium & Backlick Rd. & 40,000 & $\begin{array}{c}\text { Developed, High } \\
\text { Intensity }\end{array}$ & 2.55 & 1 \\
\hline
\end{tabular}


The EPA 40 CFR 261.4 regulatory limits are based on the leachable concentrations of metals using the Toxicity Characteristic Leaching Procedure (TCLP) EPA method 1311 (US EPA, 1992). This method exposes the soil or sediment to conditions typical of landfill leachate or acid rain using a mixture of acids. The TCLP method provides a much gentler digestion than the total digestion used in this research. That being said it would be expected that the leachable concentrations of metals in these samples would be much lower than their total concentrations provided here.

\subsection{Oil and Grease}

Very little research currently exists on oil and grease concentrations in RDS. The results of this research provide new insight into a pollutant commonly associated with the liquid fraction of road runoff. The concentrations of the oil and grease in the samples ranged from $33.6 \mathrm{mg} / \mathrm{kg}$ to $3,440.914 \mathrm{mg} / \mathrm{kg}$. As with $\mathrm{PAHs}$ and heavy metals, a small degree of correlation was shown between ADT and O\&G concentrations. This result can be seen in Figure 17 below. However, O\&G did see a decrease in concentration with decreasing land use intensity. The average concentration of $O \& G$ in samples from the developed, high intensity NLCD category was $1,338.09 \mathrm{mg} / \mathrm{kg}$ while the developed, open space NLCD category had an average concentration of $312.97 \mathrm{mg} / \mathrm{kg}$. This represents an almost $77 \%$ reduction in O\&G concentration between the highest and lowest intensity NLCD categories. Similarly, a 54\% reduction was seen between the developed, high intensity and medium intensity NLCD categories. These results indicate that while ADT may not be a good indicator of O\&G concentrations in RDS, land use could provide better insight. 


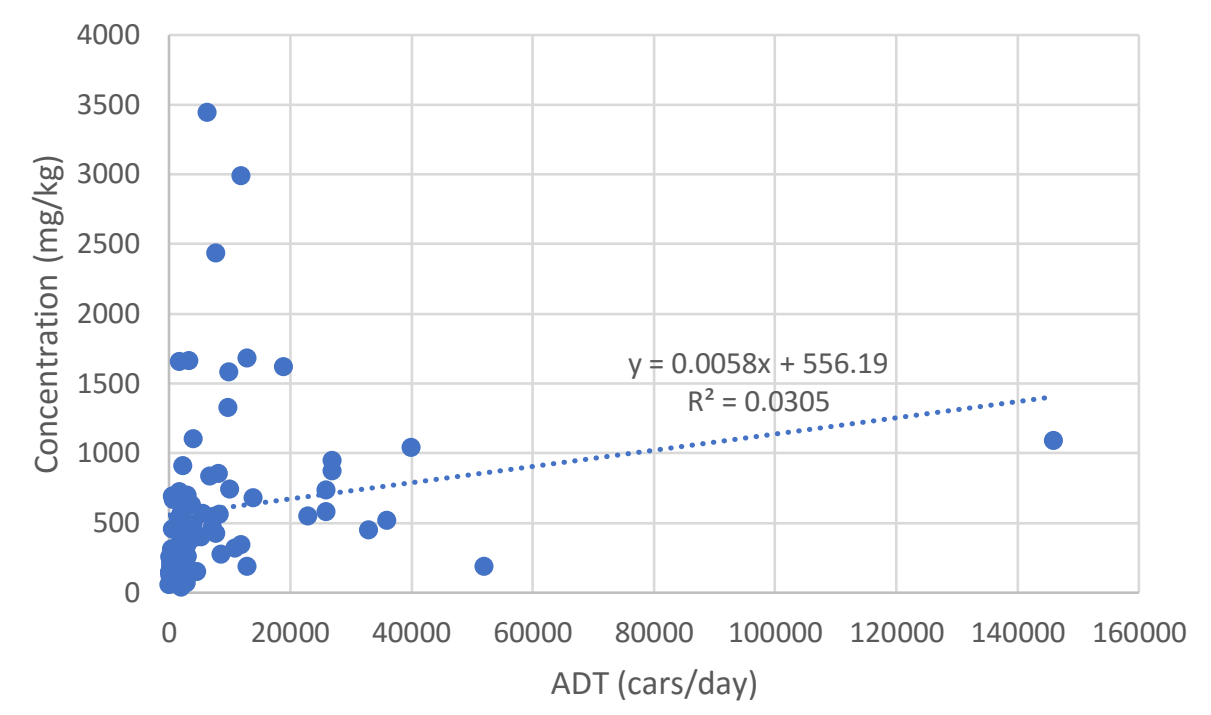

Figure 18: Concentration of oil and grease as a function of average daily traffic volume. 


\section{Chapter 7 Conclusion}

As street sweeping becomes a more prominent means of meeting TMDL regulations in the Commonwealth of Virginia an increasing amount of RDS will be collected. Under the current regulations this material is considered a solid waste by the VADEQ and must be disposed of in an appropriate landfill. In order to mitigate the expected increase in disposal cost as landfill capacity begins to diminish, the Virginia Department of Transportation is seeking to gain a beneficial reuse determination from the VADEQ for this waste stream. This research could provide VDOT with a better understanding of the factors that impact the concentrations of PAHs, heavy metals, and oil and grease in RDS collected during street sweeping. Based on the results above it appears that both the ADT and land use of the surrounding area cannot be used to reliably predict whether or not a road will have elevated concentrations of any of these contaminants. However, based on the results of the size fractionated samples, it can be seen that the finer fraction of RDS acts as a sink for pollutants. Reductions in concentrations of up to $67.96 \%$ for $\sum$ PAHs and from $99.87 \%$ to $35.47 \%$ for heavy metals could be realized if particles smaller than $300 \mu \mathrm{m}$ were screened from the collected material. Furthermore, particles greater than $300 \mu \mathrm{m}$ make up from $66 \%$ to $90 \%$ of the material collected. This means that at most $33 \%$ of the material collected would need to go to a landfill, saving VDOT the cost of transportation and disposal of this material. This would provide a simple treatment procedure for VDOT since all material would be treated the same. Material would not need to be separated based on the source as it was collected. Furthermore, by screening out this material the end product would be ready for reuse as winter traction sand. As was outlined above, municipalities have already implemented this treatment method to RDS collected during street sweeping. Places like 
Edmonton, Canada have implemented an extensive sieving operation, this locality is managing a much larger volume of material than the state of Virginia. Based on the results of this research this process could potentially be scaled down and modified to meet the treatment levels and volumes needed by VDOT. 
Appendix

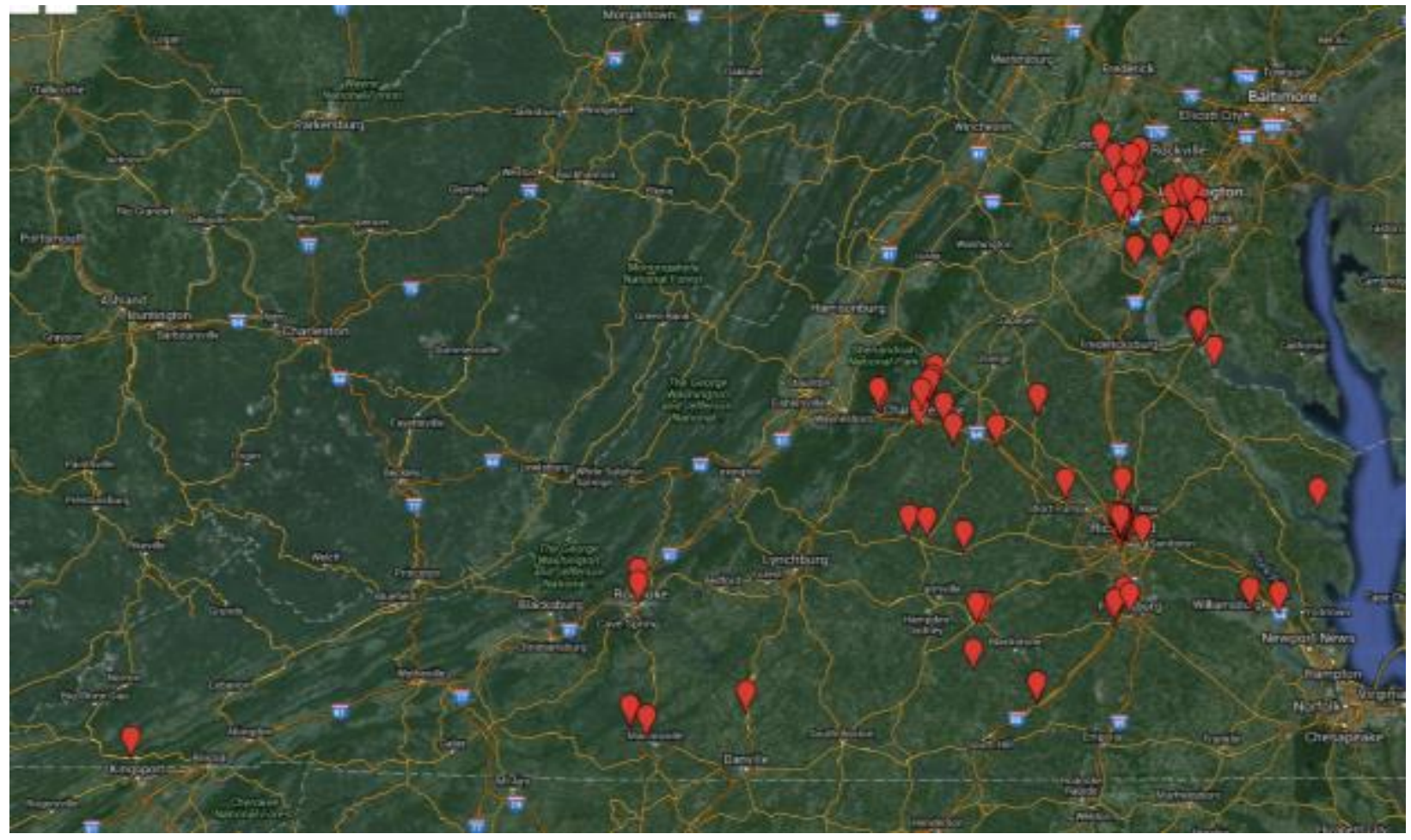

Figure 19: Map of all sampling sites across the state of Virginia. 


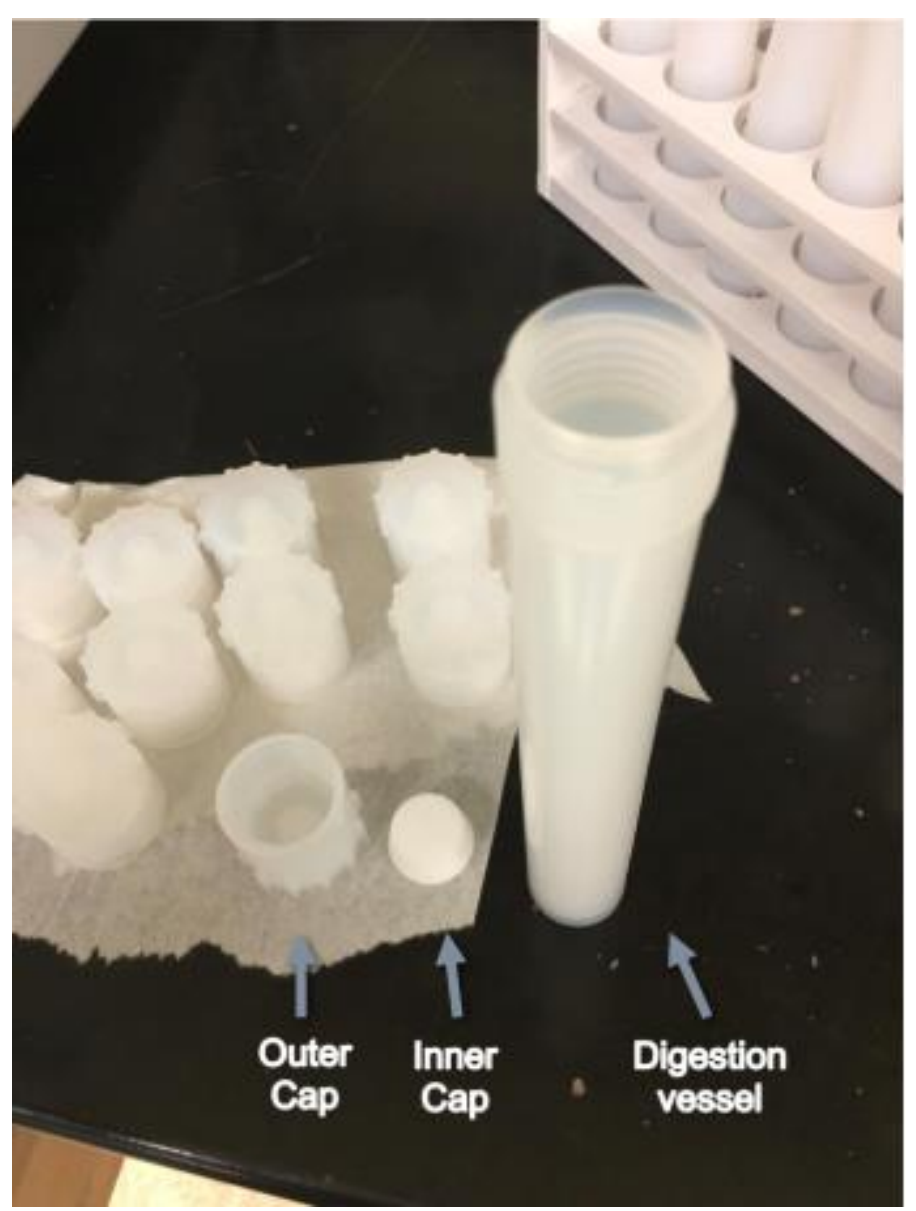

Figure 20: Vessels used for both heavy metal digestion and PAH extraction. 
Appendix-Heavy Metals

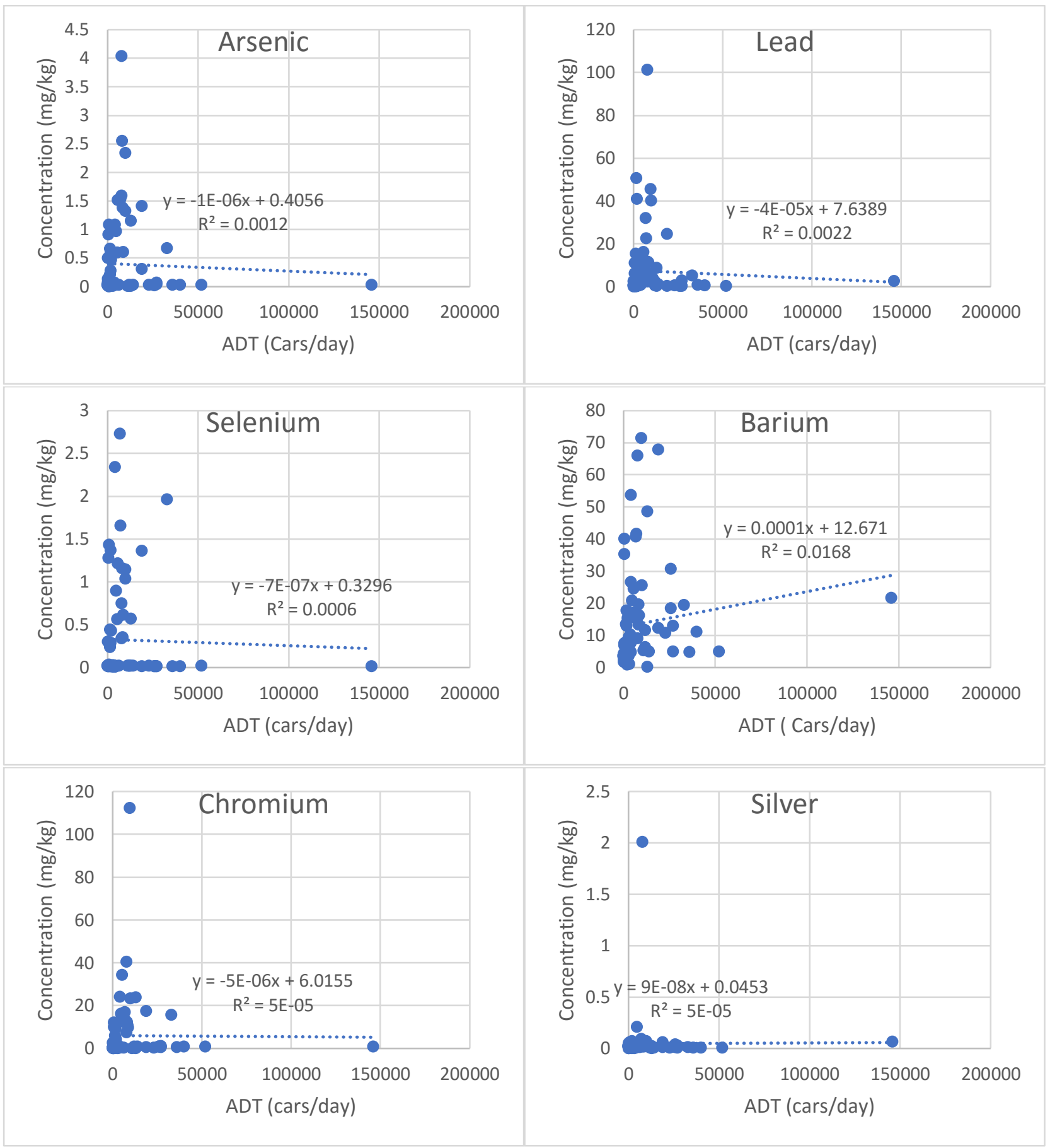



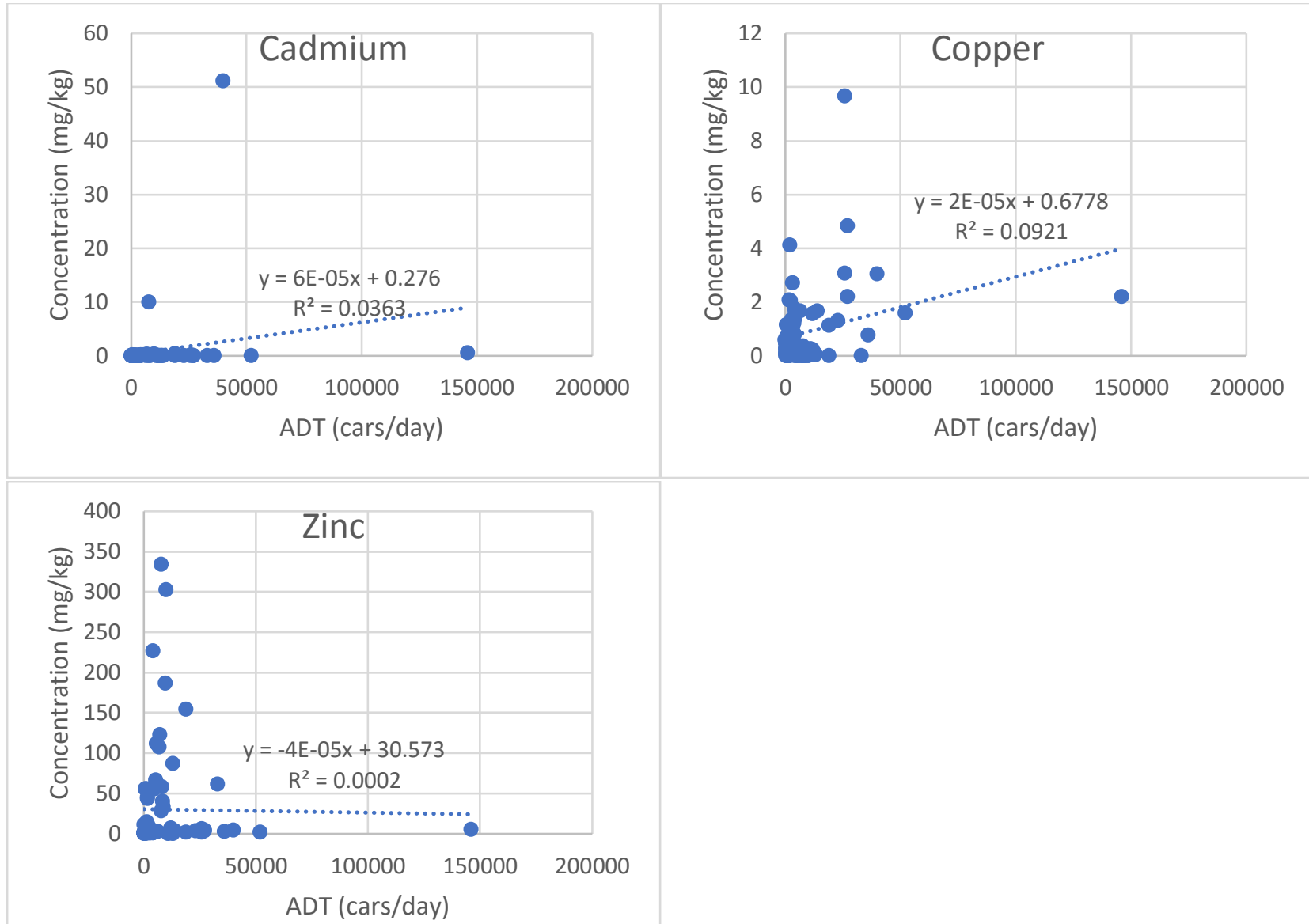

Figure 21: Concentrations of heavy metals as a function of average daily traffic volume. 


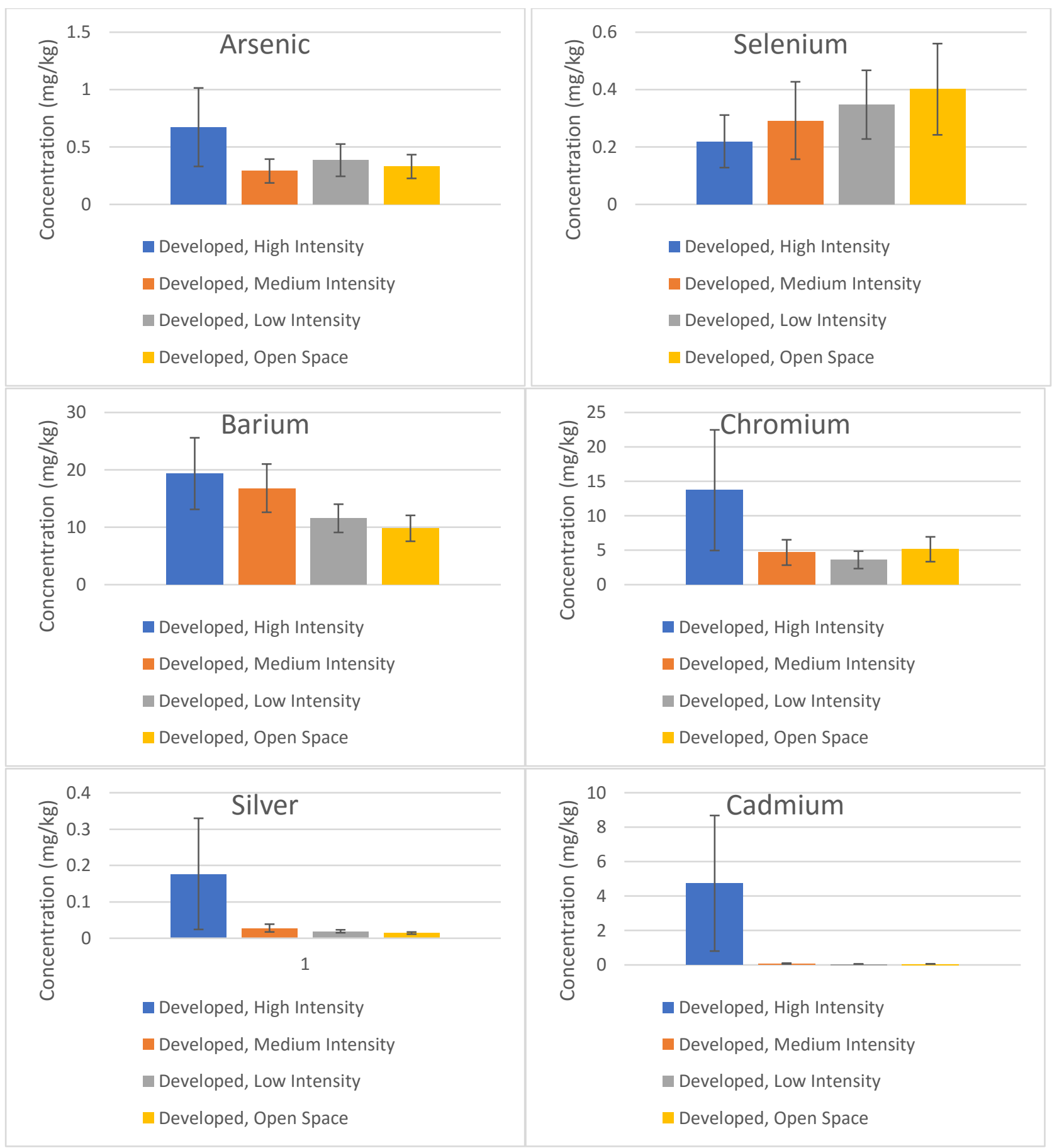



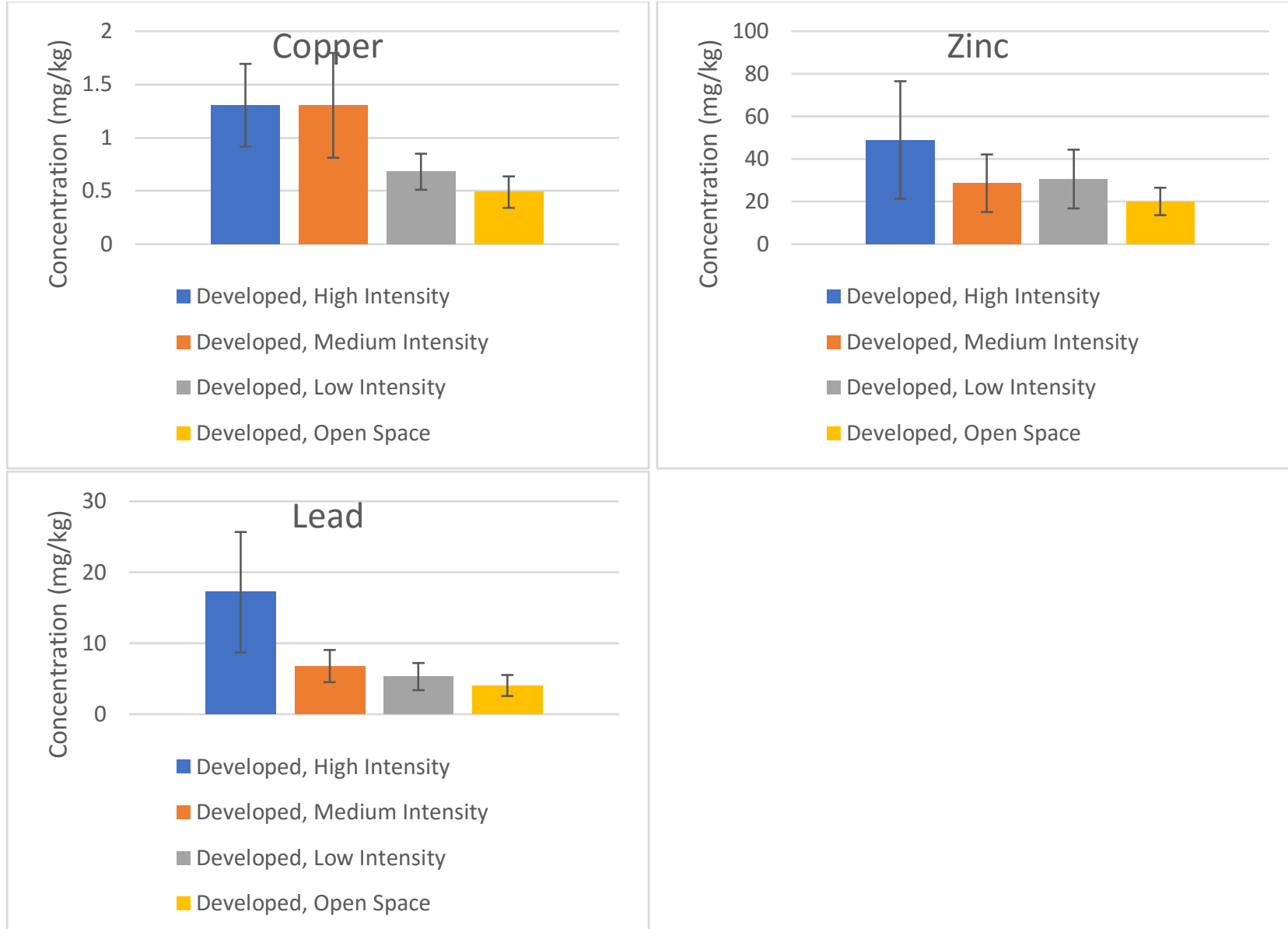

Figure 22: Concentrations of heavy metals in each national land cover database category. 
Appendix-Polycyclic Aromatic Hydrocarbons
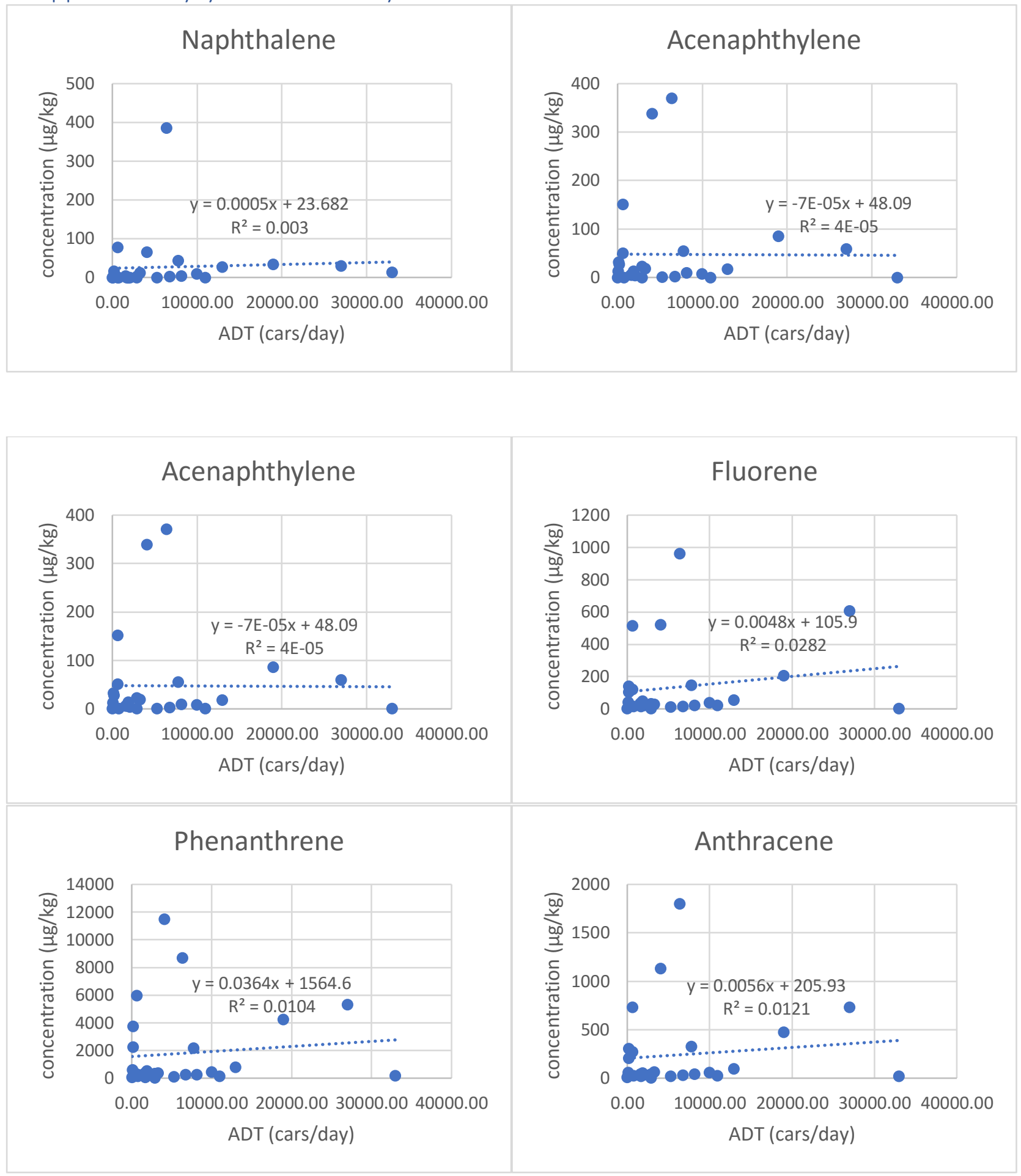


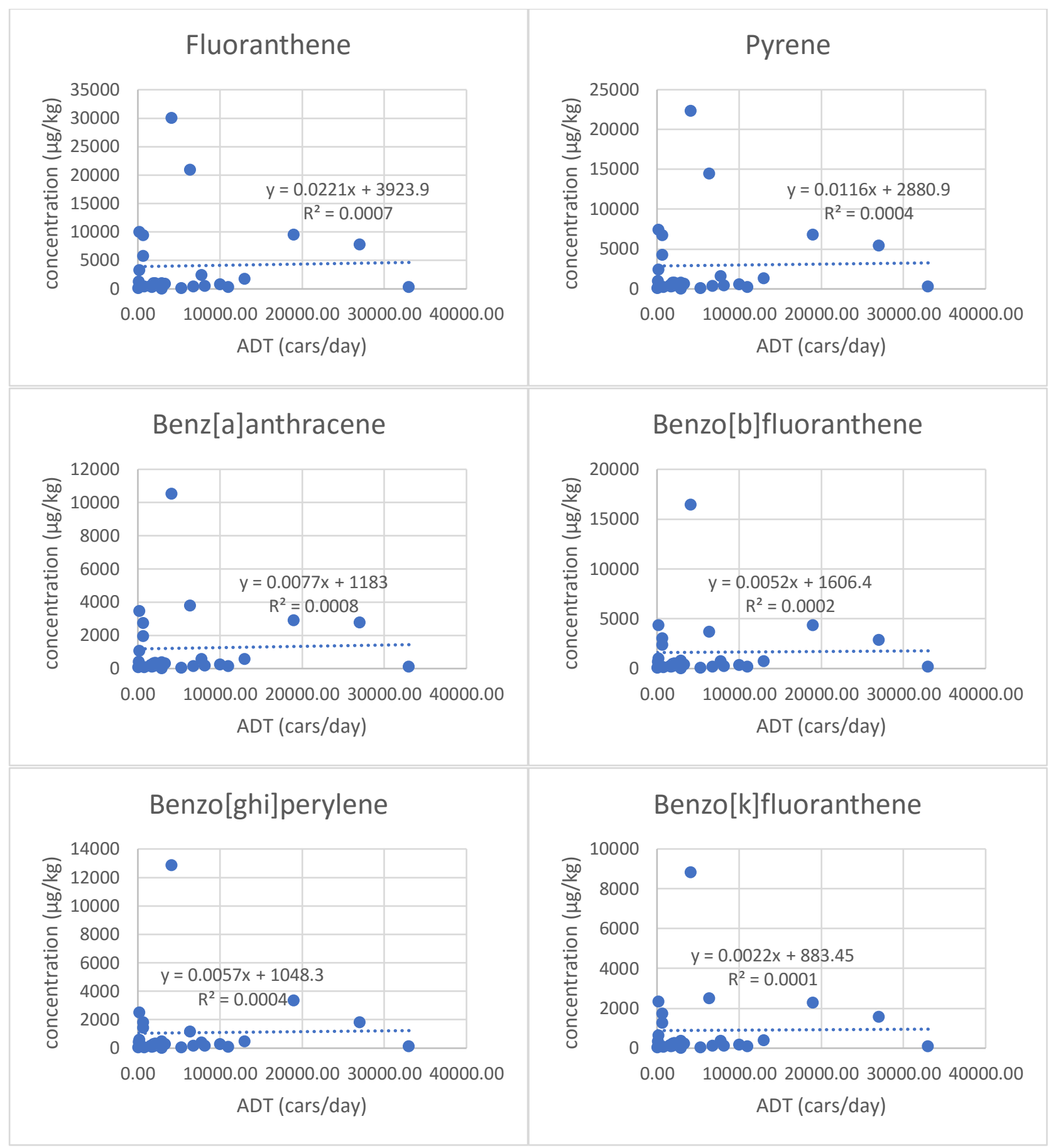



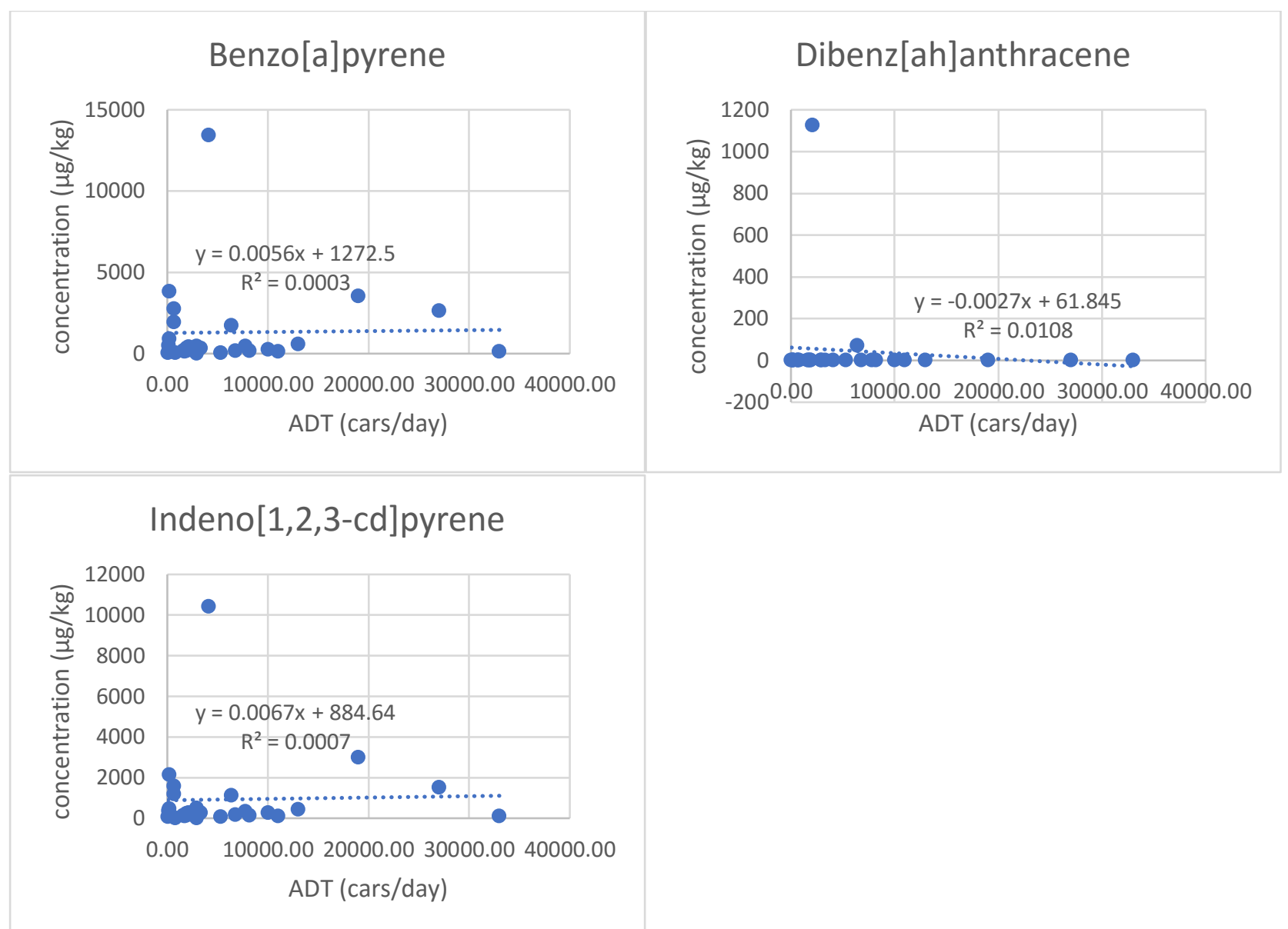

Figure 23: Concentration of each individual PAH as a function of ADT 


\section{References}

Abdel-Shafy, H. I., \& Mansour, M. S. M. (2015). A review on polycyclic aromatic hydrocarbons: Source, environmental impact, effect on human health and remediation. Egyptian Journal of Petroleum, 25(1), 107-123. http://doi.org/10.1016/j.ejpe.2015.03.011

Amato, F., Querol, X., Johansson, C., Nagl, C., \& Alastuey, a. (2010). A review on the effectiveness of street sweeping, washing and dust suppressants as urban PM control methods. Science of the Total Environment, 408(16), 3070-3084.

http://doi.org/10.1016/j.scitotenv.2010.04.025

Apeagyei, E., Bank, M. S., \& Spengler, J. D. (2011). Distribution of heavy metals in road dust along an urban-rural gradient in Massachusetts. Atmospheric Environment, 45(13), 23102323. http://doi.org/10.1016/j.atmosenv.2010.11.015

Azah, E., Kim, H., \& Townsend, T. (2015). Source of polycyclic aromatic hydrocarbon in roadway and stormwater system maintenance residues. Environmental Earth Sciences, 74(4), 30293039. http://doi.org/10.1007/s12665-015-4336-4

Bian, B., Lin, C., \& Wu, H. suo. (2015). Contamination and risk assessment of metals in roaddeposited sediments in a medium-sized city of China. Ecotoxicology and Environmental Safety, 112, 87-95. http://doi.org/10.1016/j.ecoenv.2014.10.030

Bojes, H. K., \& Pope, P. G. (2007). Characterization of EPA's 16 priority pollutant polycyclic aromatic hydrocarbons (PAHs) in tank bottom solids and associated contaminated soils at oil exploration and production sites in Texas. Regulatory Toxicology and Pharmacology, 47(3), 288-295. http://doi.org/10.1016/j.yrtph.2006.11.007

Bostrom, C.-E., Gerde, P., Hanberg, A., Jernstom, B., Johansson, C., Kyrklund, T., ... Westerholm, R. (2002). Cancer Risk Assessment, Indicators, and Guidelines for Polycyclic Aromatic Hydrocarbons in the Ambient Air. Stockholm.

Boxall, A. B. A., \& Maltby, L. (1995). The characterization and toxicity of sediment contaminated with road runoff. Water Research, 29(9), 2043-2050. http://doi.org/10.1016/00431354(95)00029-K

Bucheli, T. D., Blum, F., Desaules, A., \& Gustafsson, Ö. (2004). Polycyclic aromatic hydrocarbons, black carbon, and molecular markers in soils of Switzerland. Chemosphere, 56(11), 10611076. http://doi.org/10.1016/j.chemosphere.2004.06.002

Cai, Q. Y., Mo, C. H., Li, Y. H., Zeng, Q. Y., Katsoyiannis, A., Wu, Q. T., \& Férard, J. F. (2007). Occurrence and assessment of polycyclic aromatic hydrocarbons in soils from vegetable fields of the Pearl River Delta, South China. Chemosphere, 68(1), 159-168. http://doi.org/10.1016/j.chemosphere.2006.12.015

Cedar Rapids Public Works. (2015). Street maintenance. Retrieved from http://www.cedarrapids.org/local_government/departments_g_-_v/public_works/street_maintenance.php

Chow, M. F., Yusop, Z., \& Shirazi, S. M. (2013). Storm runoff quality and pollutant loading from commercial, residential, and industrial catchments in the tropic. Environmental Monitoring and Assessment, 185(10), 8321-8331. http://doi.org/10.1007/s10661-013-3175-6

Cincotti, A., Mameli, A., Locci, A. M., Orrù, R., \& Cao, G. (2006). Heavy metals uptake by Sardinian natural zeolites: Experiment and modeling. Industrial and Engineering Chemistry Research, 45(3), 1074-1084. http://doi.org/10.1021/ie050375z 
City of Edmonton. (2003). City of Edmonton -Winter Street Sand Recycling Program THE PROBLEM: CONTAMINATED STREET SAND.

Curtis, M. (2002). SWEEPING FOR POLLUTANT Prepared by: Mongomery County, Maryland.

Dickhut, R. M., \& Gustafson, K. E. (1995). Atmospheric Inputs of Selected Polycyclic AromaticHydrocarbons and Polychlorinated-Biphenyls To Southern Chesapeake Bay. Marine Pollution Bulletin, 30(6), 385-396. http://doi.org/10.1016/0025-326x(94)00196-g

Dickhut E., R. C., Gustafsson, K., Lui, K., Arzayus, K., Walker, S., Edgecombe, G., ... MacDonald, E. (2000). Automotive sources of PAH's associated with particulate matter in the Chesapeake Bay region. Environmental Science and Technology, 34, 4635-4640. http://doi.org/10.1021/es000971e

Dierker, C. F. (n.d.). MassDEP BUD .

Duong, T. T. T., \& Lee, B. K. (2011). Determining contamination level of heavy metals in road dust from busy traffic areas with different characteristics. Journal of Environmental Management, 92(3), 554-562. http://doi.org/10.1016/j.jenvman.2010.09.010

Environmetal Protection Agency. PART 141 - NATIONAL PRIMARY DRINKING WATER REGULATIONS Subpart A - General Subpart F - Maximum Contaminant Level Goals and Maximum Residual Dis- infectant Level Goals Subpart B - Maximum Contaminant Levels Subpart G - National Revised Primary Drinking Wat (2010). Environmental Protection Agency.

Ghezzi, M., Moore, J., \& Bretsch, K. (2001). Roadwaste management: field trials. Portlan. Goulet, N. (2011). Street Sweeping/ BMP Rea Recommendations.

Gunawardana, C., Egodawatta, P., \& Goonetilleke, A. (2014). Role of particle size and composition in metal adsorption by solids deposited on urban road surfaces. Environmental Pollution, 184, 44-53. http://doi.org/10.1016/j.envpol.2013.08.010

Gunawardana, C., Goonetilleke, A., Egodawatta, P., Dawes, L., \& Kokot, S. (2012). Role of Solids in Heavy Metals Buildup on Urban Road Surfaces. Journal of Environmental Engineering, 138(April), 490-498. http://doi.org/10.1061/(ASCE)EE.1943-7870.0000487

Harrison, R. M., Smith, D. I. T., \& Luhana, L. (1996). Source apportionment of atmospheric polycyclic aromatic hydrocarbons collected from an urban location in Birmingham, U.K. Environmental Science and Technology, 30(3), 825-832. http://doi.org/10.1021/es950252d

Herngren, L., Goonetilleke, A., \& Ayoko, G. A. (2006). Analysis of heavy metals in roaddeposited sediments. Analytica Chimica Acta, 571(2), 270-278. http://doi.org/10.1016/j.aca.2006.04.064

Herra Environmetal Consultants. (2011). Highway Runoff Characterization Monitoring Study. Portland.

Homer, C., Dewitz, J., Yang, L., Jin, S., Danielson, P., Xian, G., ... Megown, K. (2015). Completion of the 2011 National Land Cover Database for the Conterminous UNited StatesRepresenting a Decade of Land Cover Change Information. Photogrammetric Engineering and Remote Sensing, 81(4), 345-354.

Irvine, K. N., Perrelli, M. F., Ngoen-Klan, R., \& Droppo, I. G. (2009). Metal levels in street sediment from an industrial city: Spatial trends, chemical fractionation, and management implications. Journal of Soils and Sediments, 9(4), 328-341. http://doi.org/10.1007/s11368-009-0098-5

Jang, Y. C., Jain, P., Tolaymat, T., Dubey, B., Singh, S., \& Townsend, T. (2010). Characterization of 
roadway stormwater system residuals for reuse and disposal options. Science of the Total Environment. http://doi.org/10.1016/j.scitotenv.2010.01.036

Khan, S., Lau, S.-L., Kayhanian, M., \& Stenstrom, M. K. (2006). Oil and grease measurement in highway runoff - sampling time and event mean concentrations. Journal of Environmental Engineering, 132(3), 415-422. http://doi.org/10.1061/(ASCE)0733-9372(2006)132:3(415)

Lau, S. L., \& Stenstrom, M. K. (2005). Metals and PAHs adsorbed to street particles. Water Research, 39(17), 4083-4092. http://doi.org/10.1016/j.watres.2005.08.002

Link, D. D., Walter, P. J., \& Kingston, H. M. (1998). Development and validation of the new EPA microwave-assisted leach method 3051A. Environmental Science and Technology, 32(22), 3628-3632. http://doi.org/10.1021/es980559n

Liu, A., Liu, L., Li, D., \& Guan, Y. (2015). Characterizing heavy metal build-up on urban road surfaces: Implication for stormwater reuse. Science of the Total Environment, 515-516, 20-29. http://doi.org/10.1016/j.scitotenv.2015.02.026

Liu, G., Tong, Y., Luong, J. H. T., Zhang, H., \& Sun, H. (2010). A source study of atmospheric polycyclic aromatic hydrocarbons in Shenzhen, South China. Environmental Monitoring and Assessment, 163(1-4), 599-606. http://doi.org/10.1007/s10661-009-0862-4

Liu, L., Liu, A., Li, Y., Zhang, L., Zhang, G., \& Guan, Y. (2016). Polycyclic aromatic hydrocarbons associated with road deposited solid and their ecological risk: Implications for road stormwater reuse. Science of the Total Environment, 563-564, 190-198. http://doi.org/10.1016/j.scitotenv.2016.04.114

Mielke, H. W., Wang, G., Gonzales, C. R., Powell, E. T., Le, B., \& Quach, V. N. (2004). PAHs and metals in the soils of inner-city and suburban New Orleans, Louisiana, USA. Environmental Toxicology and Pharmacology, 18(3 SPEC.ISS.), 243-247. http://doi.org/10.1016/j.etap.2003.11.011

Miller, C. M., \& Iv, W. H. S. (2013). Procedures for Waste Management from Street Sweeping and Stormwater Systems : Interim Report.

Minnesota Pollution Control Agency. (2010). Managing Street Sweepings.

Minnicino, M. J., Draper, D. R., Dresden Robin TerraSciences, I., \& Jersey City, N. J. (1993). Analysis of Urban Street Sweepings in New Jersey and Their Reuse Feasibility. Air \& Waste Managment Association, $4 B$.

Pant, P., \& Harrison, R. M. (2013). Estimation of the contribution of road traffic emissions to particulate matter concentrations from field measurements: A review. Atmospheric Environment, 77, 78-97. http://doi.org/10.1016/j.atmosenv.2013.04.028 Review

Pantano, G., Ferrizzi, V. C., Bisinoti, M. C., \& Moreira, A. B. (2016). Source of polynuclear aromatic hydrocarbons found in sediment in a region of expanding sugarcane cultivation of S??o Paulo State, Brazil. Journal of Soils and Sediments, 16(5), 1599-1611. http://doi.org/10.1007/s11368-015-1329-6

Rauckyte, T., Zak, S., PAwlak, Z., Oloyede, A., Rauckyte, T., Żak, S., ... Oloyede, A. (2010). Determination of oil and grease, total petroleum hydrocarbons and volatile aromatic compounds in soil and sediment samples. Journal of Environmental Engineering and Landscape Management, 18(3), 163-169. http://doi.org/10.3846/jeelm.2010.19

Seattle Public Utilities, \& Herrera Environmental Consultants. (2009). Seattle Street Sweeping Pilot Study. Agricultural Economics. Seattle.

Selbig, W. R., \& Bannerman, R. T. (2007). Evaluation of Street Sweeping as a Stormwater- 
Quality-Management Tool in Three Residential Basins in Madison, Wisconsin Scientific Investigations Report 2007 - 5156. Madison Wisconsin.

Sole, M. (2004). Guidance for the Management of Street Sweepings, Catch Basin Sediments and Stormwater System Sediments. Florida.

Stenstrom, M. K., Silverman, G. S., \& Bursztynsky, T. a. (1984). Oil and Grease in Urban Stormwaters. Journal of Environmental Engineering, 110(1), 58-72. http://doi.org/10.1061/(ASCE)0733-9372(1984)110:1(58)

Sutherland, R. A., Tack, F. M. G., \& Ziegler, A. D. (2012). Road-deposited sediments in an urban environment: A first look at sequentially extracted element loads in grain size fractions. Journal of Hazardous Materials, 225-226, 54-62. http://doi.org/10.1016/j.jhazmat.2012.04.066

Thorpe, A., \& Harrison, R. M. (2008). Sources and properties of non-exhaust particulate matter from road traffic: A review. Science of the Total Environment, 400(1-3), 270-282. http://doi.org/10.1016/j.scitotenv.2008.06.007

Tian, P., Li, Y., \& Yang, Z. (2009). Effect of rainfall and antecedent dry periods on heavy metal loading of sediments on urban roads. Frontiers of Earth Science in China, 3(3), 297-302. http://doi.org/10.1007/s11707-009-0042-4

Townsend, T. G., Jang, Y.-C., Thurdekoos, P., Booth, M., Jain, P., \& Tolaymat, T. (2002). CHARACTERIZATION OF STREET SWEEPINGS, STORMWATER SEDIMENTS, AND CATCH BASIN SEDIMENTS, IN FLORIDA FOR DISPOSAL AND REUSE Final Report.

US EPA. (1992). Toxicity Characteristic Leaching Porcedure, Method 1311.

Van Dolah, R. F., Riekerk, G. H. M., Levisen, M. V., Scott, G. I., Fulton, M. H., Bearden, D., ... Sanger, D. M. (2005). An evaluation of polycyclic aromatic hydrocarbon (PAH) runoff from highways into estuarine wetlands of South Carolina. Archives of Environmental Contamination and Toxicology, 49(3), 362-370. http://doi.org/10.1007/s00244-004-02101

VDEQ. (2015). Guidance Memo No. 15-2005 - Chesapeake Bay TMDL Action Plan Guidance. Retrieved from http://www.deq.virginia.gov/Programs/Water/Laws,Regulations,Guidance/Guidance/Wat erPermitGuidance.aspx

Virginia Waste Managment Board. Beneficial Use Demonstration (2015). United States of America.

Wang, C., Li, Y., Liu, J., Xiang, L., Shi, J., \& Yang, Z. (2010). Characteristics of PAHs adsorbed on street dust and the correlation with specific surface area and TOC. Environmental Monitoring and Assessment, 169(1-4), 661-670. http://doi.org/10.1007/s10661-009-12051

Wijesiri, B., Egodawatta, P., McGree, J., \& Goonetilleke, A. (2015). Process variability of pollutant build-up on urban road surfaces. Science of the Total Environment, 518-519, 434-440. http://doi.org/10.1016/j.scitotenv.2015.03.014

Yee, C. (2005). Road Surface Pollution and Street Sweeping. UNiversity of California, Berkeley. Yuen, J. Q., Olin, P. H., Lim, H. S., Benner, S. G., Sutherland, R. A., \& Ziegler, A. D. (2012). Accumulation of potentially toxic elements in road deposited sediments in residential and light industrial neighborhoods of Singapore. Journal of Environmental Management, 101, 151-163. http://doi.org/10.1016/j.jenvman.2011.11.017 
